\title{
Factors influencing implementation of nutritional intervention in elderly subjects after hip fracture
}

Citation for published version (APA):

Breedveld-Peters, J. J. L. (2012). Factors influencing implementation of nutritional intervention in elderly subjects after hip fracture. [Doctoral Thesis, Maastricht University]. Universitaire Pers Maastricht. https://doi.org/10.26481/dis.20121116jb

Document status and date:

Published: 01/01/2012

DOI:

10.26481/dis.20121116jb

Document Version:

Publisher's PDF, also known as Version of record

\section{Please check the document version of this publication:}

- A submitted manuscript is the version of the article upon submission and before peer-review. There can be important differences between the submitted version and the official published version of record.

People interested in the research are advised to contact the author for the final version of the publication, or visit the DOI to the publisher's website.

- The final author version and the galley proof are versions of the publication after peer review.

- The final published version features the final layout of the paper including the volume, issue and page numbers.

Link to publication

\footnotetext{
General rights rights.

- You may freely distribute the URL identifying the publication in the public portal. please follow below link for the End User Agreement:

www.umlib.nl/taverne-license

Take down policy

If you believe that this document breaches copyright please contact us at:

repository@maastrichtuniversity.nl

providing details and we will investigate your claim.
}

Copyright and moral rights for the publications made accessible in the public portal are retained by the authors and/or other copyright owners and it is a condition of accessing publications that users recognise and abide by the legal requirements associated with these

- Users may download and print one copy of any publication from the public portal for the purpose of private study or research.

- You may not further distribute the material or use it for any profit-making activity or commercial gain

If the publication is distributed under the terms of Article $25 \mathrm{fa}$ of the Dutch Copyright Act, indicated by the "Taverne" license above, 
Factors influencing implementation of nutritional intervention in elderly subjects after hip fracture 
The research presented in this thesis was conducted at the School for Public Health and Primary Care: CAPHRI, Department of Epidemiology, of Maastricht University. CAPHRI participates in the Netherlands School of Primary Care Research CaRe. CAPHRI was classified as 'excellent' by the external evaluation committee of leading international experts that reviewed CAPHRI in December 2010.

The studies underlying this thesis were supported by the Netherlands Organisation for Health Research and Development (Zon Mw) and by the Framework Programme of Maastricht University Medical Centre (MUMC+) in Maastricht.

Financial support for the publication of this thesis was kindly provided by the Department of Epidemiology (Maastricht University), Nutricia Advanced Medical Nutrion, the NVD, and Sorgente.

NEDERLANDSE VERENIGING van DIËTISTEN

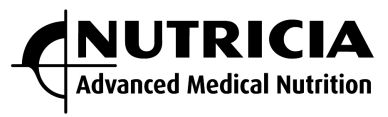

Sorgente

Thuis in voeding

(C) Copyright J.J.L. Breedveld-Peters, Maastricht 2012

ISBN : 9789461591739

Production: Datawyse / Universitaire Pers Maastricht

Cover design: René Meulenbroek

Lay out advice: Yvonne Leenders

Lay out: Tiny Wouters 


\title{
Factors influencing implementation of nutritional intervention in elderly subjects after hip fracture
}

\author{
Proefschrift
}

ter verkrijging van de graad van doctor aan de Universiteit Maastricht, op gezag van de Rector Magnificus, Prof. dr. L.L.G. Soete, volgens het besluit van het College van Decanen, in het openbaar te verdedigen op vrijdag 16 november 2012 om 14.00 uur

door

José Johanna Lamberta Breedveld-Peters 


\section{Promotores}

Prof. dr. ir. P.C. Dagnelie

Prof. dr. T. van der Weijden

Prof. dr. M.H. Prins

\section{Copromotor}

Dr. ir. P.L.M. Reijven

\section{Beoordelingscommissie}

Prof. dr. ir. C.P. van Schayck (voorzitter)

Prof. dr. P.R.G. Brink

Dr. J.F.B.M. Fiolet

Prof. dr. J.P.H. Hamers

Dr. F. G.E.M. van der Horst 
Aan mijn moeder 



\section{Contents}

$\begin{array}{lll}\text { Chapter } 1 \quad \text { Introduction } & 9\end{array}$

Part 1: Effects and feasibility

Chapter 2 Efficacy and cost-effectiveness of nutritional intervention in elderly after hip fracture: Design of a randomized controlled trial

BMC Public Health 2010(10) 212

Chapter 3 Effects of nutritional intervention on nutritional intake and status in elderly subjects after hip fracture: A randomized controlled trial

Submitted

Chapter $4 \quad$ Integrated nutritional intervention in the elderly after hip Fracture: A process evaluation Clinical Nutrition 2012(31)199-205

\section{Part 2: Barriers and facilitators}

Chapter 5 Individual recommendations and guidance were perceived as valuable: Patient views on nutritional intervention after hip fracture

Submitted

Chapter $6 \quad$ Barriers and facilitators of nutritional intervention after hip fracture in integrated care as perceived by the different health care professionals: A qualitative interview study E-SPEN Journal 2012; in press

Chapter 7 General Discussion

Summary

Samenvatting

Dankwoord

About the author 



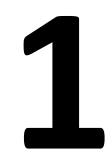

General introduction 


\section{Nutrition and malnutrition in the elderly}

Optimal nutrition is important for the overall well being of elderly individuals. However, suboptimal dietary intakes can easily occur in this age group due to illnesses, medication, social factors, and physical and/or mental handicaps. Loss of appetite, dental problems, and a decreased sense of smell and taste may further compromise dietary intake, resulting in a reduced energy and nutrient supply and a deteriorating nutritional status.

Often, elderly individuals are not aware of the importance of adequate nutrition, and lack knowledge about recommended supplementations, especially for vitamin $D^{1}$. Although health services targeted at the growing population of elderly are becoming more available, for example, there are now counselling centres that provide health checks for the elderly, these services rarely focus enough on nutrition, and professional time spent on nutrition is only reimbursed when health problems that are linked to nutrition occur. As a result, standardized preventive strategies for this age group, such as regular nutritional checks by a dietician or general practitioner in order to detect nutritional problems, are limited.

Awareness of the problem of malnutrition in our civilized, western society has been increasing since the 1970s, however, only recently hospitals and care institutions have acted to introduce screening and assessment tools for the detection and treatment of energy and protein deficiency in the elderly, and to subsequently provide nutritional supplementation when deemed necessary ${ }^{2-5}$. Furthermore, although care for the nutritional status of elderly hospitalized patients is considered a necessary step to improve the health of such individuals, nutritional care has not yet been fully implemented in usual practice, and many questions concerning the effectiveness of dietary interventions in the elderly ${ }^{6,7}$, and how effectiveness and implementation can be improved, remain to be answered.

\section{Nutrition in hip fracture patients}

Among the elderly, hip fractures are one of the most common reasons for hospitalization and subsequent nursing home admission ${ }^{8}$. In the Netherlands, the incidence of hip fractures in the elderly population is high, with a total of 17,941 cases reported in $2007^{9}$. It is expected that this number will only increase in the coming years due to changes in age demographics and increased life expectancy ${ }^{10}$. Risk factors for hip fractures are: low mineral density, reduced muscle strength, falling, reduced mobility, medical co-morbidity, and impaired nutritional status ${ }^{11}$. Thus, for a specific group of elderly hip fracture patients, the physical condition is already compromised in the period preceding the fracture. In fact, at the time of hospitalization, the prevalence of malnutrition among hip fracture patients has been reported to range from $42 \%{ }^{12}$ to $63 \%^{13}$, which is higher than the general ageing population ${ }^{11,14}$. An 
impaired nutritional status is not only a risk factor for hip fracture, but also predicts the speed of recovery after the fracture. Moreover, surgery induces a stress response that results in increased demands for energy and protein compared to before hip fracture $^{15}$. As a consequence, the nutritional status can also deteriorate during the period of hospitalization due to insufficient dietary intake ${ }^{14,16-21}$ caused by, among other things, spontaneous reduction of food intake, lack of appetite, nausea, or disliking hospital meals. Poor nutritional status in hip fracture patients has been reported to be associated with impaired muscle function, disability, loss of independence, lower mental function, decreased quality of life, delayed wound healing, a higher complication rate after surgery, prolonged rehabilitation time, and increased mortality both during and after hospital admission ${ }^{16,17,19,22-27}$. These consequences of hip fracture have a high societal impact.

The European Society of Parenteral and Enteral Nutrition (ESPEN) has formulated European guidelines for the treatment of hip fractures ${ }^{28}$, which include the advice to supply standard oral nutritional support after hip fracture. Nevertheless, guidelines specific for the Dutch medical system do not yet exist. Therefore, in the Netherlands, treatment of hip fractures is based on local policies, and incorporation of dietary support is uncertain. This creates a caveat in quality of care, as positive effects of improved dietary intakes can be expected, especially in frail hip fracture patients and patients with osteoporosis.

\section{Content of the intervention in the current study}

This thesis describes a limited effect evaluation (on nutritional intake and nutritional status) and a process evaluation that were designed within the context of a multicentre Randomized Controlled Trial (RCT) on the effectiveness and costeffectiveness of nutritional intervention in elderly subjects after hip fracture. Data on other outcomes and cost-effectiveness will be published in another thesis. A pragmatic approach $^{29}$ was utilized in this RCT so that the application of the nutritional intervention and potential barriers for future implementation during study execution could be investigated in the current usual care setting. This usual care setting was the integrated clinical pathway for hip fracture patients, involving all patients' locations of stay, including hospitals, rehabilitation settings, and at home, and involving the professionals of all the locations of stay, including home care organizations.

The nutritional intervention was a combination of regular dietetic counselling and consumption of a multi-nutrient oral nutritional supplement (ONS) for a period of three months. This was started in the hospital soon after hip surgery and continued in the rehabilitation centre, nursing home, and/or patient's home, if applicable. An overview of the main components of the nutritional intervention, i.e. structure, nutritional assessments, program content, and communication is shown in figure 1.1. 


\begin{tabular}{|c|c|c|c|c|c|c|}
\hline Structure & \multirow[t]{5}{*}{$\leftrightarrow$} & $\begin{array}{c}\text { Nutritional } \\
\text { Assessment }\end{array}$ & \multirow[t]{5}{*}{$\leftrightarrow$} & $\begin{array}{l}\text { Program } \\
\text { Content }\end{array}$ & \multirow[t]{5}{*}{$\leftrightarrow$} & Communication \\
\hline $\begin{array}{c}\text { Dietetic } \\
\text { Consultations; } \\
5 \text { face to face, } \\
5 \text { telephone calls } \\
\text { over } 3 \text { months (1) }\end{array}$ & & $\begin{array}{c}\text { Regular } \\
\text { weighing }(3,4)\end{array}$ & & $\begin{array}{l}\text { Nutritional counselling } \\
\text { and individually tailored } \\
\text { recommendations (1) }\end{array}$ & & $\begin{array}{c}\text { Reporting on } \\
\text { progress of } \\
\text { nutritional } \\
\text { therapy }(1,2,3,4,5)\end{array}$ \\
\hline \multirow[t]{3}{*}{$\begin{array}{c}\text { Delivery of } \\
\text { dietetic } \\
\text { counselling (1) }\end{array}$} & & \begin{tabular}{|c|} 
Regular \\
evaluation of \\
nutritional intake \\
by $24 \mathrm{~h}$ recall (1)
\end{tabular} & & $\begin{array}{c}\text { Arranging ONS and } \\
\text { required foods (1) } \\
\text { and delivery of ONS } \\
\qquad(2,3,4)\end{array}$ & & $\begin{array}{l}\text { Reporting of planned } \\
\text { discharge }(3,4) \text { and } \\
\text { arrange for follow up } \\
\text { of nutritional care } \\
(1,3,4)\end{array}$ \\
\hline & & \begin{tabular}{|c|} 
Signalling \\
nutritional \\
problems $(2,3,4)$
\end{tabular} & & $\begin{array}{l}\text { Arranging support for } \\
\text { nutritional care }(1,3)\end{array}$ & & $\begin{array}{l}\text { Transfer of nutritional } \\
\text { care information }(3,5)\end{array}$ \\
\hline & & \begin{tabular}{|c|} 
Registration of \\
patient \\
nutritional intake \\
$(2,3,4)$
\end{tabular} & & $\begin{array}{c}\text { Supporting patients and } \\
\text { stimulating nutritional } \\
\text { intake including ONS } \\
(2,3,4,5)\end{array}$ & & $\begin{array}{c}\text { Responsibilities and } \\
\text { working routines } \\
(1,2,3,4,5)\end{array}$ \\
\hline
\end{tabular}

Figure 1.1 Components of Nutritional Intervention program in hip fracture patients in the present study (reference to the professional who is in charge for the specific component)

Legends: 1. Dietician; 2. Nutritional assistant; 3. Nurse; 4. Nurse Assistant; 5. Medical doctor; orthopaedic surgeon or surgeon, geriatrician, general practitioner

The intervention encompassed 10 dietician-patient contacts over the three-month intervention period; i.e. one dietician visited the patient twice in hospital and three times in the rehabilitation centre or at home, and between visits, kept in contact by five telephone calls (at 3, 4, 5, 8, and 10 weeks after discharge). If necessary, a telephone call could be replaced by a home visit.

The nursing staff was responsible for regular weighing of the patients, i.e. just before a consultation by the dietician. Signalling and immediate reporting of nutritional problems in patients was the responsibility of nursing staff and nutritional assistants. If needed, the patient's nutritional intake was registered on some days by the nursing staff. During each contact with the patient, the dietician evaluated the course of the patient's weight and nutritional intake (including the ONS) using a 24-hour dietary recall.

The nutritional intervention was comprised of an energy- and protein-enriched diet, including an oral nutritional supplement (ONS), for three months. Based on the results of the assessments, the dieticians gave individually tailored recommendations regarding foods and amounts, time of consumption, and the ONS. When the patient's diet met nutritional requirements ${ }^{15,30}$, the consumption of ONS was gradually 
decreased. The dietician arranged ordering the ONS and the required foods for the patient's home or institution of stay.

Specially trained dieticians were responsible for the delivery of the nutritional intervention. They worked closely with surgeons, geriatricians and general practitioners, nursing staff (i.e. nurses and nurse assistants), and the nutritional assistants and dieticians of the different health care organizations. Before the start of the study, training sessions were held at each site in order to explain the study to staff involved at the different institutions, and to discuss their role in the execution of the nutritional intervention. This included the delivery of the ONS in the institutions and their role in giving appropriate support with eating and drinking, if needed.

The professional caregivers involved were all responsible for registering their nutritional intervention related activities in the patients' medical files. Each dietician reported details of their dietary treatment to the relevant institutional nurses, nutritional assistants, and clinicians. Nurses and nutritional assistants were responsible for reporting the intake of food- and ONS and any nutritional related problems. They were also responsible for reporting the planned discharge of patients and arranging for transfer of nutritional care information to the next setting in the clinical pathway.

\section{Evaluating interventions in real practice}

Our nutritional intervention meets the definition of a complex intervention, that is, an intervention containing several interacting components. Although there is no sharp boundary between simple and complex interventions ${ }^{31}$, complex interventions are built up from a number of components. Nutritional interventions directed to individual patients in general, such as health promotion interventions to support dietary change, are clear examples of a complex intervention ${ }^{32,33}$. Attention for adequate development, evaluation, and implementation of complex interventions with incorporation of contextual factors is warranted ${ }^{31}$. Integrating process measures with effect measures in an RCT has been recommended in order to increase our understanding of contextual circumstances of interventions, and to be able to estimate their relevance for the application of the intervention in other health care situations, for example, to determine whether effects of an intervention can be expected under other circumstances or within another context. To achieve this, both qualitative and quantitative methods may be required ${ }^{31,33,34}$.

A process evaluation can be used to monitor and document program implementation and to understand the relationship between program elements and program outcomes. A program's lack of success could be attributed to program-related reasons, including poor program design, poor or incomplete program implementation, and/or failure to reach a sufficient number of the target audience. Several important issues must be addressed when developing a process evaluation, including an understanding of the intervention program and how it is supposed to work, defining the purposes for 
the process evaluation, and considering how program characteristics and context may affect implementation. The process evaluation as performed in the present study was based on the elements of process evaluation as recommended by Saunders ${ }^{35}$. We focused our process evaluation on the following elements:

- Fidelity (to what extent was the intervention implemented consistently with the underlying protocol);

- Dose delivered (to what extent were all intended methods, strategies and/or activities used);

- Dose received (to what extent did participants receive intervention components and engage in recommended follow up behaviour); and

- Context (what contextual factors or other situational issues could potentially affect either intervention implementation or intervention outcome).

The elements 'reach' (participation of participants) and 'recruitment' (what recruitment procedures were used and which were barriers) were beyond the scope of this study and could not be investigated. The process evaluation described in this thesis is intended to be a foundation for future implementation research, and was directed at exploring barriers and facilitators for implementation at the level of stakeholders (patients and professionals) and context. It can be seen as a pilot for future large-scale implementation, and as such, our study aimed to generate valuable insights with respect to barriers and facilitators for large-scale implementation.

\section{The challenge of implementation, from small- to large-scale implementation}

Introducing health care innovations and new evidence into routine daily practice can be difficult. It is not enough to disseminate evidence through publication at conferences and in journal articles, and through integration of the evidence in the update of clinical practice guidelines. In order to actually implement a new intervention in real practice, a number of different elements are needed to address the multiple factors that will optimize the chances of achieving relevant change in practice $^{36,37}$ :

1. Involvement of the relevant stakeholders (managers, staff, informal caregivers), and development of a feasible and attractive proposal of change based on evidence as much as possible.

2. Consideration of barriers and facilitators to change, for example, obstacles at the level of the patient, the level of the professional, the level of the health care team, the level of the health care organization, and the wider environment. In this respect, the determinants of change, for example, characteristics of individual professionals, interpersonal factors, and system characteristics should be considered, and a model for change should be adapted in the approach in order to reach the level of incorporation of change in daily work practice. 
3. A set of strategies and measures at different levels, linked to the barriers at different levels, should be developed and tailored to the locally identified barriers and facilitators to implementation.

Although we know how important it is to understand factors that facilitate or hinder change in clinical practice, we still lack in depth knowledge of which factors are decisive in achieving these changes.

\section{Aims of the thesis}

We have considered the need for evaluation of complex interventions with respect to effect and process, and the lack of process evaluation data available with respect to the application of nutritional interventions in an integrated health care setting. In this thesis, data concerning the nutritional intake and nutritional status of patients, as well as data concerning study execution were generated in order to determine the effects and feasibility of the previously described nutritional intervention. To generate insights for effective implementation of the nutritional intervention on a larger scale, we investigated barriers and facilitators as perceived by the main stakeholders involved (patients and professional caregivers).

The aim of the present thesis was to evaluate the implementation of the nutritional intervention in hip fracture patients within the pragmatic study setting of a Randomized Controlled Trial.

The following sub-objectives were defined:

- To evaluate the effect of the nutritional intervention in the integrated health care trajectory on nutritional intake and status.

- To evaluate the feasibility of the nutritional intervention with respect to fidelity, dose delivered, and dose received.

- To evaluate barriers and facilitators for implementation of the nutritional intervention from the stakeholder's perspective, i.e. patients and (para)medical caregivers that were involved in the study.

\section{Outline of the thesis}

\section{Part 1: Effects and feasibility}

In Chapter 2, the design, aims, methodology, and content of the multicentre nutritional intervention RCT for hip fracture patients is presented.

In Chapter 3, the effects of the 3-month nutritional intervention with respect to dietary intake and nutritional status in elderly subjects after hip fracture are presented. 
In Chapter 4, results of the quantitative process evaluation to investigate the feasibility of the intervention with respect to number, type, duration, content of contacts, and the fit of the program within the present health care system are presented.

\section{Part 2: Barriers and facilitators}

In Chapters 5 and 6, results of the stakeholder's perspective on barriers and facilitators for large-scale implementation of the applied nutritional intervention are given. In chapter 5, we present a prospective process evaluation from the patient's perspective. The evaluation was aimed at identifying key issues necessary for improving the intervention program. Chapter 6 presents the qualitative data on the perspective of the involved professional caregivers' with respect to feasibility and perceived barriers with application of the intervention in the present usual care.

Finally, in Chapter 7, the findings of the preceding chapters are summarized and discussed. 


\section{References}

1. Guidelines for a healthy diet: Health Council of the Netherlands; 2006.

2. Richtlijn Screening en behandeling van ondervoeding. Amsterdam: Stuurgroep Ondervoeding; 2010.

3. Halfens RJG, Meesterberends E, Meijers JMM, Du Moulin MFMT, van Nie NC, Neyens JCL, Schols JMGA. Landelijke Prevalentiemeting Zorgproblemen Rapportage resultaten 2011. Maastricht: Maastricht University, Faculty of Health, Medicine and Life Sciences, Department of Health Service Research Focusing on Chronic Care and Ageing; 2011.

4. Improving Nutritional Care: A joint Action Plan from the Department of Health and Nutrition Summit stakeholders. Leeds, UK: NHS October 2007.

5. National Primary Care Collaboration Agreement on Malnutrition: Dutch College of General Practitioners, Dutch Dietetic Association (Nederlandse Vereniging van Dietisten) and the Dutch Association of Care professionals (Beroepsvereniging voor zorgprofessionals V\&VN); March 2011.

6. Ondervoeding bij ouderen. The Hague: Gezondheidsraad, Health Council of the Netherlands; 2011.

7. Avenell A, Handoll HGG. Nutritional supplementation for hip fracture aftercare in older people (Review). Cochrane Database Syst Rev 2010(1).

8. Cummings SR. Treatable and untreatable risk factors for hip fracture. Bone. 1996;18(3 Suppl):165S-7S.

9. Hoeymans N, Melse JM, Schoemaker CG. Gezondheid en determinanten, Deelrapport VTV 2010, Van gezond naar beter. Bilthoven: RIVM 2010.

10. De Laet CE, Pols HA. Fractures in the elderly: epidemiology and demography. Baillieres Best Pract Res Clin Endocrinol Metab. 2000;14(2):171-9.

11. Bonjour JP, Schurch MA, Rizzoli R. Nutritional aspects of hip fractures. Bone. 1996;18(3 Suppl): 139S-44S.

12. Maffulli N, Dougall TW, Brown MT, Golden MH. Nutritional differences in patients with proximal femoral fractures. Age Ageing. 1999;28(5):458-62.

13. Murphy MC, Brooks CN, New SA, Lumbers ML. The use of the Mini-Nutritional Assessment (MNA) tool in elderly orthopaedic patients. Eur J Clin Nutr. 2000;54(7):555-62.

14. Delmi M, Rapin CH, Bengoa JM, Delmas PD, Vasey H, Bonjour JP. Dietary supplementation in elderly patients with fractured neck of the femur. Lancet. 1990;335(8696):1013-6.

15. Kwaliteitsinstiuut voor de Gezondheidszorg CBO / Health care quality instituteCBO U, The Netherlands. Peri-operatief voedingsbeleid Guideline. 2007 september 2007:14-5.

16. Jallut D, Tappy L, Kohut M, Bloesch D, Munger R, Schutz $Y$, et al. Energy balance in elderly patients after surgery for a femoral neck fracture. JPEN. 1990;14(6):563-8.

17. Lumbers M, New SA, Gibson S, Murphy MC. Nutritional status in elderly female hip fracture patients: comparison with an age-matched home living group attending day centres. Br J Nutr. 2001;85(6): 733-40.

18. Nematy $M$, Hickson $M$, Brynes $A E$, Ruxton $C H$, Frost GS. Vulnerable patients with a fractured neck of femur: nutritional status and support in hospital. J Hum Nutr Diet. 2006;19(3):209-18.

19. Patterson BM, Cornell CN, Carbone B, Levine B, Chapman D. Protein depletion and metabolic stress in elderly patients who have a fracture of the hip. J Bone Joint Surg Am. 1992;74(2):251-60.

20. Stableforth PG. Supplement feeds and nitrogen and calorie balance following femoral neck fracture. $\mathrm{Br}$ J Surg. 1986;73(8):651-5.

21. Eneroth M, Olsson UB, Thorngren KG. Insufficient fluid and energy intake in hospitalised patients with hip fracture. A prospective randomised study of 80 patients. Clin Nutr. 2005;24(2):297-303.

22. Bastow MD, Rawlings J, Allison SP. Undernutrition, hypothermia, and injury in elderly women with fractured femur: An injury response to altered metabolism? Lancet. 1983;321(8317):143-6.

23. Paillaud E, Bories PN, Le Parco JC, Campillo B. Nutritional status and energy expenditure in elderly patients with recent hip fracture during a 2-month follow-up. Br J Nutr. 2000;83(2):97-103.

24. Bachrach-Lindstrom $M$, Johansson $T$, Unosson $M$, Ek AC, Wahlstrom $O$. Nutritional status and functional capacity after femoral neck fractures: a prospective randomized one-year follow-up study. Aging. (Milano) 2000;12(5):366-74.

25. Bastow MD, Rawlings J, Allison SP. Benefits of supplementary tube feeding after fractured neck of femur: a randomised controlled trial. BMJ (Clin Res Ed) 1983;287(6405):1589-92. 
26. Hedstrom M. Hip fracture patients, a group of frail elderly people with low bone mineral density, muscle mass and IGF-I levels. Acta Physiol Scand. 1999;167(4):347-50.

27. Lumbers M, Driver LT, Howland RJ, Older MW, Williams CM. Nutritional status and clinical outcome in elderly female surgical orthopaedic patients. Clin Nutr. 1996;15(3):101-7.

28. Volkert D, Berner YN, Berry E, Cederholm T, Coti Bertrand P, Milne A, et al. ESPEN Guidelines on Enteral Nutrition: Geriatrics. Clin Nutr. 2006;25(2):330-60.

29. Thorpe KE, Zwarenstein M, Oxman AD, Treweek S, Furberg CD, Altman DG, et al. A pragmaticexplanatory continuum indicator summary (PRECIS): a tool to help trial designers. J Clin Epidemiol. 2009;62(5):464-75.

30. Roza AM, Shizgal HM. The Harris Benedict equation reevaluated: resting energy requirements and the body cell mass. Am J Clin Nutr. 1984;40(1):168-82.

31. Craig P, Dieppe P, Macintyre S, Michie S, Nazareth I, Petticrew M. Developing and evaluating complex interventions: the new Medical Research Council guidance. BMJ. 2008;337:a1655.

32. Campbell M, Fitzpatrick R, Haines A, Kinmonth AL, Sandercock $P$, Spiegelhalter D, et al. Framework for design and evaluation of complex interventions to improve health. BMJ. 2000;321(7262):694-6.

33. Campbell NC, Murray E, Darbyshire J, Emery J, Farmer A, Griffiths F, et al. Designing and evaluating complex interventions to improve health care. BMJ. 2007;334(7591):455-9.

34. Jansen YJ, Foets MM, de Bont AA. The contribution of qualitative research to the development of tailor-made community-based interventions in primary care: a review. Eur J Public Health. 200920(2): 220-6.

35. Saunders RP, Evans MH, Joshi P. Developing a process-evaluation plan for assessing health promotion program implementation: a how-to guide. Health Promot Pract. 2005;6(2):134-47.

36. Grol R, Grimshaw J. From best evidence to best practice: effective implementation of change in patients' care. Lancet. 2003;362(9391):1225-30.

37. Grol R, Wensing M. What drives change? Barriers to and incentives for achieving evidence-based practice. Med J Aust. 2004;180(6 Suppl):S57-60. 


\section{Factors influencing implementation of nutritional intervention in elderly subjects after hip fracture}

\section{Part 1: Effects and feasibility}





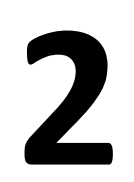

\section{Efficacy and cost-effectiveness of nutritional intervention in elderly after hip fracture: design of a randomized controlled trial}

Caroline E Wyers José JL Breedveld-Peters

Petronella LM Reijven Svenhjalmar van Helden Nick A Guldemond Johan L Severens Aart D Verburg Berry Meesters Lodewijk W van Rhijn Pieter C Dagnelie 


\section{Abstract}

\section{Purpose}

Hip fracture patients often have an impaired nutritional status at the time of fracture, which can result in a higher complication rate, prolonged rehabilitation time and increased mortality. A study was designed to evaluate the effect of nutritional intervention on nutritional status, functional status, total length of stay, postoperative complications and cost-effectiveness.

\section{Methods}

Open-labeled, multi-centre, randomized controlled trial in hip fracture patients aged 55 years and above. The intervention group receives dietetic counselling (by regular home visits and telephone calls) and oral nutritional supplementation for three months after surgery. The control group receives usual dietetic care as provided by the hospital. Outcome assessment is performed at three and six months after hip fracture.

\section{Discussion}

Patient recruitment has started in July 2007 and has ended in December 2009. First results are expected in 2011.

The trial was registered at clincialtrails.gov as NCT00523575 


\section{Introduction}

In the elderly, the incidence of hip fractures is high and it will increase in the nearby future due to the changes in the age demographics, the increased life expectancy and the continuous improvement of health care ${ }^{1,2}$. Hip fractures are one of the most common reasons for hospital admission and transfers to nursing home ${ }^{3}$. Only $37 \%$ of the hip fracture patients will return to their pre-fracture functional status, leading to high health care costs and a major burden on health care utilization. These costs are not only determined by acute hospital costs, but even more by the long term costs such as recovery in rehabilitation clinics, the need for home care and the increased burden on informal care givers ${ }^{4,5}$.

At the time of hospitalization for a hip fracture, the prevalence of malnutrition ranges from $2 \%^{6}$ to $63 \%$. Poor nutritional status in hip fracture patients is associated with impaired muscle function, disability ${ }^{8}$, loss of independency, lower mental function, decreased quality of life $^{8}$, delayed wound healing, higher complication rate ${ }^{9,10}$, prolonged rehabilitation time ${ }^{8,9,11}$ and increased mortality both during and after hospital admission ${ }^{9,12-16}$. During hospital admission, the nutritional status can deteriorate further due to increased energy expenditure caused by metabolic stress, combined with a low intake due to the lack of appetite, nausea and psychological factors.

In the past decades, several studies have been conducted to determine the effectiveness of various types of nutritional intervention in elderly hip fracture patients on the length of stay, mortality, complications, nutritional and functional status. Results of these studies are inconsistent and the evidence for nutritional supplementation remains limited ${ }^{17}$. Oral nutritional supplementation is the simplest type of nutritional intervention for hip fracture patients to improve the energy and protein intake and nutritional status, although compliance is often poor ${ }^{18}$. Personal attention from a dietetic assistant can improve compliance with and tolerance of nutritional supplements ${ }^{19}$ and help to establish a prolonged effect of the nutritional intervention.

The aim of the present study is to investigate the effect of intensive dietary intervention, comprising a combination of dietetic counselling and oral nutritional supplementation during hospitalization and after discharge, on the nutritional status, total length of stay and health care costs after hip fracture. We hypothesize that the combination of dietetic counselling and oral nutritional supplementation in hip fracture patients will improve patients' energy and protein intake, improve their nutritional status, reduce the number of complications and total length of stay in the hospital and rehabilitation clinics, and lower health care costs. 


\section{Methods}

\section{Study design, general outline and randomization}

Figure 2.1 shows the design of the study, which is an open-label, randomized controlled, multi-centre trial. Patient allocation to intervention or control group is performed after stratification for hospital, gender, and age (55-74 years vs. 75 years and above).

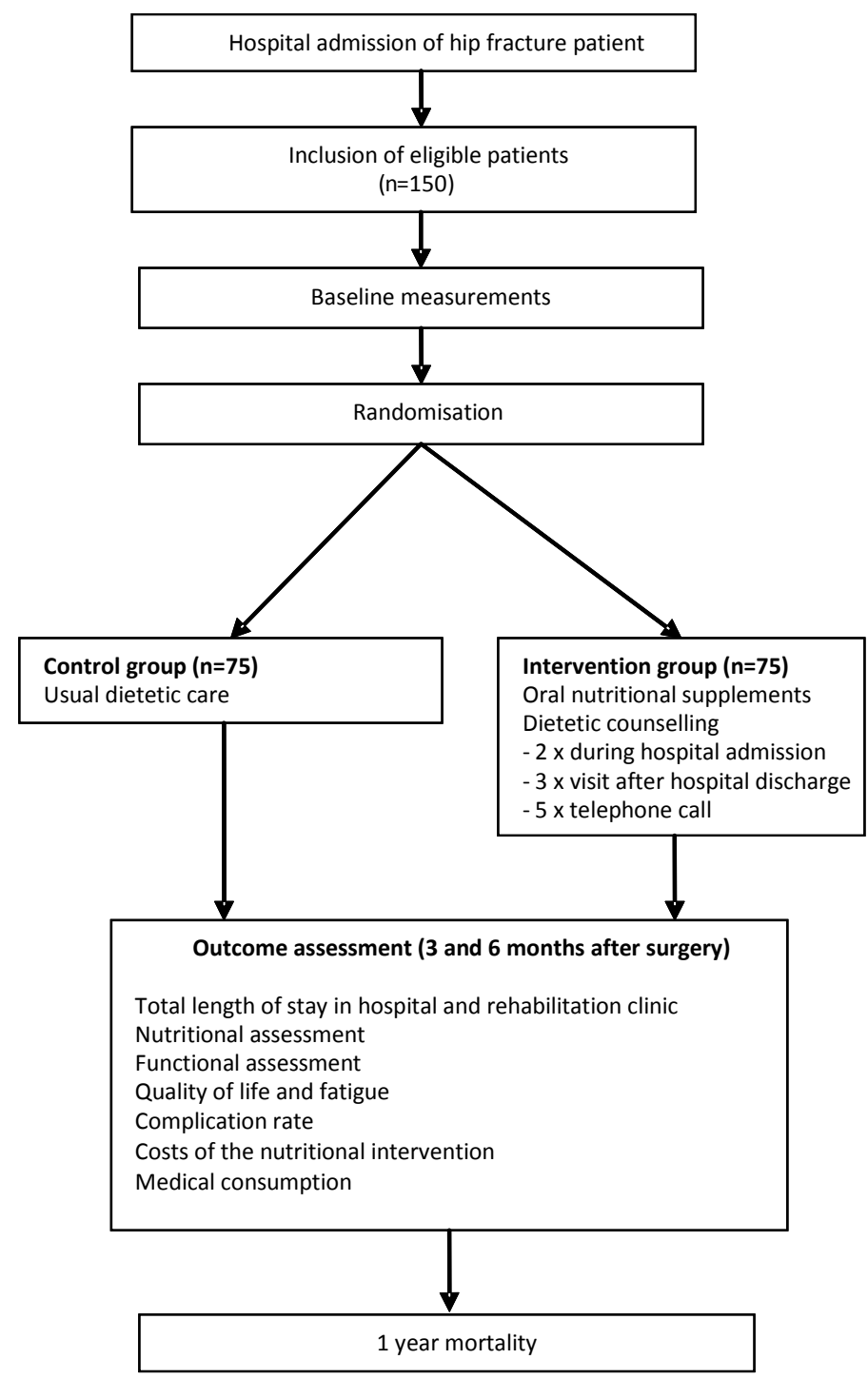

Figure 2.1 Study design 
Patients allocated to the intervention group receive dietetic counselling and oral nutritional supplementation for three months following surgery. The control group receives usual nutritional care. Patients are enrolled within five days after surgical treatment of hip fracture, and baseline measurements are performed immediately after enrolment. Outcome measurements are performed at the patient's home at three and six months following hip fracture. The study has been approved by the Medical Ethical Committee of Maastricht University Medical Centre and Maastricht University and is conducted according to the Declaration of Helsinki.

\section{Study population and recruitment of the study population}

For patient recruitment, a daily inventory is made of hip fracture patients admitted to the surgical and orthopedic wards of three hospitals in South-Limburg in The Netherlands: Maastricht University Medical Centre, Maastricht (MUMC); Atrium Medical Centre, Heerlen (AMC); and Orbis Medical Centre, Sittard (OMC). Based on this inventory, eligible candidates are invited to participate and written informed consent is obtained within 5 days after surgery. Inclusion criteria are aged 55 years and above and hospital admission for surgical treatment of hip fracture. Patients are excluded if they have a pathological or periprosthetic fracture; disease of the bone metabolism (e.g. M Paget, M Kahler, hyperparathyroidism); life expectancy of less than 1 year due to underlying disease (e.g. cancer); use oral nutritional supplements before hospital admission; are unable to speak Dutch; live outside the region of SouthLimburg, or are bedridden before the hip fracture. Patients who suffer from dementia or who are cognitively impaired according to the Abbreviated Mental Test (AMT) (a score of less than 7) are also excluded ${ }^{20,21}$.

\section{Nutritional intervention}

The nutritional intervention is a combination of dietetic counselling and oral nutritional supplements for three months. The intervention starts during hospital admission and continues after discharge during the stay at the rehabilitation clinic or at the patient's home. During hospitalization, the study dietician visits the patient twice. At the first visit, two to five days after surgery and immediately after baseline measurements, the dietician interviews the patient regarding medical and social status, and pre-fracture mobility. The dietician also performs a 24-hour recall and takes a general dietary history of the patients' diet before hospitalization. Next, the patient receives the nutritional supplement, a milk-based supplement providing $21 \mathrm{~kJ}(500 \mathrm{kcal})$ and $40 \mathrm{~g}$ of protein. The dietician advices the patient on the consumption of the supplement and arranges extra care or services to optimize the food intake if necessary. Before hospital discharge, the dietician visits the patient for the second time. During this visit, a 24-hour recall is performed and the consumption of the nutritional supplement is evaluated. Furthermore, arrangements are made to continue the dietetic advice and the consumption of the nutritional supplement at home or during the stay at the 
rehabilitation clinic. At home or during the stay in a rehabilitation clinic, the dietician visits the patient three times (one week, two weeks and six weeks after discharge) and makes five telephone calls with the patient (three, four, five, eight and ten weeks after discharge). During these visits, food intake and supplement use is assessed by a 24-hour dietary recall, and tailor-made dietetic advice is given to optimize the amount and composition of the diet. As soon as the patient meets nutritional requirements with a normal diet, the use of the nutritional supplement is stopped. Compliance with the nutritional supplement is evaluated by the 24-hour dietary recalls, patients' registration of the consumption in a diary and by collecting the capsules of the cans of the nutritional supplement during the home visits.

\section{Usual care}

Patients allocated to the control group receive usual care as provided in the hospital, rehabilitation clinic or at home, i.e. dietetic care or nutritional supplements are only provided on demand of the medical doctor in charge.

\section{Outcome assessment}

The primary outcome measure is total length of stay in hospital and rehabilitation clinics including hospital readmissions. Secondary outcome measures, assessed at three and six months after hip fracture, are nutritional status, functional status, quality of life, complication rate and one-year mortality.

Assessment of nutritional status includes total food and supplement intake, measurement of body composition, muscle strength and biochemical parameters in blood. Anthropometric measurements are body weight, height, thickness of biceps, triceps, sub-scapula and supra-iliac skinfold and circumference of mid-arm, waist and hip. Body composition is measured by bio-electrical impedance spectroscopy. Biochemical parameters include albumin, pre-albumin, CRP, hemoglobin and hematocrit in blood.

Functional status is measured by the Groningen Activity Restriction Scale (GARS) ${ }^{22}$, which assesses disability with regard to (instrumental) activities of daily living, and by the Harris Hip Score to evaluate changes in hip function.

Quality of life is measured using the EuroQoL ${ }^{23,24}$ and the Medical Outcomes Study 36 -item Short-Form Health Survey ${ }^{25,26}$. Mental state and depression is assessed by the Mini-Mental State Examination (MMSE) and the Hospital Anxiety and Depression Scale $(\mathrm{HADS})^{27,28}$. To measure fatigue, the Checklist Individual Strength $(\mathrm{CIS})^{29}$ is used.

\section{Confounders}

Pre-fracture information on co-morbidity, medication use and fracture history is obtained by interviewing the patient. Information on type of hip fracture, surgical treatment, admission and discharge dates, and post-operative complications are obtained from medical charts. 


\section{Economic evaluation}

The costs analysis will compare the costs of the nutritional intervention and the usual care over a 6-month period ${ }^{30}$. Medical and non-medical costs are obtained from a 3-month retrospective standardized costing questionnaire. Health care costs will be estimated according to the Dutch guideline for cost analysis in health care research ${ }^{31}$. Incremental costs between the strategies will be related to a difference in outcome during 6 months follow up and being expressed in an incremental cost-effectiveness ratio. Statistical uncertainty will be assessed using bootstrap simulations ${ }^{32}$.

\section{Process evaluation}

A process evaluation is carried out to evaluate whether the nutritional intervention follows the protocol, with regard to the dietetic counselling and the consumption of the nutritional supplement. The feasibility of the nutritional intervention program is evaluated through summative evaluation with the identified stakeholders being patients and health care providers (medical doctors, dieticians, nurses). Experiences and opinions on feasibility, barriers and stimulating or facilitating factors for implementing the nutritional intervention in the transmural care are identified from the stakeholders' perspective. Data are collected by structured interviews with patients and in-depth interviews in a representation of patients and health care providers. A subsample of health care providers is asked to participate in a focus group meeting. The results of the process evaluation will be used as a basis for successful implementation of the nutritional intervention program in the transmural care for hip fracture patients.

\section{Sample size / power calculation}

Nutritional intervention in hip fracture patients can result in an estimated reduction in total length of hospital and rehabilitation stay by $31.3 \%$ (SD: $59.0 \%$ ). A sample of 75 patients per treatment arm is sufficient to detect this effect with a power of $90 \%$ and a two tailed alpha of 0.05 . To detect a between-group difference in weight of $2.13 \mathrm{~kg}$ (SD: $3.72 \mathrm{~kg}$ ), a number of 61 patients per treatment arm is sufficient using the same power and alpha.

\section{Statistical analysis}

The intervention effects of primary and secondary outcome measures will be analyzed according to the intention-to-treat principle. In addition, a secondary per protocol analysis will be performed in patients with adequate compliance. After initial univariate analyses of differences in the primary outcome between the intervention and control group, multivariate analyses will be used to adjust for potential confounders such as age, gender, baseline values of nutritional status, physical disability, co-morbidity, and mental state including depression. 


\section{Discussion}

Patient recruitment has started in July 2007 and has ended in December 2009. Followup of the patients is to be completed in June 2010, except for data of one-year mortality. First results are expected in 2011. We expect that this study will answer the question whether nutritional intervention in hip fracture patients improves their nutritional and functional status, resulting in a shorter length of stay in hospital and rehabilitation clinics, fewer postoperative complications, lower mortality, and costeffectiveness. 


\section{References}

1. Barrett-Connor E. The economic and human costs of osteoporotic fracture. Am J Med. 1995;98(2A): 3S-8S.

2. De Laet CE, Pols HA. Fractures in the elderly: epidemiology and demography. Baillieres Best Pract Res Clin Endocrinol Metab. 2000;14(2):171-9.

3. Cummings SR. Treatable and untreatable risk factors for hip fracture. Bone. 1996 Mar;18(3 Suppl):165S-7S.

4. Haentjens $\mathrm{P}$, Autier $\mathrm{P}$, Barette $\mathrm{M}$, Boonen S. Costs of care after hospital discharge among women with a femoral neck fracture. Clin Orthop Relat Res. 2003(414):250-8.

5. Nurmi I, Narinen A, Luthje P, Tanninen S. Cost analysis of hip fracture treatment among the elderly for the public health services: a 1-year prospective study in 106 consecutive patients. Arch Orthop Trauma Surg. 2003;123(10):551-4.

6. Maffulli N, Dougall TW, Brown MT, Golden MH. Nutritional differences in patients with proximal femoral fractures. Age Ageing. 1999;28(5):458-62.

7. Murphy MC, Brooks CN, New SA, Lumbers ML. The use of the Mini-Nutritional Assessment (MNA) tool in elderly orthopaedic patients. Eur J Clin Nutr. 2000;54(7):555-62.

8. Lumbers M, Driver LT, Howland RJ, Older MW, Williams CM. Nutritional status and clinical outcome in elderly female surgical orthopaedic patients. Clin Nutr. 1996;15(3):101-7.

9. Paillaud E, Bories PN, Le Parco JC, Campillo B. Nutritional status and energy expenditure in elderly patients with recent hip fracture during a 2-month follow-up. Br J Nutr. 2000;83(2):97-103.

10. Patterson BM, Cornell CN, Carbone B, Levine B, Chapman D. Protein depletion and metabolic stress in elderly patients who have a fracture of the hip. J Bone Joint Surg Am. 1992;74(2):251-60.

11. Bastow MD, Rawlings J, Allison SP. Undernutrition, hypothermia, and injury in elderly women with fractured femur: An injury response to altered metabolism? Lancet. 1983;321(8317):143-6.

12. Bachrach-Lindstrom $M$, Johansson $T$, Unosson $M$, Ek AC, Wahlstrom $O$. Nutritional status and functional capacity after femoral neck fractures: a prospective randomized one-year follow-up study. Aging (Milano). 2000 Oct;12(5):366-74.

13. Bastow MD, Rawlings J, Allison SP. Benefits of supplementary tube feeding after fractured neck of femur: a randomised controlled trial. Br Med J (Clin Res Ed). 1983;287(6405):1589-92.

14. Hedstrom M. Hip fracture patients, a group of frail elderly people with low bone mineral density, muscle mass and IGF-I levels. Acta Physiol Scand. 1999;167(4):347-50.

15. Jallut D, Tappy L, Kohut M, Bloesch D, Munger R, Schutz Y, et al. Energy balance in elderly patients after surgery for a femoral neck fracture. JPEN. 1990;14(6):563-8.

16. Lumbers M, New SA, Gibson S, Murphy MC. Nutritional status in elderly female hip fracture patients: comparison with an age-matched home living group attending day centres. Br J Nutr. 2001;85(6): 733-40.

17. Avenell A, Handoll $\mathrm{HH}$. Nutritional supplementation for hip fracture aftercare in older people. Cochrane Database Syst Rev. 2006(4):CD001880.

18. Bruce D, Laurance I, McGuiness M, Ridley M, Goldswain P. Nutritional supplements after hip fracture: poor compliance limits effectiveness. Clin Nutr. 2003;22(5):497-500.

19. Duncan DG, Beck SJ, Hood K, Johansen A. Using dietetic assistants to improve the outcome of hip fracture: a randomised controlled trial of nutritional support in an acute trauma ward. Age Ageing. 2006;35(2):148-53.

20. Swain DG, Nightingale PG. Evaluation of a shortened version of the Abbreviated Mental Test in a series of elderly patients. Clin Rehabil. 1997;11(3):243-8.

21. Swain DG, O'Brien AG, Nightingale PG. Cognitive assessment in elderly patients admitted to hospital: the relationship between the shortened version of the Abbreviated Mental Test and the Abbreviated Mental Test and Mini-Mental State Examination. Clin Rehabil. 2000;14(6):608-10.

22. Kempen GI, Miedema I, Ormel J, Molenaar W. The assessment of disability with the Groningen Activity Restriction Scale. Conceptual framework and psychometric properties. Soc Sci and Med. 1996;43(11):1601-10. 
23. Tidermark J, Bergstrom G, Svensson O, Tornkvist H, Ponzer S. Responsiveness of the EuroQol (EQ 5-D) and the SF-36 in elderly patients with displaced femoral neck fractures. Qual Life Res. 2003;12(8):1069-79.

24. Tidermark J, Zethraeus N, Svensson O, Tornkvist H, Ponzer S. Femoral neck fractures in the elderly: functional outcome and quality of life according to EuroQol. Qual Life Res. 2002;11(5):473-81.

25. Aaronson NK, Muller M, Cohen PD, Essink-Bot ML, Fekkes M, Sanderman R, et al. Translation, validation, and norming of the Dutch language version of the SF-36 Health Survey in community and chronic disease populations. J Clin Epidemiol. 1998;51(11):1055-68.

26. Ware JE, Jr., Sherbourne CD. The MOS 36-item short-form health survey (SF-36). I. Conceptual framework and item selection. Med Care. 1992;30(6):473-83.

27. Scaf-Klomp W, Sanderman R, Ormel J, Kempen GI. Depression in older people after fall-related injuries: a prospective study. Age Ageing. 2003;32(1):88-94.

28. Zigmond AS, Snaith RP. The hospital anxiety and depression scale. Acta Psychiatr Scand. 1983;67(6):361-70.

29. Beurskens AJ, Bultmann U, Kant I, Vercoulen JH, Bleijenberg G, Swaen GM. Fatigue among working people: validity of a questionnaire measure. Occup Environ Med. 2000;57(5):353-7.

30. Drummond MF, Sculpher MJ, Torrance GW, O'Brien BJ, Stoddart GL. Methods for the economic evaluation of health care programmes. Third ed. Oxford: Oxford University Press; 2005.

31. Oostenbrink JB, Bouwmans CAM, Koopmanschap MA, Rutten FFH. Handleiding voor kostenonderzoek; methoden en standaard kostprijzen voor economische evaluaties in de gezondheidszorg. Amstelveen: Instituut voor Medical Technology Assessment, Erasmus MC in opdracht van College voor Zorgverzekeringen; 2004.

32. Briggs $\mathrm{AH}$. Handling uncertainty in economic evaluation and presenting the results. In: Drummond MF, McGuire A, editors. Economic evaluation in health care: merging theory with practice. Oxford: Oxford University Press; 2001. p. 172-214. 


\title{
Effects of nutritional intervention on nutritional intake and status in elderly subjects after hip fracture: a randomized controlled trial
}

\author{
Caroline E Wyers \\ José JL Breedveld-Peters \\ Petronella LM Reijven \\ JJ Chris Arts \\ Bregje JW Thomassen \\ Aart D Verburg \\ Ide C Heyligers \\ Martien CJM van Dongen \\ Piet $A$ van den Brandt \\ Svenhjalmar van Helden \\ Pieter C Dagnelie \\ Submitted for publication
}




\begin{abstract}

\section{Background \& aims}

Hip fracture patients are often malnourished at hospitalization and nutritional status can deteriorate further during admission. We investigated whether nutritional intervention combining dietetic counselling and oral nutritional supplementation improves nutritional intake and nutritional status in elderly subjects after hip fracture.
\end{abstract}

\title{
Methods
}

Open-label multi-centre randomized controlled trial with patients in the intervention group receiving nutritional intervention comprising regular dietetic counselling and oral nutritional supplementation for three months. The control group received usual dietetic care. Nutritional intake and nutritional status were assessed at baseline during hospitalization and at three and six months postoperatively.

\section{Results}

One-hundred fifty-two patients were included; 73 were randomized to the intervention group and 79 to the control group. Three months postoperatively, dietary intake of fat, fatty acids, calcium and vitamins, as well as weight, BMI, supra-iliac skin fold thickness, and blood levels of vitamin $C$ and 5-methyl-tetrahydrofolate had increased to a significantly larger extent in the intervention group compared to the control group. At six months postoperatively, only the increase of the supra-iliac skin fold thickness remained significantly different.

\section{Conclusions}

Intensive dietetic counselling and oral nutritional supplementation for three months improved nutritional intake of both macro-and micro-nutrients, and induced weight gain in elderly hip fracture patients. 


\section{Introduction}

The incidence of hip fractures in the elderly is high, with a total number of 17941 reported cases in the Netherlands in 2007, and it is expected that the incidence will increase in the future ${ }^{1,2}$. Hip fractures are one of the most common reasons for hospital admission and transfers to nursing homes in the elderly ${ }^{3}$.

An impaired nutritional status is not only a risk factor for hip fracture, but also a predictor of recovery after hip fracture ${ }^{4}$. At the time of hospitalization, the prevalence of malnutrition ranges from $42 \%{ }^{5}$ up to $63 \%{ }^{6}$ within hip fracture patients. During hospitalization, dietary intake is often insufficient ${ }^{7-13}$, due to a spontaneous reduction of food intake, lack of appetite, nausea or disliking hospital meals, resulting in further deterioration of nutritional status. A poor nutritional status among hip fracture patients has been reported to be associated with impaired muscle function, disability, loss of independence, lower mental function, decreased quality of life, delayed wound healing, a higher complication rate after surgery, prolonged rehabilitation time, and increased mortality both during and after hospital admission ${ }^{7,8,10,14-19}$.

Previous studies on the effect of nutritional intervention have shown that nutritional intervention with oral nutritional supplements (ONS) starting soon after hospital admission improved dietary intake ${ }^{12,13,20,21}$ and nutritional status ${ }^{12}$, while others failed

to show this effect ${ }^{22-26}$. Compliance with nutritional supplements is often reported to be suboptimal ${ }^{22,23,27-29}$. In one study, the authors concluded that personal attention by a dietetic assistant was effective in stimulating both dietary intake and intake of a nutritional supplement, and helped to establish a prolonged effect of the nutritional intervention ${ }^{30}$. In a recently updated Cochrane review ${ }^{31}$ it was concluded that the overall evidence for the efficacy of ONS in elderly hip fracture patients remains limited, and future research should investigate both the role of ONS and the role of dieticians or extra staff providing feeding assistance. Furthermore, such future trials should be adequately powered and nutritional status should be taken into account as an outcome parameter $^{31}$.

The aim of the present study was to investigate the effect of intensive dietary intervention comprising combined dietetic counselling and ONS during hospitalization and after discharge on nutritional intake and status in elderly subjects after hip fracture. We hypothesized that the combination of dietetic counselling and ONS would improve patients' energy and protein intake and nutritional status.

\section{Subjects and methods}

\section{Subjects}

Eligible patients were admitted for surgical treatment of hip fracture, and aged 55 years and above ${ }^{32}$. Patients were excluded if they had a pathological or periprosthetic fracture; a disease of bone metabolism (e.g. Paget's disease, Kahler's 
disease, hyperparathyroidism); a life expectancy of less than 1 year due to underlying disease; used ONS before hospital admission; if they were unable to speak Dutch; lived outside the region; or were bedridden before the hip fracture. Patients were also excluded if they had dementia or were cognitively impaired, defined as a score of $<7$ on the Abbreviated Mental Test (AMT) ${ }^{33}$.

\section{Study design}

The study was designed as an open-label parallel multi-centre, randomized controlled trial $^{32}$. For patient recruitment, a daily inventory of hip fracture patients admitted to the surgical and orthopaedic wards of three hospitals in South-Limburg in The Netherlands was made. Eligible patients were invited to participate and written informed consent was obtained within five days after surgery. After informed consent, baseline measurements were performed by a trained researcher and randomization was performed according to a computer-generated random-number sequence list after pre-stratification for hospital, gender and age (55-74 years vs. 75 years and above) with allocation ratio 1:1. The researcher made a telephone call to an independent research assistant who took a sequentially numbered and sealed envelope, and informed the researcher to which group the patient had been allocated. Patients allocated to the intervention group received dietetic counselling and ONS for three months after fracture, whereas patients in the control group received usual nutritional care. All patients were discharged from the hospital to either a rehabilitation clinic or to the patient's home with home care or to the nursing home if they had lived there before hospitalization. Three and six months postoperatively, the trained researcher performed the outcome measurements, and one of the study dieticians took a general dietary history and 24-hour recall at the patient's home.

The study was approved by the Medical Ethical Committee of Maastricht University Hospital and Maastricht University and conducted according to the Declaration of Helsinki.

\section{Sample size calculation}

We calculated that 61 patients per treatment arm would be sufficient to detect a between group difference in weight change of $2.1 \mathrm{~kg}$ (SD: $3.7 \mathrm{~kg}$ ) with a power of $90 \%$ and a two-tailed alpha of $0.05^{25,32}$.

\section{Nutritional intervention}

The nutritional intervention was a combination of regular dietetic counselling and consumption of a multi-nutrient ONS for a period of three months, starting during hospital admission and continuing in the rehabilitation centre or at home. Dietetic counselling included the following elements: checking the patients' food habits and preferences, identifying possible deficiencies in nutrient intake, and checking practical 
difficulties with eating during hospitalization and rehabilitation, as well as in the home situation.

A dietician visited each patient twice during their hospital stay. At the first visit, the dietician took a 24-hour recall of the patient's diet. To optimise normal food intake, all patients received an energy- and protein-enriched diet and recommendations were given with regard to choice, quantity and timing of food products and the ONS. Nutritional requirements for energy were calculated according to Harris-Benedict equation $^{34}$, including an individual surplus stress and activity factor ranging from $20 \%$ to $40 \%$. Protein requirement was calculated as body weight $\times 1.5$ g protein $^{35}$. In addition to the energy- and protein enriched diet, all patients were advised to consume two bottles of an ONS daily in-between the main meals. The nutritional supplement was a milk-protein based ONS (Cubitan, N.V. Nutricia, Zoetermeer, The Netherlands) providing $2.1 \mathrm{MJ}(500 \mathrm{kcal})$ and $40 \mathrm{~g}$ of protein per two bottles. If a patient did not tolerate the milk-based supplement, a yoghurt-style or juice-style supplement (Nutridrink Yoghurt Style or Nutridrink Juice Style, N.V. Nutricia, Zoetermeer, The Netherlands) was offered. Furthermore, the dietician made necessary arrangements in order to solve any problems, e.g. feeding problems, in collaboration with the hospital medical and nursing staff.

At the second visit during hospitalization, seven to eight days after surgery, the dietician evaluated nutritional intake, including the intake of ONS using a 24-hour recall, and gave individual tailored advice to optimize dietary intake. During this visit, the transfer of the patient to the rehabilitation centre or the patient's home was prepared by evaluating the patient's physical restrictions with regard to nutritional care, i.e. purchasing food products and the preparation of meals, and by making arrangements to enable adequate food intake, e.g. support of informal caregivers and delivery of information on meal services.

After hospital discharge, the dietician visited each patient three times $(1,2$ and 6 weeks after discharge) at the patient's home or in the rehabilitation centre to evaluate dietary intake including the intake of the ONS, to evaluate the constraints in the nutritional care, and to give dietary advice if necessary. If the patient was still unable to meet nutritional requirements by normal food intake, continuation of the ONS consumption was advised. In addition, in-between these face to face contacts, weekly telephone calls were made $(3,4,5,8$, and 10 weeks after discharge) to evaluate both the dietary intake and the intake of the ONS by a 24-hour recall. If necessary, a telephone call was replaced by a home visit. As the patient's diet increased towards the nutritional requirements according to the guidelines for a healthy diet, the consumption of the ONS was gradually decreased and the patient was advised to maintain a healthy diet. If necessary, a vitamin D supplement was advised. 


\section{Usual care}

Patients allocated to the control group received usual care as provided in the hospital, rehabilitation clinic or at home, i.e. dietetic care or nutritional supplements were only provided on demand of the medical doctor in charge.

\section{Outcome assessment}

To evaluate dietary intake, the dietician took a 24-hour recall at baseline, one week, three months and six months postoperatively. Intake of energy, protein and other nutrients were calculated by Komeet (BaS Nutrition Software, Arnhem, The Netherlands) using the Dutch Food Composition Table 2006 (NEVO, The Hague, The Netherlands). The intake of energy was sufficient if the patient consumed at least $80 \%$ of the energy requirements as proposed by the Netherland Nutrition Centre Foundation (women 55-70 years $1900 \mathrm{kcal} /$ day; women >71 years $1600 \mathrm{kcal} /$ day; men $55-70$ years $2300 \mathrm{kcal} /$ day; men $>71$ years $1900 \mathrm{kcal} /$ day).

Patients' adherence to recommendations regarding the ONS and on improving dietary intake were evaluated over two periods; an early post-operative period (between 0-10 days after surgery), and a late postoperative period (between 11 days after surgery until 3 months after surgery). Patients were considered to be adherent with ONS advice if the intake of the supplement was at least $75 \%$ of the recommended amount. With regard to the nutritional recommendations, patients were considered to be adherent if they had followed the recommendations in at least $75 \%$ of the visits and telephone calls. Patients not needing nutritional advice were considered to be adherent.

Anthropometric measurements were performed at baseline, three months and six months postoperatively. At baseline, body weight and height were reported by the patient and used for calculation of energy and protein requirement, and Body Mass Index (BMI). Three and six months postoperatively, weight and height were measured using an electronic weighing scale (Seca 862, Seca Ltd, Birmingham, UK), and a portable stature meter (Instrument Development Engineering \& Evaluation - IDEE Maastricht University Medical Center, Maastricht, The Netherlands). Upper arm circumference was measured with a flexible measuring tape (Seca 201, Seca Ltd, Birmingham, UK). A Holtain Skin fold Caliper (CMS weighing equipment LTD, London, UK) was used to measure the thickness of biceps, triceps, and supra-iliac skin folds. Handgrip strength was measured using a Jamar hydraulic handgrip dynamometer (Saehan Corp., Masan, Korea). Mid arm muscle area was calculated according to the formula of Frisancho ${ }^{36}$.

Biochemical parameters, albumin, pre-albumin, C-reactive protein (CRP), vitamin A, vitamin $E$, vitamin $C$, uric acid, homocysteine, and 5-methyl-tetrahydrofolate were measured in blood samples at baseline, three weeks, and three and six months postoperatively. 


\section{Confounders and stratification variables}

The following potential confounders were recorded from the medical charts; fracture type (medial neck, pertrochanteric fracture, subtrochanteric fracture), type of surgery (gamma nail, dynamic hip screw, 3 cannulated screws, hemi-arthroplasty, total hip replacement), type of anaesthesia, medical history, and medication use. All patients received daily physical therapy during hospitalization, and after discharge in the rehabilitation clinic or at the patient's home.

At baseline, the Mini Nutritional Assessment (MNA) was used to classify the patients according to their risk of malnutrition at baseline $(38,39)$. The MNA distinguishes three categories; malnutrition, at risk of malnutrition and no malnutrition. For our study, the categories malnutrition and at risk of malnutrition were combined, further called "malnourished", and compared with not malnourished patients, called "well nourished".

\section{Data analysis}

Statistical analysis was performed using SPSS 15.0 for Windows (SPSS Inc., Chicago, IL, USA). Baseline characteristics were analyzed using descriptive statistics. Normality was tested using the Komolgorov-Smirnov test. Normally distributed data are presented as means \pm standard errors (SEM); not normally distributed data as median and range. Data analysis was performed according to the intention-to-treat principle, and missing values for outcome parameters six months postoperatively for patients who otherwise had a complete data set were imputed by last observation (three months) carried forward. Data substitution for all patients, including deceased patients, did not yield different results and were therefore not reported. First, analyses to detect differences between both groups were performed using, analysis of covariance, adjusting for the stratification variables (centre, gender, and age), and baseline values of the concerned outcome parameter. Next, multivariate analyses of covariance were performed with additional adjustment for fracture type, neurological disease, Crohn's disease, and rheumatoid arthritis, and health status before fracture. The results of both models were not different, and only fully adjusted models are presented. The intervention effect was defined as the difference in change between the intervention and control group from baseline to one week, three weeks, three months and six months postoperatively. P-values of $<0.05$ were considered to be statistically significant.

\section{Results}

\section{Participants and baseline measurements}

From July 2007 until December 2009, a total of 1304 hip fracture patients were screened for eligibility, resulting in 895 (69\%) patients who did not meet the inclusion criteria, mainly due to cognitive impairment (52\%) (Figure 3.1). Two-hundred fifty- 
seven (20\%) patients refused to participate. Of the resulting 152 patients who gave informed consent, 73 were allocated to the intervention group and 79 to the control group. During the three-month intervention period, seven patients passed away, and seven patients withdrew their participation, resulting in 138 assessable patients (68 intervention, 72 control) at 3 months. During the follow-up (3-6 months after surgery), four patients passed away, and three patients withdrew their participation, resulting in 63 patients in the intervention group and 68 patients in the control group who completed follow-up

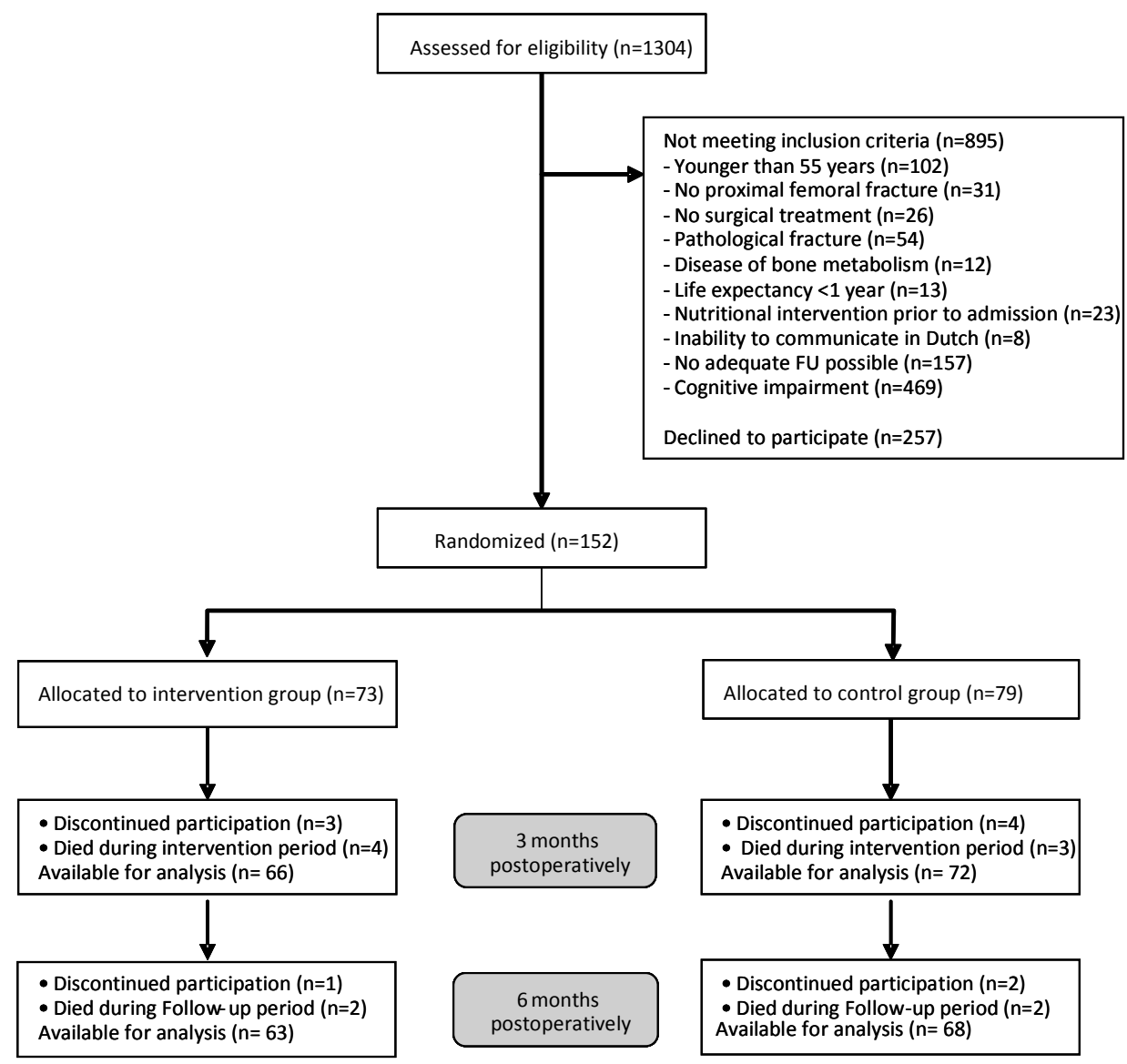

Figure 3.1 Trial flow chart.

At baseline, both groups were comparable with respect to sex and age (Table 3.1). In both groups, the majority of the patients had sustained a fracture of the medial neck of the femur ( $49 \%$ vs. $57 \%$ ), but in the intervention group as compared to the control 
group more patients had received gamma nail (51\% vs. 30\%) and fewer patients had received hemi-arthroplasty ( $26 \%$ vs. $38 \%)$. With respect to medical history, rheumatoid arthritis was more prevalent in the intervention group (30\% vs. $20 \%$ ), whereas neurological diseases were less prevalent than in the control group (23\% vs. $35 \%)$. Furthermore, in the intervention group $35 \%$ of the patients were malnourished (including patients at risk of malnutrition as defined by the MNA) as compared to $47 \%$ of the patients in the control group (Table 3.1). Baseline nutritional intake of macroand micro-nutrients (Table 3.2) and biochemical parameters (Table 3.4) were comparable in both groups. With respect to baseline nutritional and functional status (Table 3.3), all mean values of the parameters were higher in the intervention group, except handgrip strength was higher in the control group.

Table 3.1 Baseline characteristics of the study population.

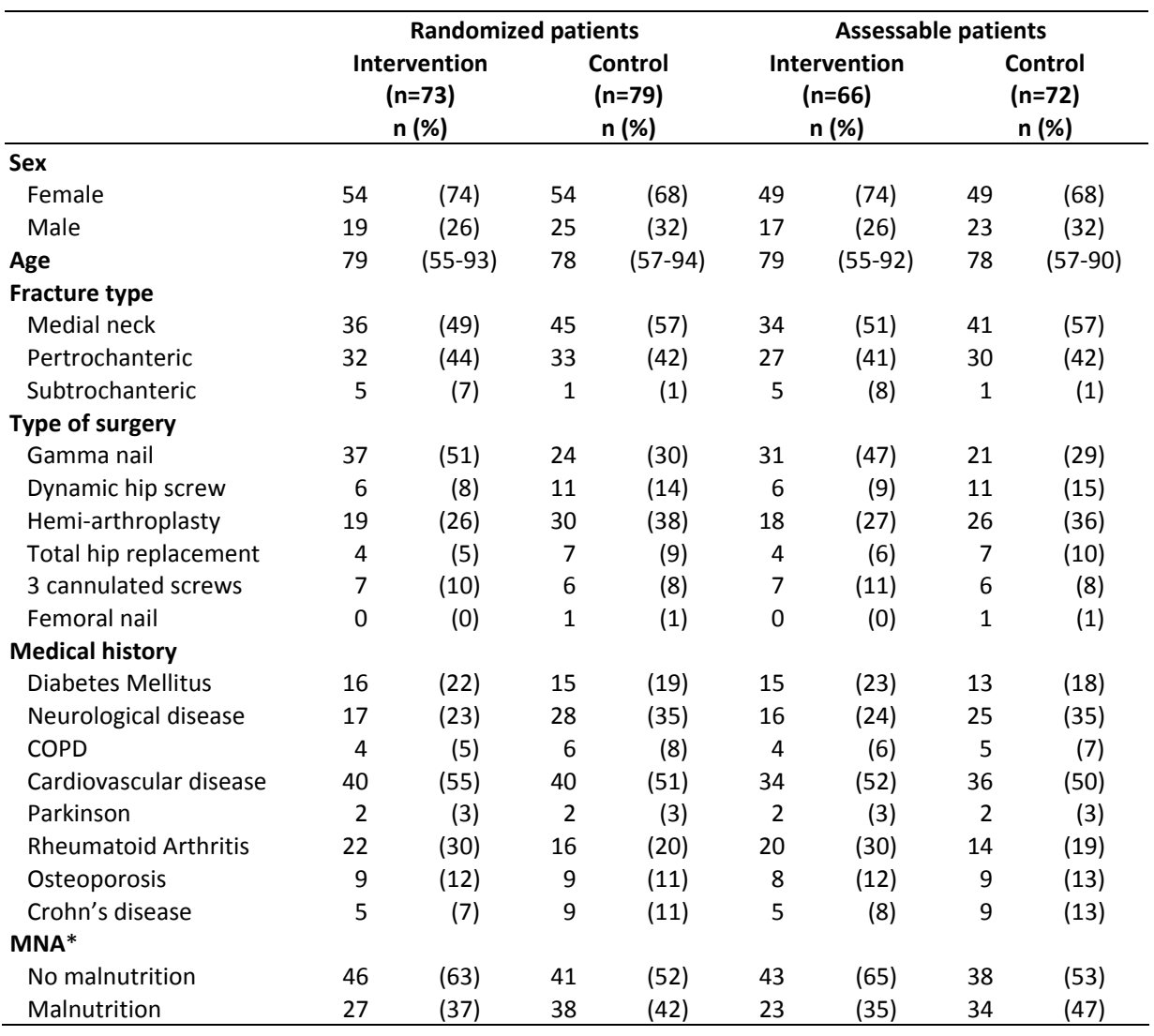

* Mini Nutritional Assessment. In our study, malnourished patients and patients at risk of malnutrition were combined. 


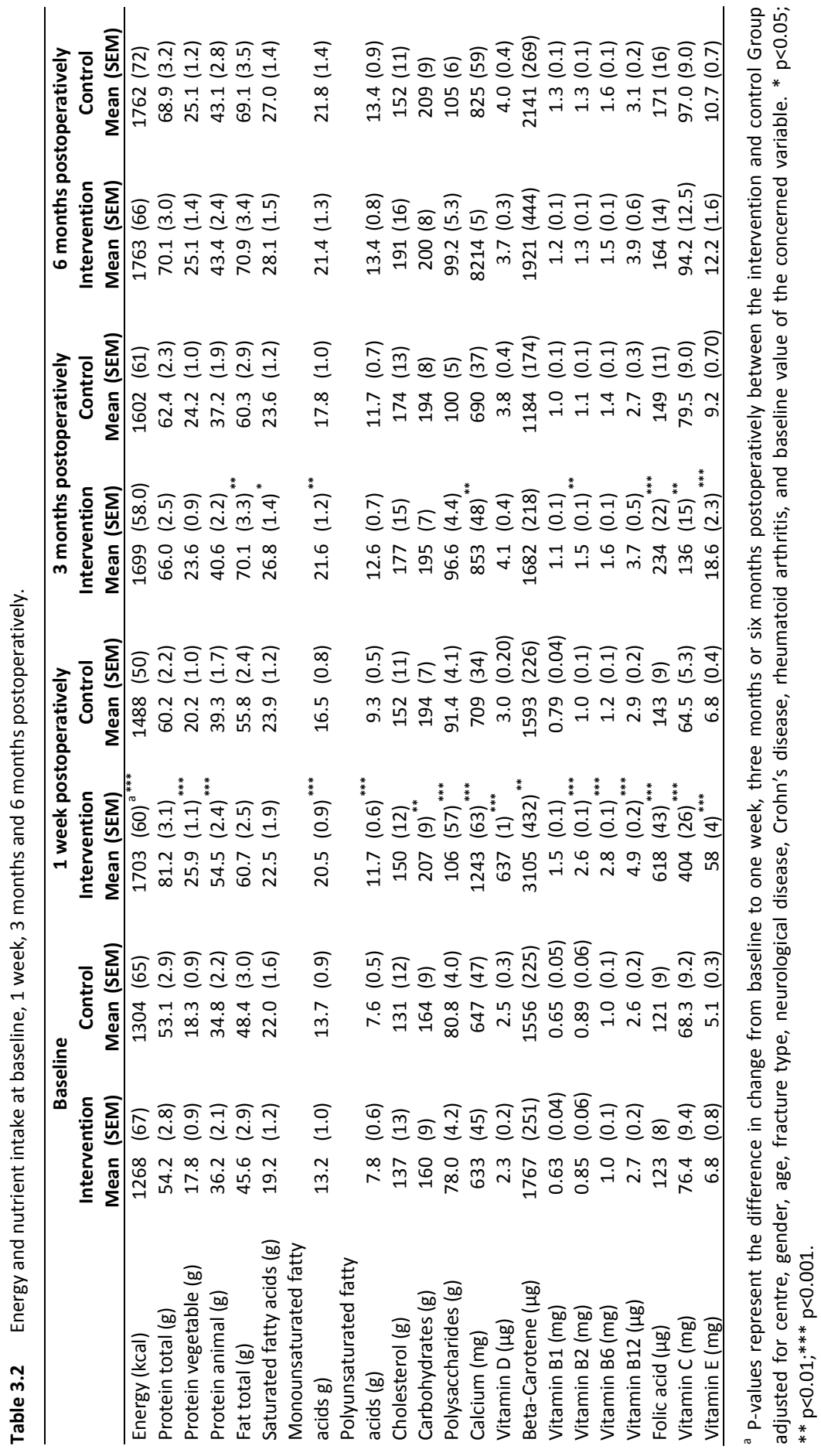



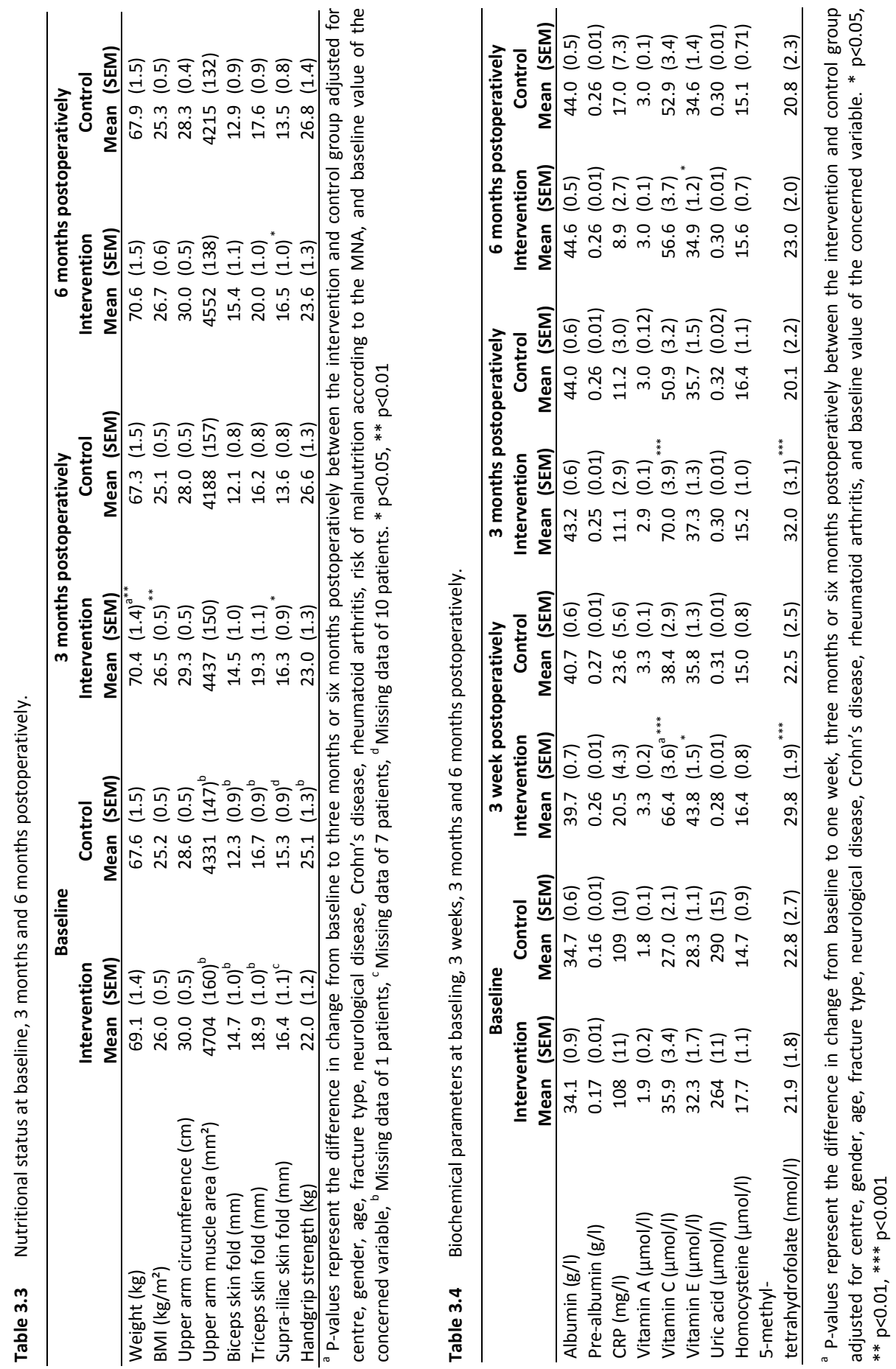


\section{Oral nutritional supplementation and dietetic counselling}

In the intervention group, three out of 73 patients already had started with the consumption of an ONS on medical indication. After randomization, all patients in the intervention group, except one, had started the consumption of ONS, with a median delay of 4 days (range: 1-6 days) postoperatively. The median period of supplementation use was 76 days (range: 3-91 days). At the end of the intervention period ( 3 months postoperatively), 11 (15\%) patients randomized to the intervention group still did not meet the nutritional requirements and were therefore transferred to the home care dietician for continued dietetic counselling.

During hospitalization, $67 \%$ of the patients were adherent with the nutritional recommendations as given by the dietician and $79 \%$ were adherent with ONS. After discharge, the adherence with the nutritional recommendations increased up to $73 \%$, and the adherence with ONS remained at $80 \%$. One patient in the intervention group developed bleeding due to a stomach ulcer. The ONS was temporarily stopped and restarted after recovery. No adverse events related to the nutritional intervention were noted.

In the control group, five out of 79 patients had started with the consumption of ONS on medical indication before randomization; over the 6 months study period, seven additional patients randomized to the control group received ONS provided by the usual care dietician on demand of the medical doctor in charge ( 2 patients during hospitalization, 3 patients in the rehabilitation clinic, and 2 patients at home). Seven patients received dietetic counselling by a dietician and were advised to change their diet ( 3 patients during hospitalization, and 4 patients in the rehabilitation clinic).

\section{Dietary intake}

At baseline, the median required energy intake according to Harris-Benedict ${ }^{34}$ including $20 \%$ stress factor was similar in both groups. In both groups, energy and protein intake increased during the intervention period, and the increase was higher in the intervention group, mainly due to ONS consumption (Figure 3.2, Figure 3.3). One week postoperatively, the intake of all nutrients except total fat, saturated fatty acids and cholesterol had increased to a significantly larger extent in the intervention group compared to the control group (Table 3.2). In the intervention group, $75 \%$ of the patients met their energy requirements as compared to only $55 \%$ in the control group. Mean protein intake in the intervention group was $1.2 \mathrm{~g} / \mathrm{kg}$ as compared to $0.9 \mathrm{~g} / \mathrm{kg}$ in the control group.

Three months postoperatively, this intervention effect remained significant for total fat, saturated fatty acids, mono-unsaturated fatty acids, calcium, vitamin B2, vitamin C, vitamin $E$ and folic acid (Table 3.2). Seventy percent in the intervention group vs. $68 \%$ in the control group met the nutritional requirements for energy. Mean protein intake was similar in both groups $(0.9 \mathrm{~g} / \mathrm{kg})$. 
Six months postoperatively, the intervention effect on nutritional intake was no longer statistically significant (Table 3.2). The energy intake met the nutritional requirements in $75 \%$ of the intervention group and in $69 \%$ of the control group. Mean protein intake was similar in both groups $(1.0 \mathrm{~g} / \mathrm{kg})$.

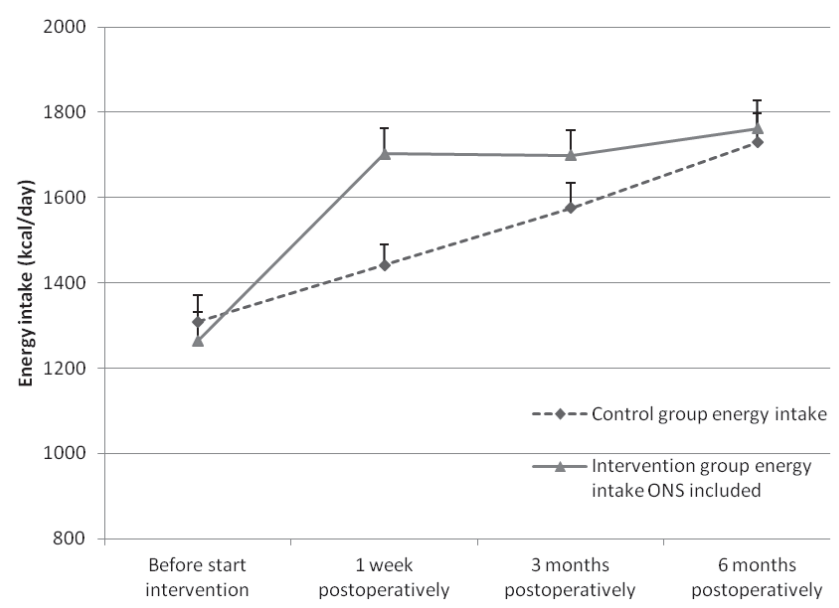

Figure 3.2 Energy intake over time in the intervention and control group.

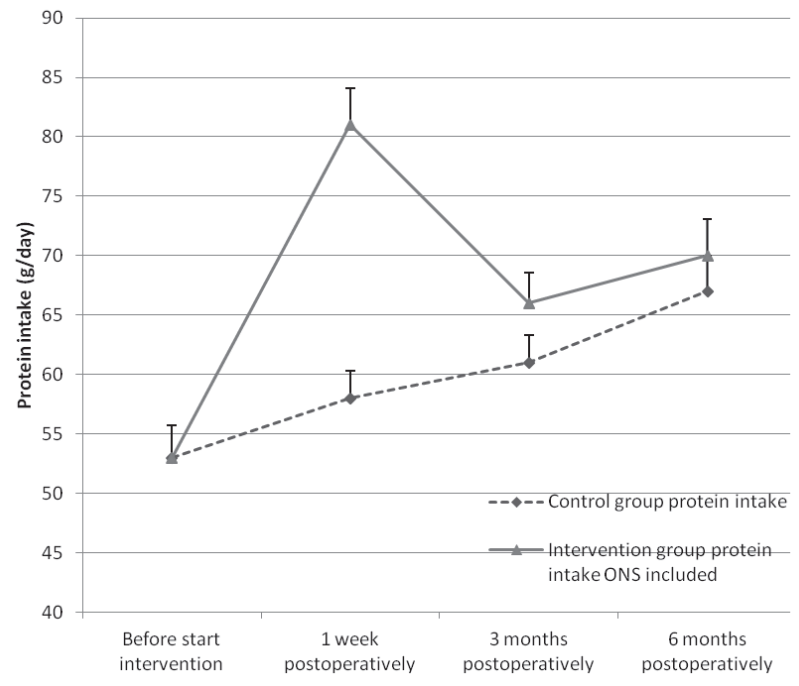

Figure 3.3 Protein intake over time in the intervention and control group. 


\section{Nutritional status}

As shown in Table 3.3, three months postoperatively, weight and BMI had significantly increased to a larger extent in the intervention group compared to the control group ( $p=0.005$ for weight; $p=0.005$ for $\mathrm{BMI}$ ); a positive intervention effect was also found for supra-iliac skin fold thickness $(p=0.022)$. No differences were found for other parameters. Six months postoperatively, the significant intervention effect only remained for supra-iliac skin fold thickness $(p=0.021)$.

With respect to handgrip strength, no significant intervention effect was found at three and six months postoperatively.

At three weeks postoperatively, a positive intervention effect was found for the blood levels of vitamin C, vitamin E and 5-methyl-tetrahydrofolate (Table 3.4). At three months postoperatively, a positive intervention effect remained for the levels of vitamin C and 5-methyl-tetrahydrofolate. At six months postoperatively, a negative intervention effect was found for the blood level of vitamin E, it decreased to a significantly larger extent in the intervention group compared with the control group. The other levels of biochemical parameters did not show an intervention effect.

\section{Discussion}

In this study we aimed to assess whether nutritional intervention comprising dietetic counselling and ONS would improve dietary intake and nutritional status of elderly subjects after hip fracture. Results showed that the intake of energy, protein, fat, carbohydrates, vitamins and micro-nutrients increased to a significantly larger extent in the intervention group at one week postoperatively. Blood levels of vitamin C, vitamin $\mathrm{E}$, homocysteine and 5-methyl-tetrahydrofolate measured at three weeks postoperatively, also showed a positive intervention effect. At three months postoperatively, the positive intervention effect for the intake of total fat, fatty acids, calcium and several vitamins was still statistically significant. A positive intervention effect was also found for weight, BMI, supra-iliac skin fold thickness, and blood levels of vitamin C and 5-methyl-tetrahydrofolate at three months postoperatively. At six months postoperatively, the effect of the nutritional intervention on dietary intake was no longer significantly different; only supra-iliac skin fold thickness and the level of vitamin $\mathrm{C}$ in blood showed a positive intervention effect at this time point.

To our knowledge, this is the first study in hip fracture patients combining dietetic counselling and ONS over a three month period. Because of the regular home visits and telephone calls, as a part of the dietetic counselling, study dieticians could anticipate quickly if the patient experienced problems with their normal diet or with the consumption of ONS. Usual dietary intake was not decreased by the ONS (data not shown), possibly because it was offered as an in-between meal. We chose for a long intervention period of three months with continuation of the intervention after hospital discharge, because full recovery after hip fracture takes several months, and 
in addition, requires adaptations in the home environment due to increased nutritional requirements for energy an protein, combined with patient's physical restriction with regard to nutritional care, i.e. purchasing food products and the preparation of meals. We have included both well-nourished and malnourished patients as both are at risk to become malnourished or more severely malnourished during hospitalisation, due to a decline in nutritional intake caused by fasting before surgery and/or lack of appetite or nausea after surgery. By providing the nutritional intervention to all hip fracture patients regardless their baseline nutritional status, we aimed to minimise the effects of metabolic trauma after hip fracture.

Our data confirm the results of previous studies, which used only ONS or dietetic assistants as a nutritional intervention, with regard to the positive intervention effect on intake of energy, protein, micro-nutrients and vitamins ${ }^{12,13,21,30}$. Moreover, with regard to nutritional status, our data show an additional consistent positive intervention effect on weight, BMI, and supra-iliac skin fold thickness, while previous studies showed no or non-significant improvements only ${ }^{12,24,27}$. Compliance with the ONS and the nutritional recommendations was high in our study, as also confirmed by blood levels of vitamin C and vitamin $\mathrm{E}$ three weeks postoperatively, as compared to studies in hip fracture patients in which compliance with the nutritional supplements was often suboptimal ${ }^{22,27-29}$. Our results corroborate the findings of Duncan et al. ${ }^{30}$ who showed that patients receiving dietetic assistance had an improved supplement intake compared with patients not receiving assistance. Very recently, Hoekstra et al. ${ }^{41}$ reported an improvement of nutritional intake after nutritional intervention in nonrandomized in hip fracture patients; however, body composition was not improved.

Some limitations of our study should be noted. First, during the inclusion period, $68 \%$ of the patients who were screened for eligibility did not meet the inclusion criteria, mainly due to cognitive impairment, and $20 \%$ of patients refused to participate. To explore whether this might have influenced the external validity, we measured body weight, height, upper arm circumference and triceps skin fold thickness within a random selection of patients not meeting the inclusion criteria or refusing participation. Results indicated that these patients did not significantly differ in these nutritional status parameters from the patients included in the trial (data not shown). Second, our study was not blinded, meaning that patients, dieticians and researcher were not blinded for group allocation, which could have introduced bias. We tried to minimize this bias by having the outcome measurements performed by a trained researcher who was not involved in the nutritional intervention. Finally, several patients randomized to the control group have received nutritional support by ONS or dietetic counselling. It is possible that our study increased the awareness of nursing staff or dieticians with regard to malnutrition or identifying hip fracture patients at risk of malnutrition, resulting in a higher request for dietetic care, and thereby attenuating the effect of our nutritional intervention.

In conclusion, the combination of intensive dietetic counselling and ONS over three months after hip fracture had a favourable effect on energy, protein and micro- 
nutrient intake at one week postoperatively. Furthermore, we found a positive effect of the nutritional intervention on weight, BMI, and supra-iliac skin fold thickness at three months after hip fracture. At six months postoperatively, dietary intake and nutritional status were no longer significantly different between both groups. Our results indicate that future intervention studies should focus on long-lasting intervention, comprising both frequent dietetic counselling and ONS. 


\section{References}

1. Hoeymans N, Melse JM, Schoemaker CG. Health and determinants. Section of the report Public Health Future Exploration 2010. From Healthy to better. [Gezondheid en determinanten. Deelrapport van de Volksgezondheid Toekomst Verkenning 2010. Van gezond naar beter. ]. Bilthoven: National Institute for Public Health and the Environment [RIVM]2010.

2. De Laet CE, Pols HA. Fractures in the elderly: epidemiology and demography. Baillieres Best Pract Res Clin Endocrinol Metab. 2000;14(2):171-9.

3. Cummings SR. Treatable and untreatable risk factors for hip fracture. Bone. 1996 Mar;18(3 Suppl):165S-7S.

4. Bonjour JP, Schurch MA, Rizzoli R. Nutritional aspects of hip fractures. Bone. 1996 Mar;18(3 Suppl):139S-44S.

5. Maffulli N, Dougall TW, Brown MT, Golden MH. Nutritional differences in patients with proximal femoral fractures. Age Ageing. 1999;28(5):458-62.

6. Murphy MC, Brooks CN, New SA, Lumbers ML. The use of the Mini-Nutritional Assessment (MNA) tool in elderly orthopaedic patients. Eur J Clin Nutr. 2000 Jul;54(7):555-62.

7. Jallut D, Tappy L, Kohut M, Bloesch D, Munger R, Schutz Y, et al. Energy balance in elderly patients after surgery for a femoral neck fracture. JPEN. 1990;14(6):563-8.

8. Lumbers M, New SA, Gibson S, Murphy MC. Nutritional status in elderly female hip fracture patients: comparison with an age-matched home living group attending day centres. Br J Nutr. 2001;85(6): 733-40.

9. Nematy $\mathrm{M}$, Hickson $\mathrm{M}$, Brynes $\mathrm{AE}$, Ruxton $\mathrm{CH}$, Frost GS. Vulnerable patients with a fractured neck of femur: nutritional status and support in hospital. J Hum Nutr Diet. 2006 Jun;19(3):209-18.

10. Patterson BM, Cornell CN, Carbone B, Levine B, Chapman D. Protein depletion and metabolic stress in elderly patients who have a fracture of the hip. J Bone Joint Surg Am. 1992;74(2):251-60.

11. Stableforth PG. Supplement feeds and nitrogen and calorie balance following femoral neck fracture. $\mathrm{Br}$ J Surg. 1986 Aug;73(8):651-5.

12. Delmi M, Rapin CH, Bengoa JM, Delmas PD, Vasey H, Bonjour JP. Dietary supplementation in elderly patients with fractured neck of the femur. Lancet. 1990 Apr 28;335(8696):1013-6.

13. Eneroth M, Olsson UB, Thorngren KG. Insufficient fluid and energy intake in hospitalised patients with hip fracture. A prospective randomised study of 80 patients. Clin Nutr. 2005 Apr;24(2):297-303.

14. Bastow MD, Rawlings J, Allison SP. Undernutrition, hypothermia, and injury in elderly women with fractured femur: An injury response to altered metabolism? Lancet. 1983;321(8317):143-6.

15. Paillaud E, Bories PN, Le Parco JC, Campillo B. Nutritional status and energy expenditure in elderly patients with recent hip fracture during a 2-month follow-up. Br J Nutr. 2000;83(2):97-103.

16. Bachrach-Lindstrom $M$, Johansson $T$, Unosson $M$, Ek AC, Wahlstrom $O$. Nutritional status and functional capacity after femoral neck fractures: a prospective randomized one-year follow-up study. Aging (Milano). 2000 Oct;12(5):366-74.

17. Bastow MD, Rawlings J, Allison SP. Benefits of supplementary tube feeding after fractured neck of femur: a randomised controlled trial. BMJ. (Clin Res Ed). 1983;287(6405):1589-92.

18. Hedstrom M. Hip fracture patients, a group of frail elderly people with low bone mineral density, muscle mass and IGF-I levels. Acta Physiol Scand. 1999;167(4):347-50.

19. Lumbers M, Driver LT, Howland RJ, Older MW, Williams CM. Nutritional status and clinical outcome in elderly female surgical orthopaedic patients. Clin Nutr. 1996;15(3):101-7.

20. Stratton RJ, King CL, Stroud MA, Jackson AA, Elia M. Malnutrition Universal Screening Tool predicts mortality and length of hospital stay in acutely ill elderly. British Journal of Nutrition. 2006;95(02): 325-30.

21. Neumann M, Friedmann J, Roy MA, Jensen GL. Provision of high-protein supplement for patients recovering from hip fracture. Nutrition. 2004 May;20(5):415-9.

22. Williams CM, Driver LT, Older J, Dickerson JW. A controlled trial of sip-feed supplements in elderly orthopaedic patients. Eur J Clin Nutr. 1989 Apr;43(4):267-74.

23. Lawson RM, Doshi MK, Ingoe LE, Colligan JM, Barton JR, Cobden I. Compliance of orthopaedic patients with postoperative oral nutritional supplementation. Clin Nutr. 2000;19(3):171-5. 
24. Botella-Carretero JI, Iglesias B, Balsa JA, Zamarron I, Arrieta F, Vazquez C. Effects of oral nutritional supplements in normally nourished or mildly undernourished geriatric patients after surgery for hip fracture: a randomized clinical trial. JPEN J Parenter Enteral Nutr. 2008 Mar-Apr;32(2):120-8.

25. Tidermark J, Ponzer S, Carlsson P, Soderqvist A, Brismar K, Tengstrand B, et al. Effects of protein-rich supplementation and nandrolone in lean elderly women with femoral neck fractures. Clin Nutr. 2004 Aug;23(4):587-96.

26. Brown KM, Seabrook NA. Nutritional influences on recovery and length of hospital stay in elderly women following femoral fracture. Proc Nutr Soc. [Abstract]. 1992;51(2):132A.

27. Bruce D, Laurance I, McGuiness M, Ridley M, Goldswain P. Nutritional supplements after hip fracture: poor compliance limits effectiveness. Clin Nutr. 2003;22(5):497-500.

28. Larsson J, Unosson M, Ek AC, Nilsson L, Thorslund S, Bjurulf P. Effect of dietary supplement on nutritional status and clinical outcome in 501 geriatric patients--a randomised study. Clin Nutr. 1990 Aug;9(4):179-84.

29. Lawson RM, Doshi MK, Barton JR, Cobden I. The effect of unselected post-operative nutritional supplementation on nutritional status and clinical outcome of orthopaedic patients. Clin Nutr. 2003 Feb;22(1):39-46.

30. Duncan DG, Beck SJ, Hood K, Johansen A. Using dietetic assistants to improve the outcome of hip fracture: a randomised controlled trial of nutritional support in an acute trauma ward. Age Ageing. 2006;35(2):148-53

31. Avenell A, Handoll HH. Nutritional supplementation for hip fracture aftercare in older people. Cochrane Database Syst Rev. 2006(4):CD001880.

32. Wyers CE, Breedveld-Peters JJ, Reijven PL, van Helden S, Guldemond NA, Severens JL, et al. Efficacy and cost-effectiveness of nutritional intervention in elderly after hip fracture: design of a randomized controlled trial. BMC Public Health. 2010;10:212.

33. Swain DG, Nightingale PG. Evaluation of a shortened version of the Abbreviated Mental Test in a series of elderly patients. Clin Rehabil. 1997;11(3):243-8.

34. Roza AM, Shizgal HM. The Harris Benedict equation reevaluated: resting energy requirements and the body cell mass. Am J Clin Nutr. 1984;40(1):168-82.

35. Wolfe RR, Miller SL, Miller KB. Optimal protein intake in the elderly. Clinical Nutrition. 2008;27(5):67584.

36. Frisancho AR. New norms of upper limb fat and muscle areas for assessment of nutritional status. Am J Clin Nutr. 1981 November 1, 1981;34(11):2540-5.

37. Suurmeijer TP, Doeglas DM, Moum T, Briancon S, Krol B, Sanderman R, et al. The Groningen Activity Restriction Scale for measuring disability: its utility in international comparisons. Am J Public Health. 1994 Aug;84(8):1270-3.

38. Guigoz Y. The Mini Nutritional Assessment (MNA) review of the literature--What does it tell us? J Nutr Health Aging. 2006 Nov-Dec;10(6):466-85; discussion 85-7.

39. Vellas B, Guigoz Y, Garry PJ, Nourhashemi F, Bennahum D, Lauque S, et al. The Mini Nutritional Assessment (MNA) and its use in grading the nutritional state of elderly patients. Nutrition. 1999 Feb;15(2):116-22.

40. EuroQol--a new facility for the measurement of health-related quality of life. The EuroQol Group. Health Policy. 1990 Dec;16(3):199-208.

41. Hoekstra JC, Goosen JH, de Wolf GS, Verheyen CC. Effectiveness of multidisciplinary nutritional care on nutritional intake, nutritional status and quality of life in patients with hip fractures: a controlled prospective cohort study. Clin Nutr. 2011 Aug;30(4):455-61. 


\section{4}

\section{Integrated nutritional intervention in the elderly after hip fracture. A process evaluation}

José JL Breedveld-Peters Petronella LM Reijven Caroline E Wyers Svenhjalmar van Helden JJ Chris Arts Berry Meesters Martin H Prins Trudy van der Weijden

Pieter C Dagnelie 


\section{Abstract}

\section{Background \& aims}

Within a multicentre randomized controlled trial aimed at improving the nutritional status and increase the speed of recovery of elderly hip fracture patients, we performed a process evaluation to investigate the feasibility of the intervention within the present Dutch health care system.

\section{Methods}

Patients in the intervention group received nutritional counselling during ten contacts. Oral nutritional supplements were advised as needed until three months after hip fracture surgery. The intervention was evaluated with respect to dieticians' adherence to the study protocol, content of nutritional counselling, and patients' adherence to recommendations given.

\section{Results}

We included 66 patients (age of 76, range $55-92$ years); $74 \%$ women. $83 \%$ of patients received all ten contacts as planned, but in $62 \%$ of the patients one or more telephone calls had to be replaced by face to face contacts. Nutritional counselling was complete in $91 \%$ of contacts. Oral nutritional supplementation was needed for a median period of 76 days; $75 \%$ of the patients took the oral nutritional supplements as recommended.

\section{Conclusions}

Nutritional counselling in elderly hip fracture patients through face to face contacts and telephone calls is feasible. However, individual tailoring of the intervention is recommended. The majority of hip fracture patients needed $>2$ months oral nutritional supplements to meet their nutritional requirements. 


\section{Introduction}

Hip fractures are one of the most common reasons for hospital admission and transfers to nursing homes ${ }^{1}$. The incidence of hip fractures in the elderly is high and the burden for society will increase in the near future due to changes in age demographics, and increased life expectancy ${ }^{2}$. The prevalence of malnutrition in older patients admitted to hospitals is high, ranging from 25 to $60 \%{ }^{3,4}$ Specifically, in hip fracture patients it ranges from $2 \%^{5}$ to $63 \%$. During hospital admission, the nutritional status can deteriorate further due to increased energy expenditure caused by metabolic stress and blood loss, combined with a low dietary intake due to the lack of appetite, nausea and psychological factors. Poor nutritional status in hip fracture patients is associated with impaired muscle function, disability ${ }^{7}$, loss of independency, lower mental function, decreased quality of life ${ }^{7}$, delayed wound healing, higher complication rate $e^{8,9}$, prolonged rehabilitation time ${ }^{7,8,10}$ and increased mortality both during and after hospital admission ${ }^{8,11,12}$.

Over the past decades, several studies have been conducted to determine the effectiveness of various types of nutritional intervention in elderly hip fracture patients on mortality, nutritional and functional status, length of hospital stay, and complications, such as infective complications, incomplete wound healing and pressure sores. The results of these studies are inconsistent and evidence for beneficial effects of nutritional supplementation remains limited ${ }^{13}$. Use of oral nutritional supplements (ONS) is suited as a simple way to improve hip fracture patients' energy and protein intake ${ }^{14,15}$, although patients' compliance is poor ${ }^{16}$. Personal attention after hip fracture from a dietetic assistant can improve adherence and tolerance with nutritional supplements ${ }^{17}$ and contribute to establish a prolonged effect of nutritional intervention.

ESPEN (European Society for Parenteral and Enteral Nutrition) guidelines on enteral nutrition in geriatrics ${ }^{18}$ recommend standard use of ONS in elderly after hip fracture surgery to reduce complications, however no recommendations on amount and duration of ONS use are given.

In order to improve medical outcome in vulnerable elderly hip fracture patients, to prevent further decline of nutritional status, and to improve implementation of the ESPEN guidelines for hip fracture patients, we initiated an open-label multicentre randomized controlled multi centre trial (RCT) comparing a combination of intensive dietetic counselling and oral nutritional supplementation over three months after hip fracture with usual nutritional care, i.e. no intervention except on specific request by medical doctor (MD) ${ }^{19}$.

This process evaluation aimed to investigate the feasibility of the proposed nutritional intervention in the present Dutch health care practice. Based on the model of Saunders et al. $^{20}$, we focused on the following aspects: Coverage of the intervention, i.e. the proportion of intended units delivered by the interventionist (dietician), general adherence of staff to the protocol, defined as: was the extent to which the 
intervention was implemented equal to what was planned, and patients' adherence defined as the extent to which participants were receptive to the intervention, or actively engaged with it.

The following research questions were formulated:

1. To what extent did the study dieticians follow the study protocol with regard to

a. number, types, duration and location of patient contacts

(face to face contacts / telephone calls)

b. content of each dietetic contact (face to face contact / telephone call); i.e. dietetic counselling, nutritional recommendations and nutritional care

2. To what extent were the given nutritional recommendations

(nutritional advice and ONS) followed by the patient

\section{Materials and methods}

\section{Study population and design}

We performed a prospective process evaluation of all patients in the intervention arm of an open-label, multi-centre randomized controlled trial (RCT).

Patients were eligible if they were aged 55 years and above, and were excluded if they had a pathological or periprosthetic fracture; a disease of bone metabolism (e.g. $\mathrm{M}$ Paget, M Kahler, hyperparathyroidism); a life expectancy of less than 1 year due to underlying disease (e.g. cancer); used ONS before hospital admission; were unable to speak Dutch; living outside the region of the participating hospitals; or were bedridden before the hip fracture. Patients were also excluded if they had dementia or were cognitively impaired, defined as a score of $<7$ on the Abbreviated Mental Test (AMT) assessed before inclusion.

For patient recruitment, a daily inventory was made of hip fracture patients admitted to the surgical and orthopedic wards of three hospitals in South-Limburg in The Netherlands: Maastricht University Medical Centre (MUMC, Maastricht), Atrium Medical Centre (AMC, Heerlen), and Orbis Medical Centre (OMC, Sittard). Eligible patients were invited to participate and written informed consent was obtained within five days after surgery. After informed consent, baseline measurements were performed by a trained researcher. Following baseline measurements, patients were stratified for hospital, gender and age (55-74 years vs. 75 years and above) and randomly assigned to the intervention group or control group using block randomization with permutation blocks of four. After randomization, all patients were visited by a study dietician who took a general dietary history and 24-hour recall.

Patients allocated to the intervention group received dietetic counseling and oral nutritional supplementation for three months after fracture, while patients in the control group received usual nutritional care as provided in the hospital, rehabilitation centre or at home, i.e. dietetic care or nutritional supplements were only provided on demand of the medical doctor (MD) in charge. All patients were discharged from the 
hospital to either a rehabilitation centre, to a nursing home, to a home for the elderly if they had lived there before hospital admission, or to the patient's home with home care. Three and six months postoperatively, a study dietician took a general dietary history and 24-hour recall to evaluate nutritional intake at the patient's home.

The study was approved by the Medical Ethical Committee (METC) of Maastricht University Medical Centre and the METC of the two other participating hospitals and conducted according to the Declaration of Helsinki.

\section{Nutritional intervention in the intervention group}

The nutritional intervention was a combination of regular dietetic care and consumption of a standard multi-nutrient ONS for a period of three months. The following elements were included: checking the patient's food habits and preferences, identifying possible deficiencies in nutrient intake, and checking the presence of any practical limitation that might interfere with optimal food intake. The nutritional intervention started during hospital admission and continued in the rehabilitation centre and/or at home if applicable. In Table 4.1 the schedule and content of contacts of the nutritional intervention according to the protocol is shown.

Table 4.1 Number, timing and composition of nutritional intervention contacts according to protocol during different periods after surgery.

\begin{tabular}{cllllll}
\hline \multicolumn{2}{c}{ Time line } & & \multicolumn{3}{c}{ Elements of the concerned contact } \\
\hline Nr. of contact & Days post surgery & Type of contact & A & B & C & D \\
\hline 1 & $0-6$ & Face to face ${ }^{\text {a }}$ & $\mathrm{X}$ & $\mathrm{X}$ & $\mathrm{X}$ & $\mathrm{X}$ \\
2 & $5-11$ & Face to face $^{\mathrm{a}}$ & & $\mathrm{X}$ & $\mathrm{X}$ & $\mathrm{X}$ \\
3 & $17-23$ & Face to face $^{\mathrm{b}}$ & & $\mathrm{X}$ & $\mathrm{X}$ & $\mathrm{X}$ \\
4 & $19-21$ & Face to face $^{\mathrm{b}}$ & & $\mathrm{X}$ & $\mathrm{X}$ & $\mathrm{X}$ \\
5 & $22-28$ & Telephone call & & $\mathrm{X}$ & $\mathrm{X}$ & $\mathrm{X}$ \\
6 & $29-35$ & Telephone call & & $\mathrm{X}$ & $\mathrm{X}$ & $\mathrm{X}$ \\
7 & $36-42$ & Telephone call & & $\mathrm{X}$ & $\mathrm{X}$ & $\mathrm{X}$ \\
8 & $43-49$ & Face to face ${ }^{\mathrm{b}}$ & & $\mathrm{X}$ & $\mathrm{X}$ & $\mathrm{X}$ \\
9 & $57-63$ & Telephone call & & $\mathrm{X}$ & $\mathrm{X}$ & $\mathrm{X}$ \\
10 & $78-84$ & Telephone call & & $\mathrm{X}$ & $\mathrm{X}$ & $\mathrm{X}$ \\
\hline
\end{tabular}

Legends:

A Explanation oral nutritional supplement use and registration to patient

B 24-hour dietary recall

C Evaluation of nutritional intake and oral nutritional supplement intake Discussion of findings with the patient and individual nutritional advise

D Arranging for nutritional adaptations of the patient. Report on findings to medical and nursing staff and nutritional assistant. Arranging dietetic transfer of patient to rehabilitation centre and/ or to home (when applicable)

a In the hospital

b In the rehabilitation centre or at home, depending on habitual residence of patient

A study dietician visited each patient twice during hospital stay. At the first visit, immediately after baseline measurements, the dietician interviewed the patient regarding medical and social status (e.g. living alone, having help with household tasks, 
etc.), and pre-fracture mobility (e.g. use of walking aids). In addition, she took a general dietary history on the patient's diet preceding hospitalization including supplement use and feeding problems. Next, the dietician took a 24-hour recall of the patient's diet during hospitalization. To optimize normal food intake all patients received an energy- and protein-enriched diet and recommendations were given with regard to choice, quantity and timing of food products, the ONS, and increasing the intake of energy-dense and protein-rich products both within and in between meals. Recommendations were based on the patient's individual requirements, including diet and texture adaptation, and took individual preferences and possibilities of the patient into account. Nutritional requirements for energy were calculated according to HarrisBenedict equation $^{21}$, using a factor of $20 \%$ surcharge for medium metabolic stress due to hip fracture and additional surcharge for activity, desired increase of body weight and/or energy-losses if indicated, with a maximum surcharge of $40 \%$. Protein requirement was calculated as body weight $x 1.5 \mathrm{~g}$ protein ${ }^{22}$. As a part of the energyand protein-enriched diet, all patients were advised to consume two bottles of an ONS daily in-between the main meals, in order to secure optimal intake in the vulnerable period after hip fracture surgery. The nutritional supplement was a milk-based ONS (Cubitan), kindly provided by Nutricia Advanced Medical Nutrition (Zoetermeer, The Netherlands) providing $2.1 \mathrm{MJ}(500 \mathrm{kcal})$ and $40 \mathrm{~g}$ of protein per two bottles. If a patient did not tolerate the milk-based supplement, a yoghurt-based supplement or a juice-based supplement (Nutridrink Yoghurt Style or Nutridrink Juice Style, Nutricia Advanced Medical Nutrition, Zoetermeer, The Netherlands) was offered. Adherence to the nutritional supplement was evaluated by 24-hour recalls and by patient's registration in a diary. Based on the information of the first visit, the dietician made necessary arrangements to solve any problem, e.g. feeding problem, in collaboration with the medical and nursing staff. Finally, the dietician assisted the patient in choosing the preferred taste of the nutritional supplement and ordered the preferred supplement.

At the second visit during hospitalization, seven to eight days after surgery, the dietician evaluated food intake and the consumption of the nutritional supplement using a 24-hour recall and individual tailored advice was given to the patient to optimize nutritional intake. Furthermore, transfer of the patient to the rehabilitation centre or home was prepared to safeguard optimal food and ONS intake during the stay at the rehabilitation centre or at home. For this purpose, the care for nutrition at the patient's home was discussed with the patient and, if present, with the patient's caregiver. Arrangements were made to ensure adequate food intake. Recommendations were related to the individual situation of the patient (i.e. mobility and environment) and were focused on overcoming obstacles in food availability (i.e. purchase of food by family, friends or delivery service of the supermarket), in preparation of food (i.e. support of informal caregivers of delivery by meal services), and in choosing foods which supported recovery and were easy to use and prepare. If necessary, arrangements were made to enable adequate food-intake, e.g. by asking 
support from informal caregivers (if present) and by providing information on meal services. Patients were encouraged to increase their dietary intake from a varied choice of healthy foods, based on individual preference and were guided in organizing delivery of readymade meals if needed. Next, the dietician communicated all relevant information to the family doctor as well as to the nursing staff, and the dietician or nutritional assistant of the rehabilitation centre and (where relevant) to informal caregivers.

Continuation of the nutritional intervention in the different rehabilitation centres and at home was accomplished through close collaboration between the study dieticians and the involved caregivers, i.e. the medical doctors, nurses, nutritional assistants and dieticians in the 15 involved rehabilitation centres and four home care organizations. In institutions, the recommendations given by the dieticians consisted of drawing the staff's attention to monitoring, delivering and supporting the patient's dietary food and fluid intake

After hospital discharge, the study dietician visited each patient three times (1, 2 and 6 weeks after discharge) at the patient's home or in the rehabilitation centre (whatever was applicable) in order to evaluate dietary intake, to evaluate the bottlenecks in the nutritional care at home, and to give nutritional advice if necessary. During each contact continuation of ONS was advised to patients who were still unable to meet nutritional requirements by normal food intake. In addition, in-between and after these face to face contacts, telephone calls were made $(3,4,5,8$, and 10 weeks after discharge) to evaluate both the diet and the intake of the nutritional supplements, if still consumed, by a 24-hour dietary recall. If necessary, a telephone call was replaced by a home visit. As the patient's diet increased towards the nutritional requirements (according to the guidelines of the Health council of the Netherlands) the amount of ONS advised was gradually decreased and the patient was advised to maintain a healthy diet. If dietary intake of vitamin $D$ did not meet the nutritional requirements, a vitamin $D$ supplement was advised. The contacts were conducted by dieticians in a standardized way, guided by a checklist and standardized forms for each study contact. To ensure continuity of care, patients were contacted by the same dietician throughout the intervention period.

In special meetings on site medical staff, and nutritional assistants were informed about the study and their role in the execution of the study was highlighted, i.e. supplying the ONS to the patient, supporting the patient with regard to food and ONS intake, weighing the patient at regular intervals, and reporting nutritional problems to the study dietician.

\section{Data collection}

In the present process evaluation, the planned nutritional intervention according to the study protocol was compared with the practice of execution of this intervention within the intervention group regarding the following aspects ${ }^{20}$ : 
- $\quad$ Adherence of staff to the protocol; i.e. the extent to which the intervention had been implemented according to the underlying protocol with regard to the number of contacts, duration of contacts, type of contacts (face to face, telephone calls), and location of visits (hospital, rehabilitation centre, home)

- Coverage of content; i.e. the extent to which the intended content of each contact was delivered by the dieticians, with regard to dietetic counselling, nutritional recommendations including ONS and nutrition care (e.g. safeguarding availability of food and meals, and assistance with shopping, cooking, and meal preparation)

- Patient's adherence to recommendations; i.e. the extent to which recommendations given by the dieticians, i.e. dietary intake and ONS use, were followed by the patients.

For this purpose, process data of the nutritional intervention were recorded by a study dietician during all study contacts, with regard to date, type, location, and duration of contacts; content of nutritional recommendations, content of ONS advice, and nutritional care recommendations. Deviations from the protocol were noted. Also, patients were requested to register their ONS intake (date and time, type and quantity of the ONS) in a diary.

Patients' adherence to recommendations regarding the ONS and on improving dietary intake were evaluated over two periods; 1 . Early post-surgery period: from day 0 until day 10 after inclusion, 2 . Late post-surgery period: from day 11 until the end of the intervention period 3 months after inclusion. Patients were considered to be compliant with ONS advice when the reported intake was $75 \%$ or more of the recommended amount. Patients were considered to be compliant with the content of the intervention if they had followed the recommendations in at least $75 \%$ of the contacts. Patients who needed no advice were considered to be compliant.

\section{Data analysis}

Quantitative data-analysis on data from the intervention group only was performed using descriptive statistics from SPSS-15.0 for Windows (SPSS Inc. Chicago, IL, USA). Open text data were categorized in codes and also assessed using descriptive statistics.

\section{Results}

\section{Patient characteristics}

Of the 73 patients in the intervention group, four patients (5\%) died during the study, three patients $(4 \%)$ stopped their participation due to lack of interest $(n=1)$ or lack of motivation to participate with regard to extra consultations $(n=1)$ or ONS use $(n=1)$. 
The 66 remaining patients had a mean age of 76 years (range 55-92) on admission; 49 (74\%) were women and 17 (26\%) were men.

\section{Dieticians' adherence to the study protocol}

Table 4.1 shows the structure and content of the nutritional intervention as planned; During a period of 3 months after surgery, 10 contacts (both face to face and telephone calls) were planned to be performed, consisting of intensive dietetic counselling, and ONS. A comparison between the planned nutritional intervention and the actual execution of the intervention is shown in Table 4.2.

Table 4.2 Dieticians' adherence to the study protocol.

\begin{tabular}{llcc}
\hline & & \multicolumn{2}{c}{ Number of contacts } \\
\cline { 3 - 4 } & & Protocol & Execution \\
\hline Consultation $^{\text {a }}$ & Total & 10 & $10.0(6-18)^{\mathrm{b}}$ \\
\hline Type & Face to face contact & & $6.8(4-18)$ \\
& Telephone call & 5 & $3.3(0-6)$ \\
\hline \multirow{2}{*}{ Location of face to face contact } & Hospital & 5 & $2.3(1-14)$ \\
& RC or at home & 2 & $4.4(1-10)$ \\
\hline
\end{tabular}

Legends:

${ }^{a}$ Consultations by a dietician

${ }^{\mathrm{b}}$ Mean (range)

${ }^{\mathrm{c}}$ Face to face contact on the site of residence (i.e. hospital, rehabilitation centre, home)

\section{Number of contacts}

The mean number of study contacts was 10.0 ranging from (6-18, Table 4.2). Of the 66 patients, $55(83 \%)$ received all ten planned contacts with the dietician, $8(12 \%)$ received nine contacts and $3(5 \%)$ six to eight contacts.

Out of a total of 660 planned contacts, 17 (4\%) contacts were cancelled in 11 patients;

- 8 contacts ( 3 patients) because the patients considered the visit to be too burdensome;

- 5 contacts ( 4 patients) were considered to be unnecessary by the dietician because these patients had a sufficient nutritional intake and no nutrition-related problems and therefore prolongation of dietetic guidance was no longer needed;

- 4 contacts (4 patients) due to time constraints of the dietician.

Eight patients (12\%) received additional study contacts, of whom five received one extra contact; the remaining three patients received two, five and eight additional contacts. Reasons for the additional contacts were: readmission to hospital $(n=2)$, change in location of patient (2), deteriorating clinical status or weight loss (3), and inability to deal with the amount of information in one visit (1). 


\section{Location of face to face contacts; hospital rehabilitation centre and home}

As for the location of the face to face contacts, the two planned hospital contacts were generally executed as planned (Table 4.2). In contrast, the mean actual number of face to face contacts after hospital discharge was 4.4 (range 1-10) instead of the planned three. Of these face to face contacts, an average of 2.3 (range 0-9) were in a rehabilitation centre and 2.1 (range $0-8$ ) were performed at the patient's home.

\section{Type of contacts; face to face contacts and telephone calls}

The actual number of face to face contacts was higher than planned (mean 6.8 vs. 5.0, Table 4.2), whereas the number of telephone calls was lower than planned (mean 3.3 vs. 5.0, Table 4.2). In 41 out of 66 patients (62\%) one or more telephone calls were changed into a visit; for 13 patients (20\%) this happened one time, for ten patients (15\%) two times and for eighteen patients $(27 \%)$ three times or more. On the other hand, only four face to face contacts were changed into a telephone consultation.

Reasons for the change of telephone calls into face to face contacts were: communication difficulties related to distant speaking: i.e. hearing difficulties or problems to contact patients by telephone (25\%), loss of body weight, dietary problems or deteriorating health $(20 \%)$, change in location of stay $(18 \%)$, arrangements to be made in rehabilitation centre e.g. explanation on nutritional intervention to nursing staff or delivery of ONS supplies (13\%), non-adherence with intervention (8\%), readmission to hospital $(5 \%)$, combination with other visit on the same site $(5 \%)$, and other reasons ( $8 \%)$. The reported reason for the changing face to face contacts into telephone calls was in all cases rapid recovery, rendering face to face contact superfluous.

\section{Duration of patient contacts}

The actual duration of patient contacts was 32 minutes for face to face contacts, and 17 minutes for telephone calls. This agreed well with expectations ( $30 \mathrm{~min}$. and $15 \mathrm{~min}$. respectively). In Figure 4.1, the mean time expenditure within each consultation spent on nutritional counselling, ONS counselling and organizational issues is shown. During telephone calls, time spent with dietetic counselling was higher than during face to face contacts ( $75 \%$ vs. $58 \%$ of the time) because the focus of the telephone calls was on checking nutrition-related problems. For face to face contacts compared to telephone calls, more time was spent with ONS-counselling ( $18 \%$ vs. $12 \%$ ), and organizational issues $(24 \%$ vs. $12 \%)$, for instance, checking patients' files, communication with staff to discuss the required nutritional support and ONS in institutions, or at the patients' homes, and delivery of the ONS. 


\section{Content coverage of contacts by dieticians}

According to the study protocol, dietetic counselling during all contacts (face to face contacts and telephone calls) should include 1. nutritional intake, 2. ONS intake and 3. nutrition care. In the large majority of all contacts (91\%), dietetic counselling covered all three aspects as planned.

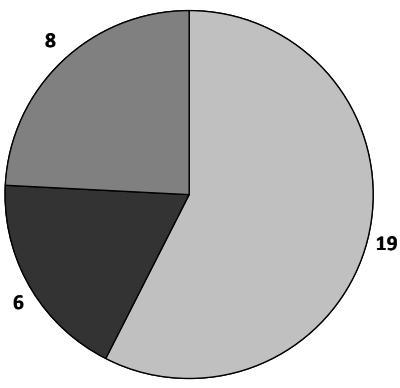

A. Face to face contacts

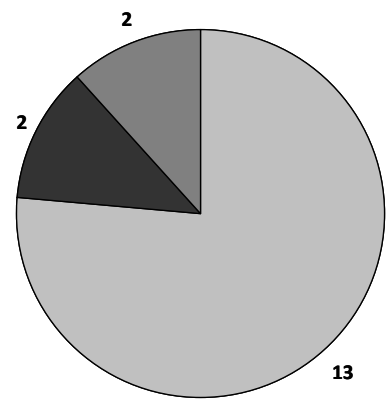

B. Telephone calls

Figure 4.1 Dieticians' mean time expenditure (minutes per contact) to nutritional counseling, oral nutritional supplement counselling and organizational issues, in face to face contacts and telephone calls.

\section{Nutritional counselling}

Oral nutritional supplement counselling

Organizational issues, i.e. arranging oral nutritional supplements and foods, and reporting to involved medical staff

\section{ONS recommendations by the dietician}

ONS was planned for all intervention patients within 5 days post surgery. In practice, consumption of the ONS started $3.5 \pm 1.3$ (mean \pm SD) days post surgery; 63 patients $(95 \%)$ started within the planned 5 days post-surgery and the remaining 3 patients (5\%) started on day 6 , due to a full agenda.

Based on inadequate oral intake from the regular diet; as the criterion for ONS prescription, ONS was recommended for a median period of 76 days (range 3-91), thus the majority of patients needed the ONS for more than 10 weeks. At 10 days post surgery, 65 patients (98\%) were in need of ONS and were therefore advised to use ONS, and at 30 days post surgery still 58 patients (88\%) needed ONS; 39 patients (59\%) were still in need of ONS at 60 days post-surgery, and 28 patients (42\%) could stop ONS intake within 90 days post surgery. The remaining 11 patients (17\%) needed continuation of ONS and were transferred to a home care dietician at the end of the 3-monthy study intervention period. 


\section{Nutritional recommendations by the dietician}

Before the start of the intervention, the energy intake, based on the 24-hour recall from the previous day, was $1281 \pm 68 \mathrm{kcal} / \mathrm{d}(5.4 \pm 0.3 \mathrm{MJ} / \mathrm{d})$, and protein intake was $55.0 \pm 2.9 \mathrm{~g} / \mathrm{d}$. Nutritional recommendations were given with regard to choice, quantity and timing of food products and included the use of ONS, and increase the intake of energy-dense and protein-rich products both within and in between meals. One week after starting the intervention, the 24-hour recall showed that energy-intake had increased to $1733 \pm 61 \mathrm{kcal} / \mathrm{d}(7.3 \pm 0.3 \mathrm{MJ} / \mathrm{d})$ and protein intake to $82.3 \pm 3.1 \mathrm{~g} / \mathrm{d}$.

\section{Patients' adherence to nutritional recommendations and ONS}

Fifty-eight patients (88\%) took the ONS for the total period as advised by the dietician. Eight patients (12\%) stopped the ONS intake earlier than advised.

Forty of 66 patients kept a study diary on ONS use. Reported reasons for the absence of study diaries were: poor vision and/or difficulties with writing $(n=7)$, refusal to keep a diary $(n=6)$, loss of study diary $(n=5)$, inability to keep a diary because of physical condition $(n=4)$, no reason available $(n=4)$. Adherence to the ONS as recorded by the dietician of the 26 non-diary patients was similar to the 40 diary patients in the first post surgical period, but lower in the non-diary patient group in the second post surgical period (0-10 days post surgery: $78 \%$ vs. $80 \%$; $11-90$ days post surgery: $70 \%$ vs. $87 \%)$. Results of self-reported adherence to ONS was remarkably similar compared to the dieticians' reports, i.e. $74 \%$ of the 40 patients reported to be compliant with ONSrecommendations in the first post surgical period until 10 days post surgery, and $75 \%$ from day 11-90 post surgery.

For the overall group ( $n=66)$, the patients adherence to nutritional recommendations as assessed by the dietician was $67 \%$ and to ONS $79 \%$ in the early post surgical period until 10 days after inclusion. In the subsequent period from day 11-90, the adherence to nutritional advice was $73 \%$ and to ONS $80 \%$.

Forty-one percent and of patients experienced problems with using ONS in the first post surgical period until 10 days post surgery, $43 \%$ of the patients from $11-30$ days post surgery, and $24 \%$ from $31-90$ days post surgery, such as aversion against the taste of the ONS, experiencing high satiation by the ONS, physical constraints, and delivery failure of the supplement.

\section{Discussion}

Especially in elderly hip fracture patients, it is important to prevent loss of muscle mass because impaired recovery and loss of lean mass can result in loss of functional capacity and loss of independency ${ }^{7,23}$. ESPEN guidelines ${ }^{18}$ recommend standard use of ONS in elderly patients after hip fracture surgery in order to reduce complications. Nevertheless, oral nutritional supplementation is not yet common in Dutch health care 
practice. The present process evaluation of an integrated nutritional intervention program comprising dietary counselling and ONS showed that overall the applied intervention was feasible in the present Dutch health care system, with regard to number and duration of contacts.

Adherence figures with ONS in studies in elderly hip fracture and orthopaedic patients range from $15-100 \%{ }^{24-27}$. Generally speaking, a short intervention period in combination with small amounts of $\mathrm{ONS}^{24,25,27}$ does not always lead to better adherence compared to studies with a longer period of ONS use and larger amounts of ONS (more than one can a day) ${ }^{27,28}$. In some studies a fixed amount of ONS was used $^{24,25,27}$. In our study we used variable amounts of ONS, based on individual requirements of patients. This individual approach may be one reason for patients to consume the ONS over a longer period of time and in a larger amount, and with a relatively high adherence $(79-80 \%$ over two periods as assessed by dieticians and $74-75 \%$ as reported by patients). Also continuity of care with respect to personnel and type of advice in our intervention, may have contributed to the high adherence to ONS and to nutritional advice. Furthermore, personal coaching of patients by the dietician with frequent personal contacts (face to face or telephone), may have played a role.

The present process evaluation indicates that implementation of the nutritional intervention for elderly hip fracture patients is feasible, though not easy to achieve in a complex health care setting. Dietary intake in hip fracture patients usually fails to meet requirements not only during hospital admission ${ }^{29,30}$, but also for a prolonged period thereafter. Even in our study almost all patients (98\%) needed additional ONS during hospital admission and the majority (59\%) of intervention patients needed additional ONS for a >2 months period. This finding shows that even relatively uncomplicated hip fracture patients fail to meet nutritional requirements and usually need ONS in the period after hospital discharge in addition to their normal dietary intake. Our individually tailored approach aimed at improving regular food intake, proved to be a suitable way to meet patient's nutritional requirements and to safeguard dietary intake in this vulnerable post-surgical period. Of note, the content as well as the number, the types and frequency of contacts can be adjusted to the individual patient's needs.

\section{Study limitations}

Several limitations of our study should be considered. First, the intervention was executed amongst elderly hip fracture patients in a study setting. Care should be taken when extrapolating data to cognitively impaired patients, patients who are bedridden before hip-fracture, and patients with underlying disease. In these patients implementation of the intervention might be more difficult, especially more telephone calls may have to be replaced by face to face contacts.

Second, study execution and data collection was executed by the same person (study dietician). Participants might have given socially accepted answers causing biased data. 
Third, continuity of in the context of our study dietetic care was guaranteed, since a study dietician took care of a proper follow up of the patient after discharge from the hospital. However, in practice hip-fracture patients will often meet different dieticians in the hospital, rehabilitation centre and at home, which may substantially affect successful implementation. Also, limited possibilities in nutritional services in institutions, e.g. absence or limited presence of a nutritional assistant, limited possibilities to deliver the ONS, and limited possibilities in offering and timing of specific foods with high nutritional value to the patient, were met by the study dieticians, which are likely to hamper successful implementation in routine health care.

Fourth, communication on medical and nutritional issues between institutions, e.g. from hospital to rehabilitation centre, was not standardized, which may lead to discontinuity in nutritional care. The study dieticians noted that in present usual care insufficient attention was usually paid to nutritional care. Especially in the integrated care trajectory; diagnosing nutrition related problems, facilitating nutritional support and follow up of treatment and transfer of nutrition related therapies are not yet common practice and seem to be a major problem in the present integrated nutritional care trajectory.

Finally, the intervention was expected to be cost-effective, as results of retrospective cost analysis of published trials suggested potential savings between 5,792 and 12,342 Euro per patient as a consequence of reduced complication rates. The cost of the intervention as estimated a priori amounted to 1000 euro, including both the dietary supplement and additional labour costs by a dietician); the estimated reduction in length of stay (-16.8 days) would lead to savings of ca. 5660 Euro minus intervention costs $=4660$ euro. A formal cost-effectiveness study of our trial will follow'.

\section{Conclusions}

Based on the results of the present process evaluation, we conclude that the implementation of the integrated nutritional intervention in elderly hip fracture patients is feasible with regard to number, duration and content of contacts. Based on the dieticians' judgment nutritional support for hip fracture patients is needed for a prolonged period after surgery, and the ONS was needed for more than two months in the majority of hip fracture patients, in order to meet their nutritional requirements. Further studies are needed to elaborate the factors influencing the continuity of the nutritional intervention in the context of usual health care in the settings of hospital and rehabilitation centre and in the home setting, as well as effects and costs. 


\section{References}

1. Cummings SR. Treatable and untreatable risk factors for hip fracture. Bone. 1996 Mar; 18(3 Suppl):165S-7S.

2. De Laet CE, Pols HA. Fractures in the elderly: epidemiology and demography. Baillieres Best Pract Res Clin Endocrinol Metab. 2000 Jun; 14(2):171-9.

3. Compan B, di Castri A, Plaze JM, Arnaud-Battandier F. Epidemiological study of malnutrition in elderly patients in acute, sub-acute and long-term care using the MNA. J Nutr Health Aging. 1999; 3(3):146-51.

4. Constans T, Bacq Y, Brechot JF, Guilmot JL, Choutet P, Lamisse F. Protein-energy malnutrition in elderly medical patients. J Am Geriatr Soc. 1992 Mar; 40(3):263-8.

5. Maffulli N, Dougall TW, Brown MT, Golden MH. Nutritional differences in patients with proximal femoral fractures. Age Ageing. 1999 Sep; 28(5):458-62.

6. Murphy MC, Brooks CN, New SA, Lumbers ML. The use of the Mini-Nutritional Assessment (MNA) tool in elderly orthopaedic patients. Eur J Clin Nutr. 2000 Jul; 54(7):555-62.

7. Lumbers M, Driver LT, Howland RJ, Older MW, Williams CM. Nutritional status and clinical outcome in elderly femalesurgical orthopaedic patients. Clin Nutr. 1996 Jun; 15(3):101-7.

8. Paillaud E, Bories PN, Le Parco JC, Campillo B. Nutritional status and energy expenditure in elderly patients with recent hip fracture during a 2-month follow-up. Br J Nutr. 2000 Feb; 83(2):97-103.

9. Cochrane Database Syst Rev Patterson BM, Cornell CN, Carbone B, Levine B, Chapman D. Protein depletion and metabolic stress in elderly patients who have a fracture of the hip. J Bone Joint Surg Am. 1992 Feb; 74(2):251-60.

10. Bastow MD, Rawlings J, Allison SP. Undernutrition, hypothermia, and injury in elderly women with fractured femur: An injury response to altered metabolism? Lancet. 1983; 321(8317):143-6.

11. Bachrach-Lindstrom $M$, Johansson $T$, Unosson $M$, Ek AC, Wahlstrom $O$. Nutritional status and functional capacity after femoral neck fractures: a prospective randomized one-year follow-up study. Aging (Milano). 2000 Oct; 12(5):366-74.

12. Hedstrom M. Hip fracture patients, a group of frail elderly people with low bone mineral density, muscle mass and IGF-I levels. Acta Physiol Scand. 1999 Dec; 167(4):347-50.

13. Milne AC, Potter J, Vivanti A, Avenell A. Protein and energy supplementation in elderly people at risk from malnutrition. Cochrane Database Syst Rev. 2009(2):CD003288.

14. Silver HJ. Oral strategies to supplement older adults' dietary intakes: comparing the evidence. Nutr Rev. 2009 Jan; 67(1):21-31.

15. Price RJ, McMurdo ME, Anderson AS. A personalized snack-based intervention for hip fracture patients: development, feasibility and acceptability. J Hum Nutr Diet. 2006 Apr; 19(2):139-45.

16. Avenell A, Handoll HGG. Nutritional supplementation for hip fracture aftercare in older people. Cochrane Database Syst. 2010 Jan 20; (1): CD001880.

17. Duncan DG, Beck SJ, Hood K, Johansen A. Using dietetic assistants to improve the outcome of hip fracture: a randomised controlled trial of nutritional support in an acute trauma ward. Age Ageing. 2006 Mar; 35(2):148-53.

18. Volkert D, Berner YN, Berry E, Cederholm T, Coti Bertrand P, Milne A, et al. ESPEN Guidelines on Enteral Nutrition: Geriatrics. Clin Nutr. 2006 Apr; 25(2):330-60.

19. Wyers CE, Breedveld-Peters JJ, Reijven PL, van Helden S, Guldemond NA, Severens JL, et al. Efficacy and cost-effectiveness of nutritional intervention in elderly after hip fracture: design of a randomized controlled trial. BMC Public Health. 2010; 10:212.

20. Saunders RP, Evans MH, Joshi P. Developing a Process-Evaluation Plan for Assessing Health Promotion Program Implementation: A How-To Guide. Health Promotion Practice. April 2005: 134-47.

21. Roza AM SH. The Harris Benedict equation reevaluated: resting energy requirements and the body cell mass. Am J Clin Nutr. 1984 1984; 40: 168-82.

22. Richtlijn peri-operatief voedingsbeleid. Utrecht: Dutch institute for Health care improvement $\mathrm{CBO}$ 2007.

23. Roubenoff R. Sarcopenia and its implications for the elderly. Eur J Clin Nutr. 2000 Jun; 54 Suppl 3:S407.

24. Bruce D, Laurance I, McGuiness M, Ridley M, Goldswain P. Nutritional supplements after hip fracture: poor compliance limits effectiveness. Clin Nutr. 2003 Oct; 22(5):497-500. 
25. Espaulella J, Guyer H, Diaz-Escriu F, Mellado-Navas JA, Castells M, Pladevall M. Nutritional supplementation of elderly hip fracture patients. A randomized, double-blind, placebo-controlled trial. Age Ageing. 2000 Sep; 29(5):425-31.

26. Williams CM, Driver LT, Older J, Dickerson JW. A controlled trial of sip-feed supplements in elderly orthopaedic patients. Eur J Clin Nutr. 1989 Apr; 43(4):267-74.

27. Lawson RM, Doshi MK, Ingoe LE, Colligan JM, Barton JR, Cobden I. Compliance of orthopaedic patients with postoperative oral nutritional supplementation. Clinical Nutrition. 2000; 19(3):171-5.

28. Miller MD, Daniels LA, Bannerman E, Crotty M. Adherence to nutrition supplements among patients with a fall-related lower limb fracture. Nutr Clin Pract. 2005 Oct; 20(5):569-78.

29. Delmi M, Rapin CH, Bengoa JM, Delmas PD, Vasey H, Bonjour JP. Dietary supplementation in elderly patients with fractured neck of the femur. Lancet. 1990 Apr 28;335(8696):1013-6.

30. Eneroth M, Olsson UB, Thorngren KG. Insufficient fluid and energy intake in hospitalised patients with hip fracture. A prospective randomised study of 80 patients. Clin Nutr. 2005 Apr; 24(2):297-303. 


\section{Factors influencing implementation of nutritional intervention in elderly subjects after hip fracture}

Part 2: Barriers and facilitators 



\section{Individual recommendations and guidance were perceived as valuable: Patient views on nutritional intervention after hip fracture}

José JL Breedveld-Peters

Petronella LM Reijven

Caroline E Wyers

Svenhjalmar van Helden

Paul C Willems

Marionne Vaessen

Trudy van der Weijden

Pieter C Dagnelie 


\begin{abstract}
Objective

Within a multicentre RCT aimed at improving the nutritional status and speed of recovery of elderly hip fracture patients, a prospective process evaluation from the patient's perspective was performed, to identify key issues for improving the intervention program.
\end{abstract}

\title{
Methods
}

Over a period of 3 months after operative treatment of a hip fracture, patients received a nutritional intervention, comprising dietetic counselling and oral nutritional supplementation (ONS). In 37 patients, from August 2008 to June 2010, data were collected in two structured face to face interviews to evaluate patients' experiences with nutritional counselling and ONS. An additional in-depth interview was performed in a selection of ten patients.

\section{Results}

Mean age of the patients was 75 years; 26 (70\%) were women. Patients perceived the nutritional intervention as useful (89\%) and adequate regarding the number $(87 \%)$ and duration (78\%) of counselling contacts, as well as the period of ONS (65\%) and daily amount of ONS (76\%). Main reported positive aspects were: the individually tailored nutritional recommendations, the spreading of information, and the use of ONS. Factors limiting the execution of recommendations were: physical constraints, dependency on others, time needed to become accustomed to new dietary habits, and difficulties with the ONS-intake.

\section{Conclusions}

In general, hip fracture patients perceived the content, structure and individual dietetic guidance of the nutritional intervention as useful, adequate and valuable. However, assistance for nutritional care in institutions and at home was not always sufficient. 


\section{Introduction}

The prevalence of malnutrition in elderly patients admitted to hospital after hip fracture is high, with reported values ranging from $2 \%^{1}$ to $63 \%{ }^{2}$ depending on the used definition of malnutrition. A poor nutritional status in hip fracture patients has been reported to be associated with adverse effects on recovery ${ }^{3-7}$ and increased mortality ${ }^{5,6,8}$. During hospital admission, the nutritional status can deteriorate further due to increased energy expenditure caused by metabolic stress, combined with low dietary intakes due to anorexia, nausea and psychological factors.

Several studies have been conducted to determine the effectiveness of various types of nutritional intervention in elderly hip fracture patients on nutritional and functional status, length of hospital stay, complications and mortality. Results of these studies are inconsistent and knowledge on the effect of nutritional supplementation remains point of discussion?. In addition to normal meals and snacks, Oral Nutritional Supplementation (ONS) is a simple tool to improve the patient's energy and protein intake; however adherence is often poor, limiting its overall effectiveness ${ }^{9,10}$.

After literature review only one process evaluation of nutritional interventions in hip fracture patients was found. This "personalized snack-based intervention" showed difficulties with implementation and adherence to the snacks which were served in between meals in a hospital setting in the acute phase after hip surgery ${ }^{11}$. Another study, described day-to-day problems with nutrition-related tasks in frail elderly women living at home and receiving home care, showing these women having troubles in getting the food cooked and struggling with moving and standing while cooking, but this study was not targeted to (hip fracture) patients ${ }^{12}$. Reasons for non-adherence in patients may be related to the ONS itself, but also to circumstantial or personal factors. Involvement of the target group as the main stakeholder is necessary to enable further improvement of nutritional intervention.

Therefore, within the context of a randomized controlled trial (RCT) of nutritional intervention in hip fracture patients, a prospective process evaluation from the patient's perspective was performed. Our aim was to identify key issues for improving the nutritional intervention program in elderly patients after hip fracture. Specific research questions were:

1. What is the patients' overall opinion on the applied nutritional intervention

a. How do patients experience the structure of the nutritional intervention program?

b. How did patients experience the content of the program (dietetic guidance)

2. How do patients experience the use of ONS? 


\section{Materials and methods}

\section{Population and design}

The present study was embedded in an open label multicentre RCT on the effectiveness and cost-effectiveness of nutritional intervention in elderly hip fracture patients. For the RCT the primary outcome measure is total length of stay in hospital and rehabilitation clinics including hospital readmissions. Secondary outcome measures, assessed at three and six months after hip fracture, are nutritional status, functional status, quality of life, complication rate and one-year mortality.

Intervention group patients received a combination of intensive dietetic counselling (by regular home visits and telephone calls) and ONS for three months after surgery. The control group received usual dietetic care as provided by the hospital. Hip fracture patients admitted to the surgical and orthopedic wards of three hospitals in SouthLimburg in The Netherlands were recruited: Maastricht University Medical Centre, Maastricht (MUMC); Atrium Medical Centre, Heerlen (AMC); and Orbis Medical Centre, Sittard (OMC). Inclusion criteria were: $>55$ years, and admittance for surgical treatment of a hip fracture. Exclusion criteria were: pathological or periprosthetic fracture; disease of bone metabolism; limited life expectancy; the use of ONS before hospital admission; being unable to speak Dutch; being bedridden before the hip fracture, cognitive impairment, defined as a score of $<7$ on the Abbreviated Mental Test (AMT) as assessed before inclusion ${ }^{13}$.

The present patients' process evaluation with mixed methods started in the second year of the study, after study logistics were installed and staff was familiarised to all procedures. Subsequently, all patients of the intervention group were asked to participate in two structured face to face interviews.

The study was conducted according to the Declaration of Helsinki (verified Seoul, 2008). The Institutional Review Board of Maastricht University and the University Hospital Maastricht approved the study protocol and all participants provided written informed consent. Additional ethical approval was obtained for conducting and audio taping in-depth interviews with patients, and informed consent for audio taping was obtained from all involved patients preceding these interviews.

\section{Nutritional intervention}

The nutritional intervention was a combination of regular dietetic counselling and consumption of a multi-nutrient ONS for a period of three months, starting during hospital admission immediately after base line measurements and continuing in the rehabilitation centre and/or at home if applicable ${ }^{13}$.

A dietitian visited each patient twice during hospital stay. At the first visit the dietitian took a 24-hour recall of the patient's diet. Patients were asked to recall all foods and beverages they consumed in the twenty-four hours prior to the interview; time of 
consumption of food, type and amount of food consumed, method of preparation and additional ingredients used to prepare foods were registered. Reported dietary intakes form the 24-hour recalls were calculated for energy, protein and other nutrients, and evaluated by a study dietician. Nutritional requirements for energy were calculated according to Harris-Benedict equation ${ }^{14}$ using additional surcharges as required, with a maximum surcharge of $40 \%$. Protein requirement was calculated as body weight $x$ $1.5 \mathrm{~g}$ protein ${ }^{15-18}$. To optimize normal food intake, all patients received an energy- and protein-enriched diet and recommendations were given with regard to choice, quantity and timing of food products. As a part of the energy- and protein-enriched diet, all patients were advised to consume two bottles of an ONS daily in-between the main meals, in order to secure the dietary intake in the vulnerable period after hip fracture surgery. The nutritional supplement was a milk-based ONS (Cubitan ${ }^{\circledR}$ ) providing $2.1 \mathrm{MJ}(500 \mathrm{kcal})$ and $40 \mathrm{~g}$ of protein per two bottles. If a patient did not tolerate the milk-based supplement, a yoghurt-based supplement (Nutridrink Yoghurt Style ${ }^{\circledR}$ ) or a juice-based supplement (Nutridrink Juice Style ${ }^{\circledR}$ ) was offered. Oral nutritional supplements were provided by Nutricia Advanced Medical Nutrition, (Danone Research - Centre for Specialized Nutrition, Wageningen, The Netherlands). Adherence to the ONS was evaluated by 24-hour recalls. Based on the information from the first visit, the dietitian made necessary arrangements in order to solve any problems, in collaboration with the hospital medical and nursing staff.

At the second visit during hospitalization, seven to eight days after surgery a dietician evaluated the patient's nutritional intake, including the intake of ONS, by a 24-hour recall and gave individual tailored advice to optimize dietary intake. During this visit the transfer of the patient to the rehabilitation centre or the patient's home was prepared by evaluating the patient's physical restriction with respect to nutritional self-care, i.e. purchasing food products and the preparation of meals. Arrangements were made to enable adequate food-intake, e.g. support from informal caregivers and by providing information on meal services.

After hospital discharge the dietician visited each patient three times (1, 2 and 6 weeks after discharge) at the patient's home or in the rehabilitation centre in order to evaluate dietary intake, including the intake of ONS, and nutritional care and to give additional dietary advice if necessary. If the patient was still unable to meet nutritional requirements by normal food intake, continuation of the ONS consumption was advised.

In-between the face to face contacts, telephone calls were made $(3,4,5,8$, and 10 weeks after discharge) to evaluate dietary intake (including ONS, if still consumed), using a 24-hour dietary recall. If necessary, a telephone call could be replaced by a home visit. As soon as the patient's diet increased towards the nutritional requirements ${ }^{19,20}$, the consumption of ONS was gradually decreased and the patient was advised to continue with a healthy diet. 


\section{Data collection}

The present patients' process evaluation comprised two short questionnairestructured face to face interviews, and additional in-depth interviews. From August 2008 onwards up to June 2010, all intervention patients were asked to participate in the two structured face to face interviews, and we included 37 (out of the overall group of 73) intervention group patients. The first interview, evaluating the ONS, was held immediately after the patient stopped the ONS-intake. The second interview, evaluating the applied nutritional intervention and factors stimulating or hampering the application of the nutritional intervention, was held at the end of the intervention period three months after hip fracture. Both interviews were based on a questionnaire with closed and open ended questions providing quantitative and qualitative data. An additional in-depth interview was performed in a selection of patients in order to obtain more detailed information on patients' experiences with the nutritional intervention and/or the use of the ONS. Specific issues which had been raised in the previous structured interviews were discussed by posing open ended non-directive questions. In order to obtain maximal variation in data, purposive sampling was performed for the selection of in-depth interviews patients, based on the following selection criteria: 1 . location of stay after hospital discharge; home vs. rehabilitation centre; 2 . living alone vs. with a partner; 3 . adherent vs. non-adherent with the dietary and ONS-recommendations, and 4. successful vs. not successful with regard to meeting the required nutritional intake as assessed by the study dietician. All in-depthinterviews were recorded using a digital audio taping device. In-depth interviews were continued until saturation of data was achieved i.e. a state where no new data of importance to the specific study and developing theory emerge from the interviews. Data saturation occurred after 8 interviews, which means that no new themes emerged. Two additional interviews were used to confirm this result.

\section{Data analysis}

Quantitative data analysis was performed using descriptive statistics from SPSS-15 (2009, IBM Corporation, Armonk, New York, USA). Reported dietary intakes (24-hour recalls) were evaluated and calculated by Eetmeter (Voedingscentrum, The Hague, The Netherlands) using the Dutch Food Composition Table 2006 (NEVO the Hague, The Netherlands). Content analysis was performed on the qualitative data from the structured- and the in-depth interviews. The transcribed texts from the interviews were coded and classified by two persons using the software program Nvivo-2.0 (19992002, QSR International Ltd., Southport, PR9 OPA, UK). 


\section{Results}

\section{Patient characteristics}

Baseline characteristics of the patient process evaluation group $(n=37)$ as sample of RCT intervention group are shown in Table 5.1; Mean age and gender were comparable with the total intervention group of the RCT.

Table 5.1 Baseline characteristics of the patients included in the process evaluation study compared with the total RCT intervention group.

\begin{tabular}{lcc}
\hline & $\begin{array}{c}\text { RCT intervention group } \\
(\mathbf{n}=73)\end{array}$ & $\begin{array}{c}\text { Patients' process evaluation group } \\
(\mathbf{n}=\mathbf{3 7})\end{array}$ \\
\hline $\begin{array}{l}\text { Gender (n (\%)) } \\
\text { Female }\end{array}$ & $54(74)$ & $26(70)$ \\
Male & $19(26)$ & $11(30)$ \\
Age (mean (range)) & $79(55-93)$ & $75(55-92)$ \\
\hline
\end{tabular}

The questionnaire from one patient of the structured interviews evaluating the nutritional intervention was missing, and from another patient the questionnaire evaluating the ONS was missing.

Results of quantitative data (closed questions) of the two short questionnairestructured face-to-face interviews are shown in Table 5.2 and 5.3. Subsequently, the qualitative data resulting from the open ended questions from these two short questionnaire-structured face to face interviews are reported together with the data resulting from the in-depth interviews and are presented per topic.

\section{Nutritional intervention}

\section{Patients' opinion on the overall nutritional intervention program}

Overall, 33 patients (89\%) considered the nutritional intervention as useful. Thirty six patients (97\%) mentioned positive aspects of the intervention, i.e. the individual dietetic guidance, creating awareness of their diet and helping to improve their nutritional intake; the visits; the split up of information over several visits made it easier to adapt to dietary changes, and the personal attention and support received.

Thirteen patients (35\%) mentioned negative aspects of the nutritional intervention or gave suggestions for improvement, i.e.: duration of visits should not exceed one hour, visits could be replaced by telephone calls, length of the intervention period should not be too long, no attention for psychological consequences of the hip fracture, one patient was not interested in nutrition. 
Table 5.2 Results of quantitative questions from structured interviews; interview 1.

\begin{tabular}{|c|c|c|c|}
\hline \multicolumn{4}{|l|}{ Interview 1: Overall evaluation of nutritional intervention $(n=37)$} \\
\hline \multirow[t]{2}{*}{ 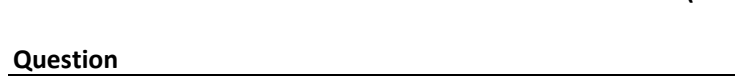 } & \multirow{3}{*}{$\begin{array}{c}\text { Answering scale* } \\
0 \text { good }\end{array}$} & \multicolumn{2}{|c|}{ Answers given } \\
\hline & & \multirow{2}{*}{$\frac{\mathbf{n}}{32}$} & \multirow{2}{*}{$\frac{(\%)}{(87)}$} \\
\hline 1. Opinion on number of consultations & & & \\
\hline & 0 too many & 2 & (5) \\
\hline & 0 too few & 0 & (0) \\
\hline & 0 otherwise & 3 & (8) \\
\hline \multirow{4}{*}{ 2. Opinion on duration of consultations } & 0 good & 29 & $(78)$ \\
\hline & 0 too long & 5 & (14) \\
\hline & 0 too short & 0 & $(0)$ \\
\hline & 0 otherwise & 3 & (8) \\
\hline \multirow{5}{*}{$\begin{array}{l}\text { 3. Adhering to recommendations to increase energy and } \\
\text { protein intake }\end{array}$} & 0 always & 20 & $(54)$ \\
\hline & 0 usually & 9 & $(24)$ \\
\hline & 0 sometimes & 4 & $(11)$ \\
\hline & 0 never & 0 & (0) \\
\hline & 0 otherwise & 4 & $(11)$ \\
\hline \multirow{5}{*}{$\begin{array}{l}\text { 4. Adhering to recommendations to increase calcium and vit D } \\
\text { intake }\end{array}$} & 0 always & 17 & $(46)$ \\
\hline & 0 usually & 10 & $(27)$ \\
\hline & 0 sometimes & 5 & $(14)$ \\
\hline & 0 never & 0 & (0) \\
\hline & 0 otherwise & 5 & $(11)$ \\
\hline \multirow{3}{*}{$\begin{array}{l}\text { 5. Dietician gave individual tailored nutritional } \\
\text { recommendations }\end{array}$} & 0 yes & 33 & (89) \\
\hline & 0 no & 1 & (3) \\
\hline & 0 otherwise & 3 & $(11)$ \\
\hline \multirow[t]{3}{*}{ 6. Change in eating habits during last 3 months } & 0 yes & 22 & $(60)$ \\
\hline & 0 no & 13 & (35) \\
\hline & 0 otherwise & 2 & (5) \\
\hline \multirow[t]{3}{*}{ 7. Overall opinion on the applied nutritional intervention } & 0 useful & 33 & (89) \\
\hline & 0 not useful & 1 & (3) \\
\hline & 0 otherwise & 3 & (8) \\
\hline 8. Is it necessary that one and the same person is providing & 0 agree & 26 & $(70)$ \\
\hline nutritional guidance to patients throughout the revalidation & 0 disagree & 7 & (19) \\
\hline period after hip fracture & 0 otherwise & 4 & $(11)$ \\
\hline \multirow[t]{3}{*}{9 Experiences with dietician } & 0 positive & 35 & (95) \\
\hline & 0 negative & 0 & (0) \\
\hline & 0 otherwise & 2 & (5) \\
\hline
\end{tabular}

* In addition to the answering categories, all questions had an open text box in which the given answer could be clarified or remarks could be made. 
Table 5.3 Results of quantitative questions from structured interviews, interview 2

\begin{tabular}{|c|c|c|c|c|}
\hline \multicolumn{2}{|c|}{$\begin{array}{l}\text { Interview } \\
\text { Question }\end{array}$} & \multirow[t]{2}{*}{ Answering scale* } & \multicolumn{2}{|c|}{ Answers given } \\
\hline & & & $\mathbf{n}$ & (\%) \\
\hline \multirow[t]{4}{*}{1.} & \multirow{4}{*}{$\begin{array}{l}\text { How did you experience the length of } \\
\text { the period of ONS use }\end{array}$} & 0 good & 24 & $(65)$ \\
\hline & & 0 too long & 6 & $(16)$ \\
\hline & & 0 too short & 0 & (0) \\
\hline & & 0 otherwise & 7 & (19) \\
\hline \multirow[t]{4}{*}{2.} & How do you consider the recommended & 0 good & 28 & (76) \\
\hline & daily amount of ONS & 0 too much & 5 & (14) \\
\hline & & 0 too little & 0 & (0) \\
\hline & & 0 otherwise & 4 & (11) \\
\hline \multirow[t]{5}{*}{3.} & Which statement reflects your situation & 0 Usually, I did not take the ONS & 2 & $(5)$ \\
\hline & best & 0 I sometimes did not take the ONS, & & \\
\hline & & but usually I took the ONS & 12 & $(32)$ \\
\hline & & 0 I took the ONS always & 19 & $(52)$ \\
\hline & & 0 otherwise & 4 & (11) \\
\hline \multirow[t]{4}{*}{4.} & How do you judge the taste of the ONS & 0 good & 18 & (49) \\
\hline & & 0 reasonable & 9 & (24) \\
\hline & & 0 bad & 3 & (8) \\
\hline & & 0 otherwise & 7 & (19) \\
\hline \multirow[t]{3}{*}{5.} & Was there enough variation in flavours & 0 yes & 27 & (73) \\
\hline & of ONS & 0 no & 3 & (8) \\
\hline & & 0 otherwise & 7 & (19) \\
\hline \multirow[t]{5}{*}{6.} & Did the ONS give a feeling of satiety & 0 very & 6 & $(16)$ \\
\hline & & 0 reasonable & 17 & (46) \\
\hline & & 0 a little & 5 & (14) \\
\hline & & 0 not & 6 & (16) \\
\hline & & 0 otherwise & 3 & (8) \\
\hline \multirow[t]{4}{*}{7.} & Did you experience difficulties with the & 0 yes & 10 & $(27)$ \\
\hline & ONS & 0 sometimes & 4 & $(11)$ \\
\hline & & 0 no & 21 & $(57)$ \\
\hline & & 0 otherwise & 2 & (5) \\
\hline \multirow[t]{3}{*}{8.} & Did your nutritional intake decrease due & 0 yes & 5 & (14) \\
\hline & to use of ONS & 0 no & 22 & (59) \\
\hline & & 0 otherwise & 10 & (27) \\
\hline \multirow[t]{4}{*}{9.} & Would you take ONS again in the same & 0 yes & 21 & (57) \\
\hline & situation & 0 I do not know & 6 & (16) \\
\hline & & 0 no & 6 & (16) \\
\hline & & 0 otherwise & 4 & $(11)$ \\
\hline \multirow[t]{4}{*}{10.} & Would you be willing to pay for the ONS & 0 yes & 10 & $(27)$ \\
\hline & & 0 I do not know & 4 & (11) \\
\hline & & 0 no & 15 & $(41)$ \\
\hline & & 0 otherwise & 8 & $(22)$ \\
\hline
\end{tabular}

* In addition to the answering categories, all questions had an open text box in which the given answer could be clarified or remarks could be made. 


\section{Patients' evaluation of the role of the dietician}

Thirty five patients (95\%) evaluated the dietician's role as positive. Patients qualified the dietary guidance as appropriate, and the content of the nutritional advice instructive, clear and valuable.

Thirty three patients (89\%) liked the fact that the dietician gave individual tailored nutritional recommendations, and that she was motivating and supporting, and gave them a feeling of safety. These patients noted that the recommendations were advantageous and feasible. Within institutions, patients appreciated the arrangements the dietician made in supplying extras; some patients noted that the attentiveness towards nutrition by the personnel within the institution had improved by the nutritional intervention program.

Twenty six patients (70\%) considered it necessary that one same person provided nutritional guidance throughout the revalidation period after hip fracture; this could be a dietician, nurse or other caregiver involved in the care for hip fracture patients.

\section{Patients' evaluation of the structure of the nutritional intervention}

Thirty two patients (87\%) considered the total number of contacts to be adequate and 29 patients $(78 \%)$ considered the duration of the visits to be acceptable. Those patients, who considered the duration of visits not good, felt that the content of visits could be limited to most relevant parts.

Patients' evaluation of the content and delivery of the nutritional intervention by the dietician

Overall, patients were well able to reproduce dietary recommendations given by the dietician; 31 patients (84\%) reproduced three out of the average number of four dietary recommendations given. Twenty nine patients (78\%) said they adhered or usually adhered to the energy- and protein recommendations.

Overall, 22 patients (60\%) reported to have changed their eating habits based on the advice given by the dietician; 13 patients (35\%) said their eating habits had remained the same.

Reasons mentioned for adhering to the recommendations were: to prevent weight loss or to gain weight, to promote recovery, to support health and growth of bone tissue, to meet nutritional requirements, to feel better, and the fact that dietary guidance was delivered by a professional dietician.

Reasons for non-adherence were: lack of appetite, not feeling well, not yet being accustomed to new eating habits; forgetfulness; dependency on others for purchasing food products and/or for taking advised foods. Some patients reported the provided assistance in their institution of stay to be excellent, whereas others mentioned lack of staff during peak hours and the fact that attention was given only after requesting it, which influenced their nutritional intake. 
Nutritional care in the period after hip-fracture surgery at home was reported to be troublesome, especially immediately after discharge, patients said they needed help, i.e. support for buying food and preparing meals. Meal service at home was not always immediately available. One patient illustrated her physical difficulties at home as follows: 'imagine how to get a cup from the dresser to the table when one walks with two walking sticks. All energy is absorbed by thinking: thinking how to walk, thinking how to organize; one has to reconsider everything'.

\section{Patients' opinion on the use of ONS}

\section{Amount and duration of ONS use}

The daily amount of ONS was perceived to be adequate by 28 (76\%) of the interviewed patients. Five patients (14\%) considered the daily amount of 2 cans as too much, with reasons given: having to get accustomed to the ONS, or increase of aversion against the ONS over time.

The duration of ONS was experienced as adequate by 24 patients (65\%) and as too long by six patients (16\%). Duration of ONS was not related to the patients' judgement. Reported reasons why patients considered the duration to be too long were: (increasing) aversion against the taste of the ONS, lack of variation, having problems with taking extra drinks, and not knowing on forehand for which period the ONS had to be taken. Although, some patients considered the period of ONS-use as too long.

\section{Patients' ONS intake and appreciation}

The majority of patients took the ONS always or usually. Main reasons given by patients for using the ONS were: possible enhancement of recovery, maintenance of body weight and acceptability of the ONS. Reasons mentioned for not using the ONS were: perceiving no need for using it and being forgetful. One patient explained that a nurse reminded her of taking the ONS daily, by putting daily the amount of ONS to be finished in her fridge. Some patients reported that the ONS in their institution was only available at meal times, but not in-between meals. Patients reported that sometimes they had to ask to receive the ONS. Others reported that ONS delivery was supervised well.

A majority of patient, 28 (76\%) experienced the ONS to be very or somewhat satiating, but still 22 patients (59\%) felt that using the ONS did not decrease their regular food intake. Fourteen patients (38\%) encountered problems in using ONS, of whom four (11\%) occasionally, and three (8\%) only at the beginning. In addition to satiation, amount and aversion against the ONS, the artificial sweet taste and viscosity of the ONS were mentioned as limitations. Some patients reported intestinal complaints.

Twenty-one patients (57\%) said they would take the ONS again in a similar situation, six $(16 \%)$ not, and six (16\%) were not yet sure. If they had to pay for the ONS, 15 patients $(41 \%)$ said they would not take it. 


\section{Discussion}

Nutritional status of elderly hip fracture patients is often impaired at the time of the fracture $^{9}$ and nutritional intake during hospital admission is usually poor ${ }^{21}$, which may slow down recovery. The present process evaluation study aimed at investigating hip fracture patients' views on the inter-institutional nutritional intervention, in order to further improve nutritional intervention.

Patients generally perceived the nutritional intervention as useful, the dietary individual recommendations as valuable, and the structure as adequate. The individual support by the dietician was well appreciated. Monitoring of the patient's weight and nutritional intake, the nutritional recommendations over a prolonged period of time (i.e. 3 months), and the ONS, were considered as main positive aspects of the program. Patients mentioned that ability to follow the nutritional recommendations was hindered by physical constraints after hip fracture, dependency on others for nutritional care, and needing time to get used to new dietary habits. However, 14 patients (38\%) had difficulties with using the ONS, due to aversion against the ONS, the satiating effect of the ONS, or the duration of ONS-use.

With advancing age, dietary patterns change and there is a substantial decline in food intake $^{23}$. Appropriate nutritional intake is a requisite to prevent deterioration of nutritional status and to support recovery. Calculations of 24-hour recalls of the patient group in this study show a mean energy-intake of $1191 \mathrm{kcal}$ (range 1058-1324), and a mean protein intake of $51 \mathrm{~g}$ (range 8-98). At 10 weeks post surgery, the mean reported energy intake was $1661 \mathrm{kcal}$ (range 1491-1832), and protein-intake was $64 \mathrm{~g}$ (range 57-71). Although, these results reflect the process evaluation group only, these figures indicate that in the first post-surgical period energy and protein intakes are lower than required, although big variations are seen in protein intakes.

Patients perceived the assistance by regular caregivers in institutions as indispensible, which is in contrast with the patients' reports on shortage of staff in peak hours, and experienced limited attention for nutrition amongst staff. A study in geriatric health care institutions and at home, mentioned difficulties with the nursing staff's attitudes towards nutritional care as well ${ }^{22}$.

Patients perceived the nutritional self-care throughout the rehabilitation trajectory as burdensome and felt that the frequent dietetic counselling over a prolonged period of time as in the current project was therefore needed to accomplish change in (eating) habits, and to overcome the nutritional problems. Feasibility data of the $\mathrm{RCT}^{24}$ showed that dietetic counselling through 5 face to face contacts (mean duration 32 minutes) and in 5 telephone calls (mean duration 17 minutes), improved dietary intakes in the intervention group. Also, it was found that the intake of ONS did not influence the intake of normal food, probably because the ONS was offered as an in between meal. Furthermore, adherence to the ONS in the total intervention group was found to be relatively high (75\%) as compared to other studies, although many patients met some 
kind of problems with the use of the $\mathrm{ONS}^{24}$. Thus, regular attention for nutrition throughout a prolonged post surgical period after hip fracture (e.g. 3 months) seems to be needed, in order to safeguard the hip fracture patients' adequate food intake. However, focusing the intervention to those patients in need of nutritional support seems necessary, since not all patients needed the full intervention. The results of the present study also show that improvement of taste, texture and satiation of supplements still can be made, and that alternatives for ONS are needed.

Some limitations of this study should be considered. First, the number of participants in the process evaluation was relatively small $(n=37)$, even though the process evaluation group turned out to be representative for the overall intervention group. Second, this study was embedded in an RCT, in which hip fracture patients over three hospitals were included. Cognitively impaired hip fracture patients, with potentially vulnerable nutritional status, were excluded from the RCT and thus from the present process evaluation. Thus, our results reflect the experiences of the cognitively well elderly hip fracture patients only.

Third, the embedding in an RCT also implied that visits included additional measurements and administration rendering these more time-consuming, which may have influenced patients' feelings about the duration of contacts.

In conclusion, overall patients experienced the nutritional intervention (dietary recommendations and ONS) as useful and valuable with respect to content and duration as well as to individual guidance by the dietician. Our data indicate that individual tailoring of nutritional guidance and nutritional care based on the patients' physical constraints and dietary problems is essential. Also patients reported that the embedding in usual care failed sometimes due to lack of staff and/or general attention to nutritional care.

Future research should focus specifically on factors influencing the continuity of nutritional intervention in the context and settings of usual care. 


\section{References}

1. Maffulli N, Dougall TW, Brown MT, Golden MH. Nutritional differences in patients with proximal femoral fractures. Age Ageing. 1999 Sep;28(5):458-62.

2. Murphy MC, Brooks CN, New SA, Lumbers ML. The use of the Mini-Nutritional Assessment (MNA) tool in elderly orthopaedic patients. Eur J Clin Nutr. 2000 Jul;54(7):555-62.

3. Bastow MD, Rawlings J, Allison SP. Undernutrition, hypothermia, and injury in elderly women with fractured femur: An injury response to altered metabolism? Lancet. 1983;321(8317):143-46.

4. Lumbers M, Driver LT, Howland RJ, Older MW, Williams CM. Nutritional status and clinical outcome in elderly female surgical orthopaedic patients. Clin Nutr. 1996 Jun;15(3):101-7.

5. Bachrach-Lindstrom $M$, Johansson $T$, Unosson $M$, Ek AC, Wahlstrom $O$. Nutritional status and functional capacity after femoral neck fractures: a prospective randomized one-year follow-up study. Aging (Milano). 2000 Oct;12(5):366-74.

6. Paillaud E, Bories PN, Le Parco JC, Campillo B. Nutritional status and energy expenditure in elderly patients with recent hip fracture during a 2-month follow-up. Br J Nutr. 2000 Feb;83(2):97-103.

7. Patterson BM, Cornell CN, Carbone B, Levine B, Chapman D. Protein depletion and metabolic stress in elderly patients who have a fracture of the hip. J Bone Joint Surg Am. 1992 Feb;74(2):251-60.

8. Lumbers M, New SA, Gibson S, Murphy MC. Nutritional status in elderly female hip fracture patients: comparison with an age-matched home living group attending day centres. $\mathrm{Br} J$ Nutr. 2001 Jun;85(6):733-40.

9. Avenell A, Handoll HGG. Nutritional supplementation for hip fracture aftercare in older people (Review). Cochrane Database Syst Rev. 2010(1).

10. Bruce D, Laurance I, McGuiness M, Ridley M, Goldswain P. Nutritional supplements after hip fracture: poor compliance limits effectiveness. Clin Nutr. 2003 Oct;22(5):497-500.

11. Price RJG, McMurdo MET, Anderson AS. A personalized snack-based intervention for hip fracture patients: development, feasibility and acceptability. Journal of Human Nutrition and Dietetics. 2006;19(2):139-145.

12. Porter EJ. Problems with preparing food reported by frail older women living alone at home. Ans. 2007 Apr-Jun;30(2):159-74.

13. Wyers CE, Breedveld-Peters JJ, Reijven PL, et al. Efficacy and cost-effectiveness of nutritional intervention in elderly after hip fracture: design of a randomized controlled trial. BMC Public Health. 2010;10:212. (http://www.biomedcentral.com/1471-2458/10/212)

14. Roza AM, Shizgal HM. The Harris Benedict equation re-evaluated: resting energy requirements and the body cell mass. Am J Clin Nutr. 1984 Jul;40(1):168-82.

15. Shaw JH, Wolfe RR. Energy and protein metabolism in sepsis and trauma. The Australian and New Zealand journal of surgery. 1987 Jan;57(1):41-7.

16. Jeevanandam M, Lowry SF, Horowitz GD, Legaspi A, Brennan MF. Influence of increasing dietary intake on whole body protein kinetics in normal man. Clin Nutr. 1986 Feb;5(1):41-48.

17. Sevette A, Smith RC, Aslani A, et al. Does growth hormone allow more efficient nitrogen sparing in postoperative patients requiring parenteral nutrition? A double-blind, placebo-controlled randomised trial. Clin Nutr. 2005 Dec;24(6):943-55.

18. Dutch institute for health care improvement $\mathrm{CBO}$, Richtlijn Perioperatief voedingsbeleid, Nutrition policy guideline in the pre- and post surgical period. Utrecht, The Netherlands. C Copy right 2007 the Dutch Association for Anaesthesists, the Dutch Association of Surgery, and the Dutch institute for health care improvement CBO; 2007. (http://www.stuurgroepondervoeding.nl/fileadmin/dbc/ Stuurgroep/Richtlijn_Perioperatieve_Voeding_CBO_2007.pdf).

19. The Health Council of the Netherlands, Guidelines for a healthy diet 2006. The Hague, The Netherlands: publication no. 2006/21E. ISBN 90-5549-656-3; 2006.

20. The Health Council of the Netherlands, Dietary reference intakes: calcium, vitamin $D$, thiamin, riboflavin, niacin, pantothenic acid, and biotin. The Hague, The Netherlands: publication no.2000/12. ISBN 90-5549-323-6; 2006.

21. Eneroth M, Olsson UB, Thorngren KG. Insufficient fluid and energy intake in hospitalised patients with hip fracture. A prospective randomised study of 80 patients. Clin Nutr. 2005 Apr;24(2):297-303. 
22. Bachrach-Lindstrom M, Jensen S, Lundin R, Christensson L. Attitudes of nursing staff working with older people towards nutritional nursing care. Journal of Clinical Nursing. 2007;16: 2007-14.

23. Drewnowski A, Evans WJ. Nutrition, physical activity, and quality of life in older adults: summary. J Gerontol A Biol Sci Med Sci. 2001 Oct;56 Spec No 2:89-94.

24. Breedveld JJL. Integrated nutritional intervention in the elderly after hip fracture. A process evaluation in Dutch health care [published ahead of print October 30 2011]. Clin Nutr. 2011. http://www.sciencedirect.com/science/article/pii/S0261561411001877). 


\section{6}

\section{Barriers and facilitators of nutritional intervention after hip fracture in integrated care as perceived by the different health care professionals: A qualitative interview study}

José JL Breedveld-Peters

Petronella LM Reijven Caroline E Wyers Angela A Hendrikx Aart D Verburg Jos MGA Schols Martin H Prins

Trudy van der Weijden Pieter C Dagnelie 


\section{Abstract}

\section{Background \& Aims}

Nutritional intervention in elderly hip fracture patients is important, but implementation is difficult. In order to identify barriers and facilitators for implementation, we conducted a qualitative interview study within the setting of a multicentre RCT, and evaluated the experiences of health care professionals with an applied intensive nutritional intervention comprised of dietetic counselling and oral nutritional supplements.

\section{Methods}

Individual semi-structured interviews were held with 22 involved health care professionals (i.e. clinicians, nursing staff, dieticians, and nutritional assistants) from different health care settings, and three focus group interviews were held with 13 dieticians and nurses.

\section{Results}

At a professional level, some health care professionals experienced lack of knowledge about nutritional care. At a system level, health are professionals reported lack of structured attention for patients' nutritional status and nurses reported lack of structured attention for patients' nutritional status. Continuity of nutritional care was perceived to be at risk, due to 1 . Incomplete communication on nutritional care between institutions, 2 . Lack of clarity in nutrition-related responsibilities, and 3 . Diversity in nutritional care policy between institutions.

\section{Conclusions}

Barriers for implementation of the nutritional intervention are related to communication problems and differences in nutritional care policies between institutions. These barriers may be improved by clearly assigning nutrition-related responsibilities, by extensive cooperation between involved disciplines, and by monitoring patients until at home. 


\section{Introduction}

The incidence of hip fractures in the elderly is high ${ }^{1}$ and will continue to increase due to changes in life expectancy ${ }^{2}$. At the moment of fracture, the nutritional status of elderly hip fracture patients is often impaired ${ }^{3}$ and nutritional intake during hospital admission is usually poor ${ }^{4}$ due to increased energy expenditure caused by a combination of metabolic stress and low dietary intakes which may slow down recovery. The results of studies on the effectiveness of nutritional intervention in elderly hip fracture patients are inconsistent with respect to nutritional and functional status, length of hospital stay, complications and mortality ${ }^{3}$. The provision of nutrition interventions directed to individual patients, such as intensive dietetic counselling to support dietary change, is an example of a complex intervention ${ }^{5}$. Also, hip fracture patients usually stay in different settings to recover after surgical repair of the fracture, and as a consequence care is delivered by various health care providers in the hospital, rehabilitation setting and at home. In view of the challenge to implement complex interventions in usual care, the incorporation of both process and outcome measurements in the evaluation of complex interventions is recommended ${ }^{5-7}$. For this reason, we performed a process evaluation as part of a multicentre RCT investigating the effectiveness and cost-effectiveness of nutritional intervention in elderly hip fracture patients ${ }^{8}$.

The extent to which the intervention of the present study was implemented as planned, and patients' adherence are described elsewhere ${ }^{9}$. In the present paper, we report on barriers for large-scale implementation of the nutritional intervention in hip fracture patients, as perceived by the key professionals involved in the clinical pathway. Specifically, we describe their views on the feasibility of the nutritional intervention, i.e. dietetic counselling, Oral Nutritional Supplements (ONS), both in the study setting and projected to the current health care settings, and on possibilities to improve perceived barriers.

\section{Materials and methods}

\section{Design}

The present qualitative interview study in a selection of professional health care givers was embedded in a multicentre RCT on the effectiveness and cost-effectiveness of nutritional intervention in elderly subjects after hip fracture surgery ${ }^{8}$. Health care professionals from 3 hospitals, 15 rehabilitation centres and/or rehabilitation settings and 4 home care organizations were involved. The interviews were held to retrieve individual information about the health care professionals' experiences with the nutritional intervention. In addition focus group interviews were held with nurses and dieticians, because these individuals had the central role in the intervention. Individual and focus group interviews were used to validate the findings. 


\section{Context}

The usual care setting of this study is the integrated clinical pathway for hip fracture patients in the Netherlands, involving all patients' locations of stay, including hospitals, rehabilitation settings, and at home, and involving the professionals of all the locations of stay, including home care organizations. In usual care, health care professionals from the institution of stay or home care organization in situations where the patient stays at home, are responsible for the nutritional care. This includes the attending physician, the nursing staff, nutritional assistant, and dietician. As soon as the patient is discharged from the hospital, these staff members are responsible for transferring the information about treatment and (nutritional) care to their colleagues in the next location of stay, i.e. information about care and treatment of a patient (including nutritional care).

All inhabitants of the Netherlands are compulsorily insured for health care costs, by which admission to a health care institution (e.g. hospital, rehabilitation centre) is paid for by the insurance company. Dietary products, like ONS, are reimbursed when they are prescribed by a medical doctor and if the reimbursement request complies with specific indications, e.g. 'risk for malnutrition'.

In institutions, the ONS is provided by the nutritional services of the institution. At home, the ONS is usually delivered by a company that delivers dietary products and services in the community. ONS can also be retrieved from a pharmacy.

\section{Participants}

In order to obtain a maximal variety of data, purposive sampling was performed based on the following selection criteria: 1 . Representation of clinicians, nurses or nurse assistants, and dieticians and nutritional assistants; 2. Representation of hospital, rehabilitation setting, and home care setting; 3. Representation from all sub regions: Maastricht, Heerlen, and Sittard.

The study was approved by the Medical Ethical Committee (METC) of Maastricht University Medical Centre in Maastricht, the Netherlands (Reference number 06-3-098). Consent for audio taping the interviews was obtained from all interviewees prior to the interview. Furthermore, interviews were depersonalized by assigning a number to each interviewee and by using no names of persons during the interviews.

\section{The nutritional intervention components}

Patients in the intervention group of the RCT received a combination of intensive dietetic counselling and oral nutritional supplements (ONS) for three months after hip fracture surgery. The nutritional intervention started during hospital admission and continued after hospital discharge during the stay at the rehabilitation setting and/or at the patient's home. 
Figure 6.1 presents an overview of the main components of the nutritional intervention, i.e. structure, nutritional assessment, program content, and communication.

\begin{tabular}{|c|c|c|c|c|c|c|}
\hline Structure & \multirow[t]{5}{*}{$\leftrightarrow$} & $\begin{array}{l}\text { Nutritional } \\
\text { Assessment }\end{array}$ & \multirow[t]{5}{*}{$\leftrightarrow$} & $\begin{array}{c}\text { Program } \\
\text { Content }\end{array}$ & \multirow[t]{5}{*}{$\leftrightarrow$} & Communication \\
\hline $\begin{array}{c}\text { Dietetic } \\
\text { Consultations; } \\
5 \text { face to face, } \\
5 \text { telephone calls } \\
\text { over } 3 \text { months (1) }\end{array}$ & & $\begin{array}{c}\text { Regular } \\
\text { weighing }(3,4)\end{array}$ & & $\begin{array}{l}\text { Nutritional counselling } \\
\text { and individually tailored } \\
\text { recommendations (1) }\end{array}$ & & $\begin{array}{c}\text { Reporting on } \\
\text { progress of } \\
\text { nutritional } \\
\text { therapy }(1,2,3,4,5)\end{array}$ \\
\hline \multirow[t]{3}{*}{$\begin{array}{c}\text { Delivery of } \\
\text { dietetic } \\
\text { counselling (1) }\end{array}$} & & \begin{tabular}{|c|} 
Regular \\
evaluation of \\
nutritional intake \\
by $24 \mathrm{~h}$ recall (1)
\end{tabular} & & $\begin{array}{c}\text { Arranging ONS and } \\
\text { required foods (1) } \\
\text { and delivery of ONS } \\
(2,3,4)\end{array}$ & & $\begin{array}{c}\text { Reporting of planned } \\
\text { discharge }(3,4) \text { and } \\
\text { arrange for follow up } \\
\text { of nutritional care } \\
(1,3,4)\end{array}$ \\
\hline & & \begin{tabular}{|c|} 
Signalling \\
nutritional \\
problems $(2,3,4)$
\end{tabular} & & $\begin{array}{l}\text { Arranging support for } \\
\text { nutritional care }(1,3)\end{array}$ & & $\begin{array}{c}\text { Transfer of } \\
\text { nutritional care } \\
\text { information }(3,5)\end{array}$ \\
\hline & & \begin{tabular}{|c|} 
Registration of \\
patient \\
nutritional intake \\
$(2,3,4)$
\end{tabular} & & $\begin{array}{c}\text { Supporting patients and } \\
\text { stimulating nutritional } \\
\text { intake including ONS } \\
(2,3,4,5)\end{array}$ & & $\begin{array}{c}\text { Responsibilities and } \\
\text { working routines } \\
(1,2,3,4,5)\end{array}$ \\
\hline
\end{tabular}

Figure 6.1 Components of Nutritional Intervention program in hip fracture patients in the present study (reference to the professional who is in charge for the specific component).

Legends: 1. Dietician; 2. Nutritional assistant; 3. Nurse; 4. Nurse Assistant; 5. Medical doctor; orthopaedic surgeon or surgeon, geriatrician, general practitioner

\section{Structure}

During the three month intervention period 10 study dietician-patient contacts were scheduled; i.e. the same dietician visited the patient twice in hospital and three times in the next location of stay, i.e. rehabilitation setting or at home, and contacted the patient in between the visits by telephone $(3,4,5,8$, and 10 weeks after discharge). If deemed necessary by the dietician, a telephone call could be replaced by a home visit.

\section{Nutritional Assessment}

The nursing staff was responsible for regular weighing of the patients, i.e. just before a consultation by the dietician. Signalling and immediate reporting of nutritional problems in patients was the responsibility of the nursing staff and nutritional assistant. If needed, the patient's nutritional intake was registered on some days by the nursing staff. The dietician evaluated the course of the patient's weight and 
evaluated the patient's present nutritional intake, including the intake of ONS during each contact, using a 24-hour dietary recall.

\section{Program content}

The nutritional intervention was comprised of an energy- and protein-enriched diet, including the use of an ONS for three months. Based on the results of the nutritional assessment, the dieticians gave individual tailored recommendations with respect to choice and quantity of products, time of consumption, and the $\mathrm{ONS}^{8}$. As soon as the patient's diet increased towards the nutritional requirements ${ }^{10,11}$ the consumption of ONS was gradually decreased. The dietician was responsible for arranging the order of the ONS and the required foods to the patient's institution of stay or at home.

The study dieticians worked closely together with surgeons, geriatricians, nursing home physicians and general practitioners, the nursing staff, and the nutritional assistants and dieticians in the different health care organizations. Before the start of the study, training sessions at the sites were held to explain the study content to the involved staff, and to discuss their role in the execution of the nutritional intervention. The nutritional assistants and nursing staff were responsible for the delivery of the ONS in the institutions and for appropriate support with eating and drinking if needed.

\section{Communication}

All involved health care professionals were responsible for recording their nutritional intervention related tasks in the medical files. The dieticians reported about their dietary recommendations to the institutional nurses, the nutritional assistant and clinician. Nurses and nutritional assistants were responsible for reporting the intake of food and ONS and any nutritional related problems. They were also responsible for reporting the planned discharge of patients and arranging for transfer of nutritional care information to the rehabilitation setting or to the home care organization in the event that the patient was going home.

\section{Data collection and analysis}

Data from the involved health care professionals were collected during the second half of the study period. During this phase their experience with the nutritional intervention was assumed to be optimal, and they were able to give their insight and ideas on further improvements of the nutritional intervention.

Interviews were based on a semi-structured interview guide that extended over the course of the study as new themes arose. A pilot interview was performed to practice interview techniques. All interviews were performed by the same researcher (JB).

Three focus group interviews were held; two with involved dieticians and nurses, and one with dieticians from the research team. In all three focus groups the different aspects of the nutritional intervention were introduced and discussed in a standardized way in all three focus groups; focus group participants individually noted 
their opinions and issues with respect to a topic given on memo cards. After a brief explanation by the different participants a group discussion followed in which every participant was stimulated to contribute to the discussion. Participants were guided by a moderator (JB or NR), and assisted by an observer (CW or JB) who took field notes.

All interviews were audio taped and transcribed verbatim, coded by content analysis according to the constant comparison approach ${ }^{12}$. At the start, descriptive codes of text passages relevant to the research question, were compared and contrasted sequential and retrospective searching within and among the interviews by two coders (JB and BW) using the software program Nvivo-2.0. The codes were grouped into larger themes, which were further explored, restructured, refined, and reduced in number. Differences in coding were solved by consensus. After procedures were installed one coder continued with coding the data. The study team, consisting of content experts (TW, NR, PD) and researchers and dieticians (JB, CW, AH), met frequently throughout the project to reflect on the research process and the findings form the analyses. Data saturation occurred after 20 interviews, indicating that no new themes emerged. Two additional interviews were used to confirm this result.

The focus groups produced additional information on the same topics that had already emerged in the semi-structured interviews. Because no new themes were mentioned in the focus groups, the findings of the in-depth interviews and focus groups are reported in an integrated way.

\section{Results}

\section{Characteristics of health care professionals}

From December 2008 to January 2010, 23 health care professionals and/or departments were asked (to assign a representative) to participate in a semistructured interview. One caregiver refused to participate. The mean age of the 22 participating health care professionals was 42 years; $64 \%$ were women (Table 6.1).

Different clinicians participated in the study; i.e. (orthopaedic) surgeons, geriatricians and nursing home physicians and general practitioners. An equal number of nurses and dieticians participated in the focus groups 1 and 2, representing all involved work settings, i.e. hospital, rehabilitation centre and home care (Table 6.2).

Table 6.1 Characteristics of the Participants in the Semi-structured Interviews.

\begin{tabular}{lccccc}
\hline Work setting & Clinicians & $\begin{array}{c}\text { Nurses or } \\
\text { nurse aids }\end{array}$ & Dieticians & $\begin{array}{c}\text { Nutritional } \\
\text { Assistants }\end{array}$ & $\begin{array}{c}\text { Total per } \\
\text { setting }\end{array}$ \\
\hline Hospital & 4 & 3 & 1 & $0.5^{*}$ & 8.5 \\
Rehabilitation centre & 2 & 3 & 2 & $0.5^{*}$ & 7.5 \\
Home care & 3 & 1 & 2 & & 6 \\
\hline Total number professionals & 9 & 7 & 5 & 1 & 22 \\
\hline
\end{tabular}

* The nutritional assistant was working both in a hospital and in a rehabilitation centre; therefore we counted this in the table as 0.5 nutritional assistant working in a hospital and 0.5 nutritional assistant working in a rehabilitation centre. 
Table 6.2 Characteristics of the Participants of the Three Focus Group Interviews.

\begin{tabular}{llccc}
\hline Focus group & Work setting & $\begin{array}{c}\text { Nurses or nurse } \\
\text { aids }\end{array}$ & Dieticians & Total per setting \\
\hline 1. Nurses and dieticians & $\begin{array}{l}\text { Hospital } \\
\text { Rehabilitation setting }\end{array}$ & 2 & 1 & 3 \\
& Home care & 1 & 1 & 2 \\
& Totals per profession & 3 & 1 & 1 \\
2. Nurses and dieticians & Hospital & 1 & 6 & 2 \\
& Rehabilitation centre & 1 & 1 & 2 \\
& Home care & $0.5^{*}$ & $1.5^{*}$ & 5 \\
& Totals per profession & 2.5 & 2.5 & 2 \\
\hline
\end{tabular}

* One participant had two professions (dietician and nurse) and took part in the focus groups as a nurse and as a dietician; therefore we counted this in the table as 0.5 dietician and 0.5 nurse.

\section{Barriers for the implementation of the nutritional intervention program in usual care}

Results are structured according to the main components of the nutritional intervention (Figure 6.1), i.e. structure, nutritional assessment, program content, and communication. Barriers may be professional, context, or patient-related (Table 6.3).

\section{Structure}

Clinicians considered frequent contacts and follow up during the entire clinical pathway (hospital, rehabilitation setting, and home) as delivered by the study dieticians as crucial aspects for keeping elderly patients involved and motivated. As these patients are inclined to be forgetful and need time to get used to the recommendations, dieticians could immediately intervene and offer solutions for the patient's nutritional problems.

Some caregivers felt that the number of consultations should be adapted to the individual needs of a patient: relatively healthy hip fracture patients may need a less extensive intervention compared to complicated patients, e.g. patients with comorbidities. One clinician proposed evaluating the nutritional status of hip fracture patients 4-weeks post surgery, and to continue the nutritional intervention only in those patients not showing improvement. Some health care professionals proposed an additional follow-up visit after the last intervention visit at 3 months post surgery; to check whether nutritional problems were solved or if additional nutritional care would be needed. In some cases study dieticians considered telephone consultations less appropriate than to face to face contacts because the revealed information was not very useful with respect to nutritional intake. Reimbursement of the costs of a dietician and of the ONS was considered essential, to safeguard the dietetic guidance and the provision of ONS. 
The fact that one dietician was responsible for the nutritional intervention over the integrated trajectory, starting in the hospital and continuing in the rehabilitation setting and at home, was perceived to be advantageous. On the other hand, dieticians stated that continuation of the nutritional therapy by another dietician should not be problematic as long as there is extensive transfer of information on nutritional status and nutrition behaviour related factors.

Table 6.3 Barriers for the implementation of the nutritional intervention program in usual care as mentioned by the Involved caregivers.

\begin{tabular}{|c|c|c|}
\hline & Nutritional intervention component & Barriers \\
\hline \multirow{8}{*}{ 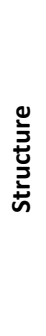 } & \multicolumn{2}{|c|}{ Consultations; 5 face to face, 5 telephone calls over $\mathbf{3}$ months } \\
\hline & \multirow[t]{2}{*}{ Professionals } & Structure not applicable to all hip fracture patient's needs \\
\hline & & Telephone calls not suitable for all patients \\
\hline & Context & Reimbursement costs \\
\hline & \multicolumn{2}{|l|}{ Timing of intervention } \\
\hline & Professionals & Late post surgical start of intervention \\
\hline & \multicolumn{2}{|l|}{ Delivery of intervention by personal dietician } \\
\hline & Context & More dieticians involved \\
\hline \multirow{7}{*}{ 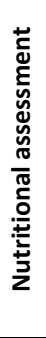 } & \multicolumn{2}{|l|}{ Regular weighing } \\
\hline & Professionals & Lack of time for of staff for regular weighing \\
\hline & \multicolumn{2}{|l|}{ Signalling nutritional problems } \\
\hline & \multirow[t]{3}{*}{ Professionals } & No multi disciplinary team for hip fracture patients \\
\hline & & Lack of nutritional knowledge of nursing staff \\
\hline & & $\begin{array}{l}\text { Tasks of home care nurses in usual care do not include } \\
\text { nutritional care }\end{array}$ \\
\hline & Context & $\begin{array}{l}\text { Absence of structured attention for the patient's } \\
\text { nutritional status and intake }\end{array}$ \\
\hline \multirow{9}{*}{ 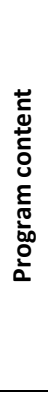 } & \multicolumn{2}{|c|}{ Nutritional counselling and recommendations } \\
\hline & Context & Institutional limitations in offering foods \\
\hline & \multicolumn{2}{|l|}{ ONS* } \\
\hline & Professionals & Continuity of delivery of ONS* in institutions \\
\hline & Context & Institutional limitations in time of delivery of ONS* \\
\hline & Patient & Adherence by patient \\
\hline & \multicolumn{2}{|c|}{ Supporting the patients nutritional intake including ONS* } \\
\hline & Professionals & $\begin{array}{l}\text { Lack of basic nutritional knowledge among nursing staff } \\
\text { Limited time available by caregivers }\end{array}$ \\
\hline & Context & Availability of nutritional care support at home \\
\hline \multirow{4}{*}{ 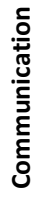 } & \multicolumn{2}{|l|}{ Reporting on progress of nutritional therapy } \\
\hline & Context & Lack of standardized communication \\
\hline & \multicolumn{2}{|l|}{ Transfer of nutritional care information } \\
\hline & Professionals & $\begin{array}{l}\text { Incomplete and inconsistent transfer of nutritional care } \\
\text { information }\end{array}$ \\
\hline
\end{tabular}

* Oral Nutritional Supplement 


\section{Nutritional assessment}

Some nurses and dieticians considered weekly weighing of patients to be too burdensome for nursing staff. Others thought the weekly weighing of patients was no problem.

The care for hip fracture patients was perceived as mainly focused on the fracture, whereas overall attention for the overall condition of the patient, e.g. co-morbidity, was found to be sometimes inadequate. The care for hip fracture patients could be further optimized through the collaboration of health care professionals in a multidisciplinary team composed of a clinician, a dietician, a nurse, and a nutritional assistant, a geriatrician or geriatric nurse, a case manager (which could be the geriatric nurse), a mental health care provider and a physiotherapist. At the same time dieticians felt that their present workload would not allow them to attend meetings of a multidisciplinary team.

Some nurses, especially those from institutions where no dietician was employed, perceived their basic nutritional knowledge as being inadequate for fulfilling the requirements of appropriate nutritional care, and indicated the need for training in this specific area. Also, these nurses thought that nutrition was getting insufficient attention. Some health care professionals stated that there was no standard attention for nutritional status and therapy, whereas others stated that attention was only paid in a late phase when nutritional problems became obvious e.g. by a deteriorating physical condition. Nurses from home care organizations reported the lack of clear responsibilities for nutritional care, in comparison with other care tasks such as e.g. wound care. They felt nutritional checks should be integrated in their daily work.

\section{Program content}

The involvement of a dietician providing individual tailored dietary advice and personal guidance to the patient was perceived as key element for success.

In rehabilitation settings with an employed dietician, nutritional services were used to delivering specific nutritional requests made by a dietician, whereas in institutions without a dietician, nutritional requests were uncommon, making the organization and logistics for ONS supply or supply of required meals or food products sometimes time consuming and difficult to arrange.

Attitudes towards the standard use of ONS were positive. ONS was perceived as necessary to prevent complications such as pressure ulcers. Dietetic guidance during ONS was considered important for adapting to patients' individual intake problems, for offering alternative supplements, and for keeping patients motivated to continue the ONS.

Logistical problems for the delivery of ONS were also mentioned by dieticians; in some institutions, there were restricted possibilities for delivering the ONS (e.g. only at 
mealtimes) whereas the recommended time for consumption of the ONS was between meals.

Some nurses reported that they had limited time available for nutrition-related tasks like supporting and stimulating the patient's nutritional intake. Therefore, the presence of nutritional assistants on the wards was considered essential because of their focus on the patients' nutritional intake. Nurses considered the availability of the informal health care professionals' support for nutritional care at home to be essential, especially for immobilized patients.

\section{Communication}

Usual care practice showed that there were differences in communication structures within institutions. In some rehabilitation settings, the nutritional therapy information of a patient was not always known to all team members. In other rehabilitation settings, a contact nurse was responsible for informing colleagues about care issues for a specific patient, and team members in these settings were well informed about the nutritional therapy.

Some hip fracture patients receiving home care lacked a care record file at home, and this made transfer of information on nutritional therapy complicated. At home, these patients once again became responsible for organizing their own activities of daily living, including the care for nutrition.

Timely reporting of a planned discharge of patients was perceived to be important by different health care professionals. They argued that in order to safeguard continuity of (nutritional) care, proper transfer of (nutritional) information is needed.

Communication problems were mentioned as a possible barrier for the implementation of the nutritional intervention program in usual care, as medical and nursing transfer information was not standardized and often incomplete. Also, nutritional care information i.e. diet and ONS, was not always incorporated in the medical and/or nursing transfer of patients. This could lead to delay or failure of information transfer to the next location of stay and made communication complicated and unclear. Health care professionals from hospitals working with electronic patient files reported that transfer of nutritional care information e.g. use of ONS and other dietary requirements, was well arranged, since all information was automatically transferred to the rehabilitation setting.

Inconsistent working routines in usual care were reported by several health care professionals. After hospital discharge, hospital dieticians themselves sometimes provided follow up of patients by out patient department or telephonic consultations, but referral to a dietician in the rehabilitation setting or home care organization also occurred. This inconsistent referral of patients requiring dietetic guidance and/or ONS after hospital discharge was considered as undesirable by dieticians. Geriatricians and nursing home physicians reported that in usual care, they did not always receive medical transfer reports from the hospital because this information is usually sent to a patient's general practitioner and remembering to additionally inform them was often 
forgotten. Some general practitioners reported visiting hip fracture patients at home to see how they were doing. Other general practitioners did not regard this as their responsibility; they said that follow up was done by the (orthopaedic) surgeon.

\section{Discussion}

Implementing complex interventions in the integrated care trajectory is a challenging task. A first step in implementation research is to analyse barriers for implementation of the intervention in usual care, with respect to the involved professionals, the context, and the patients $5,13,14$. However, to the best of our knowledge, no studies on the feasibility of a nutritional intervention in the integrated clinical care pathway have been performed so far.

In the present study, we used the setting of a nutritional intervention RCT in elderly hip fracture patients to evaluate how involved health care professionals perceive the feasibility of a nutritional intervention. Perceived barriers for implementation were mainly related to professional and contextual factors. At the professional level, there was lack of knowledge about delivery of appropriate nutritional care. Other perceived barriers were the limited time available by nursing staff for nutritional care, and the lack of structured attention for the patient's nutritional status in usual care. Furthermore, the continuity of nutritional care was perceived to be at risk when patients move to the next institution, due to incomplete and inconsistent communication about nutritional care between institutions and unclear nutritionrelated responsibilities/tasks. In some institutions, the absence of a nutritional care policy was said to hamper the appropriate application of the intervention, leading to discontinuation of (components of) the intervention. The availability of nutritional care support at the patient's home was also considered to be at risk. According to the health care professionals interviewed in this study, the intervention structure could be further improved by adapting the number and type of consultations in the intervention to the individual patient's needs.

Although attention for malnutrition in elderly patients is growing, in usual care, nutritional care as an integrated part of the medical treatment of patients is clearly not yet incorporated in common practice ${ }^{15}$. The contextual and professional related barriers we found with respect to problems with delivery of nutritional care, i.e. lack of structural attention for nutritional care, no established procedures, inadequate staffing and lack of nutritional knowledge, have also been reported in other studies set in a variety of institutions ${ }^{16-19}$. In the present study we found that the nutritional care communication between institutions was not safeguarded. In the context of our randomized controlled trial, a team consisting of the attending clinician, nurses, dieticians and nutritional assistants guaranteed adequate communication and implementation of the intervention. Health care professionals in this study felt that 
extending such a team to other disciplines, i.e. a geriatrician or a geriatric nurse and/or a case-manager, a physiotherapist, and a psychologist, was necessary in order to address the multiple care demands of this specific patient group. Interdisciplinary (geriatric) teams can assess complex nutritional problems and influence outcomes, but improvement of nutritional care depends on involvement and training all of them $^{16,20-22}$.

Results of the present study show that perceived barriers exist on different levels, and both within and between institutions. Local strategies should address perceived barriers within institutions in multiple ways and targeted at all organizational levels (professional, health care team, health care organization and wider environment), in order to increase the chances for successful change ${ }^{13,23,24}$. Some barriers may be extremely difficult to tackle, such as the inadequate number of staff available with competing demands for health care workers, and lack of nutritional knowledge. Overall, implementation of intervention should be targeted to the local context, and a local implementation plan is required to meet the specific needs of a specific site ${ }^{13}$.

Some strengths and limitations of our study should be considered. A strong point is that we ensured credibility and validated findings by using different methods of data collection (individual and focus group interviews) and continued interviews until data saturation occurred. In terms of limitations, first, although the selection process of health care professionals as participants in the present study was intended to achieve a wide variety of input from different disciplines and institutions, we had to make pragmatic choices on whom to approach, and therefore selection bias cannot be excluded. Second, the dietetic guidance of patients in our study was executed by study dieticians, whereas in usual care, different dieticians are involved in the integrated care trajectory for hip fracture patients. This may have led to underestimation of barriers. Of note, mentioned barriers with regard to e.g. continuity of care would even have become more urgent with different dieticians being involved in the clinical pathway. Third, due to limited research staff, the greater part of interviews was coded by only one person. We attempted to validate the analyses by starting with two coders in order to build a foundation by reflecting upon the content of the interviews by involving co-authors throughout the research process and by frequent discussions in the research meetings. Fourth, our data are based on the application of a nutritional intervention in the setting of a RCT. Although health care professionals' opinions regarding the application of this intervention for future implementation was part of the interview, our data do not necessarily reflect the barriers existing in daily routine practice. Barriers found in our study may even be an underestimation of the range of barriers that will be found in real usual care.

In conclusion, our study indicates that health care professionals perceived many barriers for the implementation of a nutritional intervention in hip fracture patients in usual care. Our results showed that there is inconsistent and incomplete 
communication between health care professionals from different institutions regarding information about nutritional therapy. Also, the diversity in nutritional care policies within institutions, and even complete lack of such policies in some institutions, hindered the application and continuation of nutritional care. Although our study only dealt with barriers for nutritional intervention in hip fracture patients, our results may well be applicable to nutritional and health care for the elderly in general.

Nutritional care should be integrated in the clinical care pathway. A first step in tackling barriers may be to develop a clinical practice guideline for nutritional care in the elderly in the integrated health care trajectory. This should clearly delineate nutrition-related responsibilities in multidisciplinary geriatric teams, with follow up of the patients from hospital via rehabilitation to the home setting. 


\section{References}

1. Hoeymans N, Melse JM, Schoemaker CG. Deelrapport VTV 2010. Van gezond naar beter. Bilthoven: RIVM 2010.

2. De Laet CE, Pols HA. Fractures in the elderly: epidemiology and demography. Baillieres Best Pract Res Clin Endocrinol Metab. 2000 Jun;14(2):171-9.

3. Avenell A, Handoll HGG. Nutritional supplementation for hip fracture aftercare in older people (Review). Cochrane Database Syst Rev. 2010(1).

4. Eneroth M, Olsson UB, Thorngren KG. Insufficient fluid and energy intake in hospitalised patients with hip fracture. A prospective randomised study of 80 patients. Clin Nutr. 2005 Apr;24(2):297-303.

5. Campbell NC, Murray E, Darbyshire J, Emery J, Farmer A, Griffiths F, et al. Designing and evaluating complex interventions to improve health care. BMJ. 2007 Mar 3;334(7591):455-9.

6. Craig P, Dieppe P, Macintyre S, Michie S, Nazareth I, Petticrew M. Developing and evaluating complex interventions: the new Medical Research Council guidance. Bmj. 2008;337:a1655.

7. Thorpe KE, Zwarenstein M, Oxman AD, Treweek S, Furberg CD, Altman DG, et al. A pragmaticexplanatory continuum indicator summary (PRECIS): a tool to help trial designers. J Clin Epidemiol. 2009 May;62(5):464-75.

8. Wyers CE, Breedveld-Peters JJ, Reijven PL, van Helden S, Guldemond NA, Severens JL, et al. Efficacy and cost-effectiveness of nutritional intervention in elderly after hip fracture: design of a randomized controlled trial. BMC Public Health. 2010;10:212.

9. Breedveld JJL. Integrated nutritional intervention in the elderly after hip fracture. A process evaluation in Dutch health care [published ahead of print October 30 2011]. Clin Nutr. 2011. (http://www.sciencedirect.com/science/article/pii/S0261561411001877).

10. Roza AM, Shizgal HM. The Harris Benedict equation reevaluated: resting energy requirements and the body cell mass. Am J Clin Nutr. 1984 Jul;40(1):168-82.

11. Kwaliteitsinstiuut voor de Gezondheidszorg СВO / Health care quality instituteCBO $U$, The Netherlands. Peri-operatief voedingsbeleid Guideline. 2007 september 2007:14-5.

12. Strauss, A. \& Corbin, J. (1990) Basics of Qualitative Research: Grounded Theory Procedures and Techniques. Newbury Park, CA: Sage.

13. Grol R, Grimshaw J. From best evidence to best practice: effective implementation of change in patients' care. Lancet. 2003 Oct 11;362(9391):1225-30.

14. Campbell M, Fitzpatrick R, Haines A, Kinmonth AL, Sandercock P, Spiegelhalter D, et al. Framework for design and evaluation of complex interventions to improve health. BMJ. 2000 Sep 16;321(7262):694-6.

15. Halfens RJG, Meesterberends, E., Meijers, J.M.M., Du Moulin, M.F.M.T., van Nie, N.C., Neyens, J.C.L., Schols, J.M.G.A. Landelijke Prevalentiemeting Zorgproblemen Rapportage resultaten 2011. Maastricjt: Maastricht University, Faculty of Health, Medicine and Life Sciences, Department of Health Service Research Focusing on Chronic Care and Ageing; 2011.

16. Bourdel-Marchasson I. How to improve nutritional support in geriatric institutions. J Am Med Dir Assoc. 2009 Jan;11(1):13-20.

17. Labossiere R, Bernard MA. Nutritional considerations in institutionalized elders. Curr Opin Clin Nutr Metab Care. 2008 Jan;11(1):1-6.

18. Pedersen PU. Nutritional care: the effectiveness of actively involving older patients. J Clin Nurs. 2005 Feb;14(2):247-55.

19. Rasmussen $\mathrm{HH}$, Kondrup J, Staun M, Ladefoged K, Lindorff K, Jorgensen LM, et al. A method for implementation of nutritional therapy in hospitals. Clin Nutr. 2006 Jun;25(3):515-23.

20. Crogan NL, Alvine C, Pasvogel A. Improving nutrition care for nursing home residents using the INRx process. J Nutr Elder. 2006;25(3-4):89-103.

21. Harari D, Martin FC, Buttery A, O'Neill S, Hopper A. The older persons' assessment and liaison team 'OPAL': evaluation of comprehensive geriatric assessment in acute medical inpatients. Age Ageing. 2007 Nov;36(6):670-5.

22. Caplan GA, Williams AJ, Daly B, Abraham K. A randomized, controlled trial of comprehensive geriatric assessment and multidisciplinary intervention after discharge of elderly from the emergency department--the DEED II study. J Am Geriatr Soc. 2004 Sep;52(9):1417-23. 
23. Grol R, Wensing M. What drives change? Barriers to and incentives for achieving evidence-based practice. Med J Aust. 2004 Mar 15;180(6 Suppl):S57-60.

24. McNabney MK, Willging PR, Fried LP, Durso SC. The "continuum of care" for older adults: design and evaluation of an educational series. J Am Geriatr Soc. 2009 Jun;57(6):1088-95. 
General discussion 
This thesis describes outcome- and process measures of a nutritional intervention within the context of a multicentre randomized controlled trial (RCT). The objective of the RCT was to assess whether a nutritional intervention could improve the nutritional status and speed of recovery of elderly hip fracture patients. The process evaluation was aimed at assessing the feasibility of the intervention and generating insights with respect to barriers and facilitators for effective implementation of the nutritional intervention in an usual care setting.

\section{Main findings}

\section{Effect of nutritional intervention on nutritional intake and status}

Intensive dietetic counselling and oral nutritional supplementation for a period of three months, as provided in the nutritional intervention, improved nutritional intake and induced weight gain in elderly hip fracture patients.

\section{Feasibility of the nutritional intervention}

The process evaluation showed that implementation of the integrated nutritional intervention as applied in the study context was feasible with respect to number, duration and content of contacts. According to the judgment of the dieticians, patients required nutritional support for a prolonged period after surgery in order to meet nutritional requirements. Nutritional supplementation was advised to patients for a median period of 76 days. Seventy five percent of the patients took the oral nutritional supplements as recommended.

\section{Barriers and facilitators for implementation from the stakeholder's perspective}

Patients generally perceived the nutritional intervention as useful and adequate with respect to number and duration of counselling contacts, as well as the period and daily dose of oral nutritional supplementation. Main reported positive aspects were: the individually tailored dietary recommendations, the spreading of information over several consultations, and the application of the oral nutritional supplement (ONS) itself as a means to enhance recovery and to maintain body weight following surgery. Factors that prevented patients from following recommendations (over a short or longer period of time) were: physical constraints, dependency on others, time needed to adjust to new dietary habits, aversion to taking the ONS, its satiating effect, and the long duration of ONS use. Some patients perceived the usual daily assistance for nutritional care in institutions and at home as not always sufficient.

Barriers for the implementation of the nutritional intervention as perceived by health care professionals were found at both the professional and system level. At the professional level, some health care professionals experienced lack of knowledge about appropriate nutritional care. At the system level, the lack of structured attention 
for the patient's nutritional status in institutions and ambulatory care was reported as a concern. Furthermore, continuity of nutritional care was perceived to be at risk due to 1 . incomplete communication about nutritional care between institutions; 2 . lack of clarity in nutrition-related responsibilities; and 3. diversity in nutritional care policy between institutions, or even total lack of any nutritional care policy in some institutions. The limited time available by nursing staff was also mentioned as a factor that hindered implementation. Tailoring the number and type of consultations to the individual patient's needs was seen as a challenge for further improving the nutritional intervention.

\section{Comparison of our findings with literature}

\section{Effect and feasibility}

At baseline, 35\% of the hip fracture patients in the intervention group and $47 \%$ of the control group patients were either at risk of malnutrition or malnourished (including patients at risk of malnutrition as defined by the $\mathrm{MNA}^{1,2}$, which is in line with a recent Cochrane review about impaired nutritional status of elderly hip fracture patients at the time of their fracture ${ }^{3}$. Furthermore, almost all intervention group patients in our study (98\%) required additional ONS, and in the majority (59\%) of these patients, ONS was required for more than two months. This corresponds with findings by others that nutritional intake in hip fracture patients during hospital admission is usually poor (4). Our findings show that even in relatively uncomplicated cases, hip fracture patients fail to meet nutritional requirements and usually require ONS in addition to their normal diet in the period after hospital discharge.

Our study showed a positive intervention effect with respect to energy and protein intake, which was mainly due to the ONS consumption. Several previous studies using ONS or dietetic assistants as a nutritional intervention in hip fracture patients also showed a positive intervention effect on intake of energy and protein ${ }^{4-7}$. With respect to nutritional status, our data show a positive intervention effect on weight and supra-iliac skin folds, while previous studies showed non-significant improvements only $^{5,8,9}$.

In previous studies of ONS in elderly hip fracture and orthopaedic patients, adherence figures range from $15-100 \%{ }^{9-12}$. Generally speaking, a short intervention period in combination with small amounts of $\mathrm{ONS}^{9,10,12}$ does not always lead to improved adherence compared to studies with a longer period of ONS use and larger amounts of ONS ( $>200 \mathrm{ml}$ a day $)^{12,13}$. In some studies, a fixed amount of ONS was used ${ }^{5,9,10,12}$. In our study, we used variable amounts of ONS, based on individual patient requirements. This individual approach may be one reason for the relatively high adherence, i.e. $79-80 \%$ over two periods as assessed by dieticians (based on reported intakes by patients during consultations, by which a reported intake of $75 \%$ or more of the recommended amount was considered to be compliant) and $74-75 \%$ as reported in 
patient diaries. Also, continuity of care with respect to personnel and type of advice as applied in our intervention, may have contributed to the high adherence to ONS and nutritional advice. Furthermore, personal coaching of patients by a single dietician with frequent personal contact (face to face or telephone) may have played a role.

\section{Evaluation of barriers and facilitators}

In our study, nutritional self-care throughout the rehabilitation trajectory after hip fracture was perceived by patients as burdensome. Therefore, they highly valued the frequent individual dietetic counselling over a prolonged period of time as in the current project. Patients also said that they needed this long period of support to accomplish change in (eating) habits, and to overcome their nutritional problems. This support was even more important to the $83 \%$ percent of patients who had some kind of difficulty with using the ONS due to aversion of the ONS, the satiating effect of the ONS, or the duration of ONS use. This high percentage indicates the importance of regular dietetic coaching and support by the dietician in the rehabilitation period after hip fracture. Patients perceived the individual dietary recommendations as valuable, and the structure, i.e. number and type of contacts of the nutritional intervention, as adequate.

Thus, based on the patients' experiences, regular attention for nutrition throughout a prolonged post surgical period after hip fracture (e.g. 3 months) seems necessary in order to achieve an adequate nutritional intake. Some health care professionals mentioned that the intervention structure could be further improved by also adapting the number and type of consultations in the intervention to individual patient needs, since not all patients needed the full intervention, and that tailoring of the intervention to the individual should be based on the patient's physical constraints and dietary problems. The results of the present study also indicate that there is room for improvement with respect to taste, texture and satiating effect of supplements.

In terms of the context, the involved professionals, and the patients ${ }^{14-16}$, the analysis of barriers for implementation of the intervention in usual care showed that in current usual care, often insufficient attention was paid to nutrition, especially with respect to diagnosing nutrition related problems, facilitating nutritional support and follow up of treatment, as reported by the dieticians. Soeters et al. ${ }^{17}$ have reported on a multitude of different disciplines dealing with malnourished individuals. In their opinion, there is no common marketplace in which all these stakeholders can meet to reach consensus about what malnutrition means, and how to optimally detect and treat it. This lack of consensus and the involvement of many disciplines may be an underlying reason for why both patients and professionals perceived the barrier of attention to nutritional care as insufficient. Findings from the Dutch 'nationwide prevalence measurement of care problems 2011' (LPZ) in usual care showed that despite a slightly growing number of screening activities for detection of (risk of) malnutrition, a (timely) start of nutritional intervention and adequate evaluation was still lacking in $50 \%$ of patients ${ }^{18}$. The barriers that we observed with respect to delivery of nutritional care, i.e. a lack of 
structural attention for nutritional care, lack of established procedures, inadequate staffing, and lack of nutritional knowledge, have also been reported in other studies based in hospitals, nursing homes, and geriatric institutions ${ }^{19-22}$. Price ${ }^{23}$ reported that the delivery of snacks as part of a nutritional intervention study for hip fracture patients within a hospital setting was met with difficulties, as patients had to rely on staff to retrieve the snacks. Another study showed difficulties with respect to the nursing staff's attitudes towards nutritional care, both in geriatric health care institutions and at home ${ }^{24}$.

In our study, health care professionals considered the nutritional self-care and availability of nutritional care support at the patients' home to be at risk. Furthermore, our study patients reported problems with taking care of their own food at home, for example, struggling with balance while cooking. Such a finding was also reported in a study of frail elderly individuals who lived at home alone ${ }^{25}$.

\section{Methodological considerations: Effect and feasibility}

\section{Selection of study population in the RCT}

Hip fracture patients admitted to three hospitals were included in the RCT. Because active cooperation was a necessity, cognitively impaired hip fracture patients were excluded. Patients who were bedridden before hip-fracture and patients with underlying bone disease were also excluded. These categories of excluded patients might be particularly vulnerable for malnutrition because they are more dependent on help from others. Thus, our results reflect the experiences of the subgroup of cognitively well, relatively healthy elderly hip fracture patients, and as such, extrapolating the findings to cognitively impaired patients should be done with caution.

As patients with impaired nutritional status could profit more from nutritional intervention, it is possible that potential beneficial effects of the intervention were underestimated in this study. However, since these patients are dependent on others for nutritional care such as the provision of meals and in-between meals, implementation in this patient group may have been more difficult, and this may have attenuated the intervention effect.

\section{Potential for bias}

Twelve patients (15\%) randomized to the control group additionally received nutritional support by ONS or dietetic counselling within the context of usual care. It is possible that either our study or the increasing national interest in malnutrition in health care settings (http://www.stuurgroepondervoeding.nl) heightened nursing staff and dietician awareness of malnutrition or the need to identify hip fracture patients at risk of malnutrition, resulting in a higher request for dietetic care. Regardless of the 
cause, this additional support diminished the contrast between the intervention and the control group, and may have led to an underestimation of the nutritional intervention effect.

Furthermore, patients, dieticians, and researchers involved in the RCT were not blinded for group allocation, which could have introduced bias in outcome assessment. We tried to minimize this bias by having the outcome measurements performed by a trained researcher who did not have a conflict of interest, and the dietary evaluation conducted by trained study dieticians.

\section{Measurements}

Study execution and data collection for the process evaluation were carried out by the same person (study dietician), and therefore, participants may have felt inclined to give more socially acceptable answers than would be the case if these events were carried out by different individuals. Consequently, this may have biased the data. We attempted to make the interviews as unbiased as possible by training the dieticians in interview techniques and posing standardized neutral questions. Additionally, we created a standardized introduction in which patients were made aware of the importance of objective feedback. The purpose of this was to detect intervention related factors requiring further improvement, and to make patients feel free to express their opinions. Nevertheless, response bias cannot be completely excluded, and this could have resulted in an overestimation of the feasibility of the nutritional intervention.

To monitor adherence, study participants were asked to register their ONS use in a study diary. However, only 40 out of 66 patients complied with this request, indicating that many elderly hip fracture patients have difficulties with keeping a diary and registering their ONS use. We listed a variety of reasons for this, such as loss of the diary while being transferred from one institution to another or to the patient's home, poor vision, difficulties with writing, and general physical handicaps. Although several patients experienced problems with keeping a diary, we noted that in other patients, the diary also served as a reminder. To determine whether there was a difference in adherence in ONS use between the group of 40 patients who kept a study diary versus the group of 26 patients who did not keep a study diary, we compared adherence figures. For the first post surgical period (0-10 days), adherence to the ONS of the 26 non-diary patients was similar to the adherence of the 40 diary patients (78\% vs. $80 \%$ ), as recorded by the dietician, However, in the second post surgical period (11-90 days), adherence was slightly lower in the non-diary patient group (70\% vs. $87 \%$ ). This indicates that on the long term (after 10 days post-surgery), patients who have difficulties with registering ONS consumption may be more at risk for non-adherence to ONS use. Alternatively, noncompliance with ONS may simply lead to cessation of the ONS registration in the diary. 


\section{Intervention}

At the start of the nutritional intervention, all patients from the intervention group received ONS for the first post surgical period (up to 3 weeks) in addition to their regular intake of an energy- and protein-enriched diet. It was assumed that nutritional needs were increased for all hip fracture patients after hip fracture surgery due to metabolic stress and reduced habitual nutritional intakes after surgery. During the study execution, large differences were seen: some patients suffered from severe loss of appetite and/or nausea and consequently had markedly reduced dietary intakes, whereas other patients had dietary intakes quite comparable to normal pre-surgical levels.

\section{Methodological considerations: Barriers and facilitators of implementation}

To enable the investigation of potential barriers and facilitators for future implementation, we chose to use a pragmatic approach, in which the nutritional intervention RCT was performed in the context of current usual care ${ }^{26}$. The theoretical framework of Saunders ${ }^{27}$ was chosen as a basis for incorporating a process evaluation in the present study. This framework uses a comprehensive systematic approach for developing a process-evaluation for targeted health promotion interventions in which elements from several existing frameworks have been incorporated ${ }^{28,29}$. It also includes a practical guide for the execution of a process evaluation, through which it becomes a sound and practical process evaluation tool for health care settings. The application of this methodological framework resulted in the detection of barriers at the level of fidelity (to what extent was the intervention implemented consistently with the underling protocol), dose delivered (to what extend were all intended methods, strategies and/or activities used), dose received (to what extend did participants receive intervention components and did they engage in recommended follow up behaviour), and context (what contextual factors or other situational issues could potentially affect either intervention implementation or intervention outcome). With respect to contextual factors, the large number of study locations involved (i.e. hospitals, rehabilitation settings, home care organizations) and the large number of disciplines involved (i.e. physicians, nursing staff, and dietician), resulted in different kinds of barriers, each related to different contexts. For instance, health care professionals at rehabilitation settings noticed lack of nutritional care policies available in their facility and lack of staff. Alternatively, nursing staff at home care organizations had no clear nutrition related responsibilities in their job description. A potential consequence of this approach is that it created limitations in our process evaluation; the description of our results has become rather general, with location specific issues receiving less emphasis. On the other hand, as the process evaluation was aimed at exploring barriers and facilitators for future implementation at various ecological 
levels, the range of different contexts and the large number of various types of stakeholders involved seems advantageous for detecting those barriers and facilitators.

\section{Stakeholders' evaluation of the feasibility of the intervention}

To ensure credibility and validity of findings, we used multiple methods to evaluate the acceptability of the intervention amongst stakeholders. For patients, two questionnaire-based interviews with quantitative and qualitative questioning and additional semi-structured in-depth interviews were used. For the health care professionals' evaluation, a combination of semi-structured in-depth-interviews and focus group interviews were used.

The number of participants in the questionnaire-based evaluation was relatively small $(n=37)$. Results may have been more explicit if we had included more intervention group patients in the evaluation. Additional in-depth interviews were used to obtain more detailed information about patients' experiences with the nutritional intervention, and in-depth interviews with health care professionals were held to obtain information about their experiences with applying the nutritional intervention. To select the patients and health care professionals for the in-depth interviews, we applied the technique of purposive sampling, that is, we chose a judgemental sample of individuals using certain pre-determined criteria which were relevant to the research question (e.g. location of stay after hospital discharge for patients, work setting for health care professionals) in order to obtain maximal variation in data. Semi-structured in-depth interviews were performed, and were continued until data saturation occurred, i.e. a state where no new data of importance to the specific study and developing theory emerge from the interviews.

The additional focus group interviews conducted with health care professionals were aimed at generating additional information through social interaction between focus group participants. Although the selection process of health care professionals as participants in the present study was intended to achieve a wide variety (e.g. input from different disciplines, input from all work settings), we had to make pragmatic choices on whom to approach. For instance, several GPs involved in the treatment of an intervention group patient from the area could be approached for an interview, and therefore selection bias cannot be excluded. 


\section{Interpretation of the findings}

\section{Evidence for dietary treatment in hip fracture patients}

Evidence based practice is about clinical decision making that is based on the best available scientific evidence, combined with knowledge and experience of the caregiver and the values and preferences of the individual patient. To date, scientific evidence about the effectiveness of nutritional supplementation in hip fracture patients has been scarce. Our study results show limited favourable effects with respect to nutritional intake and nutritional status.

Based on the patient's reported dietary intakes and calculated requirements, it was generally recommended by the dieticians that the intervention group patients use ONS for an extended period of time (i.e. median period $>10$ weeks). This implies that the nutritional intake of hip fracture patients is often inadequate for up to two months after surgery, which is confirmed by calculations of reported dietary intakes. At oneweek post surgery, intervention group patients had significantly higher intakes compared to the control group ( $75 \%$ vs. $55 \%$ of energy requirements), although both groups did not meet their nutritional requirements. After the intervention period of 3 months, the intervention group patients had gained weight, while there was a tendency for weight loss in the control group. This suggests that overall, higher energy intake in the intervention group allowed weight gain.

It appeared that $35 \%$ of patient from the intervention group and $47 \%$ of patients from the control group could be classified as being malnourished or being at risk for malnutrition. A recent published report from the 'Dutch Health Council' on the topic of 'Malnutrition in the elderly' addresses the application of dietary interventions in the malnourished elderly. The council states that supplementation with extra protein and energy should produce a clear health gain, such as a shorter hospital stay or lower mortality risk. However, it is impossible to identify those cases for which this would apply $^{30}$. Current clinical practice policies are based on the view that dietary treatment of (risk of) malnutrition is always worthwhile, but the health council considers this view as debatable because there are no appropriate measurements by which too many people might be classified as being malnourished or at risk of malnutrition. Unfortunately, the Dutch Health Council does not indicate how these difficult issues of determining the nutritional status of patients and starting nutritional treatment should be dealt with in clinical practice.

In reaction to the above report of the Health Council of the Netherlands, two Dutch geriatricians published a commentary in the NtvG (Nederlands tijdschrift voor Geneeskunde, Dutch Journal of Medicine $)^{31}$. They explain that undernutrition is a huge problem associated with negative health outcomes, especially in the frail elderly. They consider the review of the recent literature by the Health council of the Netherlands 
useful, but state that it does not contribute anything to clinical practice. According to these authors, the point is that evidence for firm conclusions is still lacking and that, most of all, more research is needed to really define undernutrition, with special need for RCTs in homogeneous groups of elderly to give evidence on the most effective treatment strategies in the different populations in old age. The reductionist viewpoint of the Dutch Health Council neglects the fact that undernutrition in the elderly is a geriatric syndrome, which is mainly explained by multifactorial aetiology. Therefore the geriatricians state that 'the only way forward is to study and treat undernutrition in older adults by using a broad geriatric perspective, without aiming for the holy grail of the single best evidenced definition or treatment'. Thus the authors consider weight loss (amongst other risk factors) a reason for a full geriatric examination of the patient with respect to frailty-factors, geriatric syndromes and disease burden, to be followed by a multifaceted intervention targeted at the different identified risk factors simultaneously in order to improve overall health, functional performance, and overall well-being. To enable the successful application of this multifaceted intervention, the authors propose the involvement of multiple disciplines and the cooperation between health care professionals in first and second line health care. This preventive geriatric examination will identify those hip fracture patients admitted to hospital, who are in need of nutritional supplementation.

We conclude that, considering the role of (risk of) malnutrition in geriatric syndromes on one hand, and the limited evidence with respect to clear cut off points for malnutrition on the other hand, it is necessary to perform preventive geriatric examinations, including attention to nutritional status and intake, in order to detect and treat risk factors contributing to geriatric syndromes.

\section{Achieving change in elderly hip fracture patients}

Both the hip fracture patients and the health care professionals perceived many barriers for the implementation of nutritional intervention in usual care. These barriers and facilitators can be allocated to the patient level, to the professional caregivers' level, and to the contextual level.

\section{Barriers and facilitators at the patient' level}

Although patients reported that the prolonged period of dietetic guidance (i.e. 3 months) with frequent consultations was necessary to accomplish change, our results indicate that changes in dietary intake in elderly hip fracture patients are achievable. Therefore, dietetic follow-up of nutritional intake over a longer postsurgical period is warranted to safeguard the nutritional intakes of hip fracture patients.

Despite the long period over which ONS was needed, adherence to the nutritional recommendations and ONS was relatively high. This high adherence level may be attributed to our individual patient-centered approach, but could also be a result of 
the continuity of care administered by personnel. That is, the direct support that was given to the patients contributed to their ONS intake and adherence to the nutritional recommendations. Our results indicate that effects disappeared after stopping the dietetic consultations and that elderly patients require time to adapt to dietary change. Such observations reiterate the importance of an individual long-term follow up of the nutritional intervention in elderly hip fracture patients.

\section{Barriers and facilitators at the professional caregivers' level}

An important barrier as perceived by health care professionals was their insufficient knowledge of screening, treatment, and follow-up of nutritional status and nutritional therapy. In the professional training program of physicians and nurses, attention for 'nutrition and dietetics' is inadequate. It is common that medical doctors and nursing staff have not been taught or encouraged to pay due attention to nutritional issues. For this reason, additional training of medical professional staff is warranted to improve knowledge and skills, and to allow for the proper application of clinical practice guidelines with respect to nutritional issues on therapeutic medical interventions.

As many different disciplines were involved with the nutritional care of patients, there was fragmentation of nutritional care. Furthermore, nutrition care related tasks within institutions were found to be unclear. These tasks include adequate communication within the work setting as well as to the next location of stay or to home. More intensive cooperation between health care professionals in interdisciplinary teams for the treatment of geriatric patients is thought to be important, as these teams address multiple care demands for geriatric patients ${ }^{33,34}$. The care for hip fracture patients could be further optimized by collaboration of health care professionals in a multidisciplinary team, which at minimum, should be comprised of a clinician, a dietician, a nurse, a nutritional assistant, a geriatrician or geriatric nurse, a case manager (which could be the geriatric nurse), a mental health care provider and a physiotherapist. Cooperation between health care professionals is a prerequisite for improving nutritional care. Therefore it is important to clarify tasks and ensure that health care professionals are aware of their specific role.

\section{Barriers and facilitators for nutritional intervention implementation at the contextual level}

Health care professionals perceived that the care for hip fracture patients was mainly focused on the fracture, whereas attention for the overall condition of the patient, e.g. co-morbidity, was sometimes found to be inadequate. Also, diversity in nutritional care policies between institutions hindered the application of our intervention in the next location of stay. This finding shows the need for standardization and integration of nutritional care in usual health care practice. A first step in tackling this barrier may be to develop a clinical practice guideline that is designed for nutritional care in elderly 
hip fracture patients who are in the integrated health care trajectory. This guideline should standardize nutritional care (based on best practice) and formulate explicit tasks with respect to content and responsibilities of nutritional care in all settings of the trajectory. This guideline should also connect to existing guidelines, such as the multidisciplinary guideline for proper fluid and food maintenance in elderly ${ }^{35}$, and the guideline for detection and treatment of (risk of) malnutrition in primary care, LESA ${ }^{36}$. These existing guidelines are targeted to specific settings (nursing homes and primary care setting, respectively) and do not address nutritional care as part of the integrated health care trajectory. Such a new nutritional care guideline could serve as a basis for cooperation between the dietician and all other involved health care professionals in order to address nutritional problems in the integrated health care setting.

Furthermore, this integrated nutritional care guideline for hip fracture patients can ultimately serve as a basis for integrated nutritional care for other patient groups.

Communication problems between institutions and health care professionals from different institutions were common, which hampered the continuity of nutritional care. Therefore, local collaboration between institutions and between institutions and primary care health care professionals needs to be improved. Each collaboration should include agreements on nutritional care responsibilities, a description of standardized communication, a description of dietary treatment follow-up, and should also connect to results of investigations in this field. The Dutch government has initiated a pilot project called 'national program for elderly care' (NPO) ${ }^{37}$, which focuses on the importance of co-operation and continuity of care. NPO investigates change in care for the elderly using a patient centered approach ${ }^{38}$. The program aims at early signaling of adverse factors followed by adjustments to prevent frailty in the elderly. Additionally, early treatment and linkage of care by multidisciplinary teams until the patient returns home are promoted. In the ongoing pilot project of the NPO, a central caregiver coordinates a regional cooperation network of professionals and based on the geriatric standards, quality criteria, and incorporation of patient perspectives, integrates provision of medical care, well-being and living support, especially for the frail elderly and elderly with multiple diseases.

\section{Barriers at other levels}

Investigating potential barriers and facilitators at the management level of health care organizations and at the national policy level was beyond the scope of the present study. However, potential barriers can be expected at these levels. Due to changes in age demographics, increased life expectancy, and continuous improvement of health care, a general increase in the number of elderly and consequently an increase in the number of elderly hip fracture patients can be expected in the near future. This will result in an increasing number of elderly people making use of health care facilities, which also implies increasing health care costs. Simultaneously, there will be a decrease in health care workers available to deliver the requested care for the large 
increase in volume of health care to be delivered. With the continuing escalation of health care expenditures in the Netherlands and the need to control these expenditures, there seem to be many barriers prevalent at the organizational and political level. Therefore, choices must be made with respect to the health care packages offered to the patients, including the elderly. It will be a challenge to find ways to address health care problems and to improve health care while still being effective and efficient.

\section{Implementation}

The effects of nutritional intervention in the overall hip fracture patient group remain limited. Nevertheless, nutritional interventions targeted at malnourished elderly are needed. For this, it is necessary that strucured attention to the nutritional status of elderly patients be incorporated into usual medical care.

The two main problems to be adressed are:

1. At present, there is inadequate attention for nutritional care in health care settings, and continuity of nutritional care in the integrated health care trajectory is not safeguarded. As such, there is no standard incorporation of nutritional care policies in overall medical treatment. A first step in tackling identified barrriers may be to form multidisciplinary teams of geriatric health professionals with clearly defined nutrition-related responsibilities. These teams should cover the overall integrated health care trajectory and ensure that monitoring of patients throughout the clinical pathway until at home is safeguarded.

2. An integrated nutritional care guideline specific for elderly patients with hip fractures does not exist. Development of such guideline with involvement of all relevant parties would therefore be valuable and could be an important step in tackling the barriers.

Implementing change is known to be problematic. A systematic review by Baker et al. ${ }^{39}$ showed that the odds of implementation strategies effectively changing professional practice were higher when they were tailored to barriers compared to when they were not tailored to barriers. Current views recommend that implementation strategies address identified barriers at all different levels (individual, team, organizational, and the larger health care system). Also, it is considered important to apply methods for change of behaviour based on existing theories and directed to the nature of the change to be achieved ${ }^{40}$. The implementation plan should be locally targeted, involve all relevant stakeholders, and be comprised of a set of strategies for an integrated approach, including arrangements for adequate follow-up of the implementation strategies $^{41}$. This will increase chances of successful implementation. However, different implementation methods are not equally effective, and we do not yet know which implementation strategies are most effective in addressing identified barriers. 
Recently, an EU-wide study began developing valid and efficient methods for tailoring implementation strategies to determinants of practice for chronic diseases ${ }^{42}$. This may eventually shed light on effective and efficient uses of implementation strategies. As tailoring implementation of interventions to locally identified barriers can become costly, we need to be able to weigh costs of change and benefits. In this respect, a more pragmatic approach, such as the current breakthrough project (http://www.cbo.nl/thema/Doorbraak/), might be an alternative, although costs of this approach are still considerable ${ }^{43}$. This project offers a tool for a systematic implementation of multidisciplinary guidelines in institutions. Multidisciplinary teams of health care professionals work in project teams to improve patient care. Necessary changes in care are identified, prepared, applied, and evaluated in a continuous improvement cycle of 'act-plan-do-study'. The intention of this approach is to help health care professionals to implement patient care improvement changes in their daily practice. Implementation of adequate nutritional care could be a topic of the breakthrough project.

Results of our process evaluation could serve as a starting point for investigating the local situation in delivery of nutritional care in elderly (hip fracture patients), to identify local barriers, and to subsequently formulate goals for improvement of patient nutritional care. At the professional level, this should include attention for cooperation in multidisciplinary teams, a clear division of tasks, and communication.

Insufficient knowledge about nutritional care was a main barrier for implementation, and should be considered a main barrier to tackle. The 'frame work plan medical education 2009' (in Dutch, 'Raamplan Artsopleiding 2009') ${ }^{44}$ contains a clear description of knowledge and skills a starting doctor and an experienced doctor should meet. Universities should develop their training programs based on this framework. Although nutrition and integrated care are part of the framework plan for medical education, the basic curriculum for medical doctors focuses limited attention on preand post surgical nutrition and malnutrition. Attention for nutrition related topics should be extended and intensified so that medical doctors can build a sound knowledge base. This applies also to the training for nurses. In their basic curriculum, the role of pre- and post surgical nutrition and malnutrition in (elderly hip fracture) patients (screening, possibilities in treatment, follow up) should be intensified. Furthermore, a post-graduate course to facilitate knowledge transfer in this area should be offered to medical specialists and for nursing staff, with accreditation of the course being mandatory.

At the level of organization, revision of professional roles and enhanced teamwork is needed. To accomplish this, small-scale, interdisciplinary and interactive practise oriented courses should be initiated within institutions, based on a tool in which performance is measured and improvements of services can be shown. Although individual professionals need to be informed, motivated and trained, this is especially paramount for medical doctors involved in the treatment of hip-fracture patients, for 
nursing staff, and for nutritional assistants (45). In addition to knowledge transfer, attention must also be paid to barriers and incentives for change at this level. These may include individual attitudes, motivation, behavioural routines, involvement of opinion leaders, and support of the organization itself. While training programs can address negative attitudes and provide feedback to health care professionals, audits can help to motivate personnel and improve nutritional care, and team-building activities can help enhance teamwork, especially in teams with much resistance. Furthermore, performance indicators could be developed to support the implementation. For example, baseline performance can be assessed though screening and follow-up of nutritional care activities in a department, and follow-up measures can be used to show improvements in care delivery. Finally, additional support of the educational intervention can be achieved through the application of, for example, selfeducating websites.

At the level of the patient, a patient centered approach is required to direct interventions to individual needs. This should incorporate the findings from the present study in which patients felt that frequent consultations and individually tailored advice allowed them to more easily adapt to necessary changes.

At present, the majority of political attention to healthcare is directed at reducing expenditures, and recently, the reimbursement of costs for consulting a dietician outside institutions is no longer covered in basic insurance packages. As a result, depending on the policy of health insurance companies, the cost of dietetic consultations is (partially) compensated via additional insurance packages.

Dietetic care during hospital admissions is usually incorporated in the costs for treatments as arranged for in the DBCs (Diagnose Behandel Combinaties / Diagnosis Treatment Combinations) or the DOTs (DBC op weg naar Transpartantie / Diagnosis Treatment Combinations route to transparency). Furthermore, dietetic care delivered as part of integrated interdisciplinary treatment for specific diseases is presently reimbursed. If a patient is identified to be suffering from (risk of) malnutrition, health insurance organizations do still reimburse costs for the application of ONS, which is a necessity for applying ONS in the dietary treatment of patients.

In conclusion, developing an integrated care treatment plan for (risk of) malnutrition, together with integrated (chain) financing for nutritional care, is needed to incorporate dietetic care in the care for elderly (hip fracture) patients with (risk of) malnutrition and to safeguard financing for dieticians.

\section{Implications}

Based on the preceding discussion, we perceive that our study has the following implications for health care practice and research: 


\section{Implications for practice}

1. Our study indicates that hip fracture patients require additional nutritional support over a long post-surgical period.

2. Improvement of standardized attention for nutritional care with respect to prevention and treatment; i.e. regular screening, nutritional intervention for at risk patients and follow up of nutritional care treatment, should be applied and incorporated in the overall medical treatment in all health care settings and at home. To achieve this, the content of nutritional care activities and division of responsibilities should be clearly laid down and agreed upon within and between institutions and between institutions and home care organizations and general practitioners.

3. Hip fracture patients stay in different health care settings and at home, which makes provision of continuous (nutritional) care for this group especially complicated. Cooperation within the integrated health trajectory is therefore required. To achieve this, institutions must agree on timely and appropriate transfer of information with respect to the patient's treatment.

4. The care for geriatric patients can be optimized by multidisciplinary cooperation as part of geriatric assessment to determine problematic areas in which patients need support. To enhance consistency of care, and in the light of prevention of geriatric syndromes, a systematic approach for integrating care and simultaneously addressing multiple problems (medical, functional and well being problems) is needed, especially for patients who stay at home. This approach still requires development and further exploration.

5. Development of an integrated care nutritional guideline for geriatric (hip fracture) patients is needed. This guideline should be based on best evidence and best practices in prevalent health settings and connect to existing guidelines. Representatives from all relevant stakeholders, i.e. patients, physicians, nurses and nurse assistants, nutritional assistants, dieticians, physiotherapists, and representatives from all involved health care settings (primary care, hospitals, rehabilitation settings, nursing homes, home care), should be involved in the development of the integrated care nutritional guideline for hip fracture patients, Such a guideline can serve as a basis for incorporation of nutritional care in treatment protocols for other geriatric problems and diseases. This guideline can also serve as a basis for institutions, health care organizations, and health care professionals to further develop or establish nutritional care policies in their own working environment, including standard incorporation of nutritional care activities in the medical treatment and safeguarding transfer of information to the next institution.

6. Implementation of new work practices according to a nutritional care guideline needs to be carefully prepared and planned. In order to choose an appropriate implementation approach, costs and aims must be weighed out and local barriers must be considered. Further taking the barriers as revealed in this thesis (i.e. 
knowledge, communication, cooperation in multidisciplinary teams, continuity of care) and the different levels (patients, health care professionals, context) into consideration will result in a tailored set of multiple strategies. Regular evaluation and follow up activities will be needed to further guide implementation and quality improvement.

\section{Implications for future research}

Several topics for further research emerge from this thesis.

1. To facilitate the development of a clinical practice guideline for nutritional care in the elderly in the integrated health care trajectory, a study should be executed. This gold standard should be based on a review of existing evidence and complemented with qualitative research that involves stakeholders at different levels. It will be necessary for such research to address content of the guideline, necessary cooperation, and perceived roles of health care professionals in nutritional care.

2. A second theme for further research is to find the best procedure for further integrating nutritional care into the clinical pathway. For this purpose, factors influencing the continuity of nutritional intervention in usual care practice should be investigated.

3. Further research is needed on barriers and facilitators at the organizational (management and regional organization) and the financial level. This would identify additional barriers and facilitators with respect to e.g. policy choices at the organizational level, support of introduction of new work practices, and availability of finances to support change. Such factors are likely to influence the feasibility of the intervention in health care settings, thus influencing overall feasibility in the integrated care path.

4. In the field of nutritional assessment, studies are needed to further develop practical screening tools for defining malnutrition. This will enable targeting of the nutritional interventions to those in need, and to further develop strategies to identify and treat malnourished elderly at home.

5. Finally, studies on (the barriers and facilitators of) incorporating nutritional assessment into assessments for the detection and prevention of geriatric syndromes are needed.

\section{Final conclusion}

The following conclusions on the effects, feasibility and barriers for intervention implementation can be drawn:

- Intensive dietetic counselling and oral nutritional supplementation for three months postoperatively improved dietary intake, and induced weight gain in elderly hip fracture patients. 
- Based on dieticians' judgment the majority of hip fracture patients included in our study required oral nutritional supplements for more than two months in order to meet their nutritional requirements.

- Nutritional counselling in elderly hip fracture patients is feasible and is highly valued by patients. It is recommended that the intervention be tailored to the individual needs of the patient.

- Barriers for implementation of nutritional intervention were found at a professional level (knowledge, communication, cooperation, involvement of health care professionals/ multidisciplinary teams and staff available), at a patient level (reimbursement costs, adherence), and at a contextual level (local policies, communication, health care professionals' roles, continuity of care).

- An important barrier is constituted by the large differences in nutritional care practices between institutions, and by the lack of continuity in nutritional care in the integrated health care trajectory.

- A next step on the road to effective change would be to identify local barriers and translate them into a set of strategies and measures at different ecological levels. These should be tailored to the locally identified barriers, and include, for example, active educational interventions, professional interventions such as selfeducating websites, patient directed interventions, and organizational interventions such as revision of professional roles and enhanced teamwork. Given the limited resources in the present health care environment, efficiency should also be taken into account. 


\section{References}

1. Vellas B, Guigoz Y, Garry PJ, Nourhashemi F, Bennahum D, Lauque S, et al. The Mini Nutritional Assessment (MNA) and its use in grading the nutritional state of elderly patients. Nutrition. 1999 Feb;15(2):116-22.

2. Guigoz Y. The Mini Nutritional Assessment (MNA) review of the literature--What does it tell us? J Nutr Health Aging. 2006 Nov-Dec;10(6):466-85; discussion 85-7.

3. Avenell A, Handoll HGG. Nutritional supplementation for hip fracture aftercare in older people (Review). Cochrane Database Syst Rev. 2010(1).

4. Eneroth M, Olsson UB, Thorngren KG. Insufficient fluid and energy intake in hospitalised patients with hip fracture. A prospective randomised study of 80 patients. Clin Nutr. 2005 Apr;24(2):297-303.

5. Delmi M, Rapin CH, Bengoa JM, Delmas PD, Vasey H, Bonjour JP. Dietary supplementation in elderly patients with fractured neck of the femur. Lancet. 1990 Apr 28;335(8696):1013-6.

6. Duncan DG, Beck SJ, Hood K, Johansen A. Using dietetic assistants to improve the outcome of hip fracture: a randomised controlled trial of nutritional support in an acute trauma ward. Age Ageing. 2006;35(2):148-53.

7. Neumann M, Friedmann J, Roy MA, Jensen GL. Provision of high-protein supplement for patients recovering from hip fracture. Nutrition. 2004 May;20(5):415-9.

8. Botella-Carretero JI, Iglesias B, Balsa JA, Zamarron I, Arrieta F, Vazquez C. Effects of oral nutritional supplements in normally nourished or mildly undernourished geriatric patients after surgery for hip fracture: a randomized clinical trial. JPEN J Parenter Enteral Nutr. 2008 Mar-Apr;32(2):120-8.

9. Bruce D, Laurance I, McGuiness M, Ridley M, Goldswain P. Nutritional supplements after hip fracture: poor compliance limits effectiveness. Clin Nutr. 2003;22(5):497-500.

10. Espaulella J, Guyer H, Diaz-Escriu F, Mellado-Navas JA, Castells M, Pladevall M. Nutritional supplementation of elderly hip fracture patients. A randomized, double-blind, placebo-controlled trial. Age Ageing. 2000 Sep;29(5):425-31.

11. Williams CM, Driver LT, Older J, Dickerson JW. A controlled trial of sip-feed supplements in elderly orthopaedic patients. Eur J Clin Nutr. 1989 Apr;43(4):267-74.

12. Lawson RM, Doshi MK, Ingoe LE, Colligan JM, Barton JR, Cobden I. Compliance of orthopaedic patients with postoperative oral nutritional supplementation. Clin Nutr. 2000;19(3):171-5.

13. Miller MD, Daniels LA, Bannerman E, Crotty M. Adherence to nutrition supplements among patients with a fall-related lower limb fracture. Nutr Clin Pract. 2005 Oct;20(5):569-78.

14. Grol R, Grimshaw J. From best evidence to best practice: effective implementation of change in patients' care. Lancet. 2003 Oct 11;362(9391):1225-30.

15. Campbell M, Fitzpatrick R, Haines A, Kinmonth AL, Sandercock P, Spiegelhalter D, et al. Framework for design and evaluation of complex interventions to improve health. BMJ. 2000 Sep 16;321(7262):694-6.

16. Campbell NC, Murray E, Darbyshire J, Emery J, Farmer A, Griffiths F, et al. Designing and evaluating complex interventions to improve health care. Bmj. 2007 Mar 3;334(7591):455-9.

17. Soeters PB, Schols AM. Advances in understanding and assessing malnutrition. Curr Opin Clin Nutr Metab Care. 2009 Sep;12(5):487-94.

18. Halfens RJG, Meesterberends E, Meijers JMM, Du Moulin MFMT, van Nie NC, Neyens JCL, Schols JMGA. Landelijke Prevalentiemeting Zorgproblemen Rapportage resultaten 2011. Maastricht: Maastricht University, Faculty of Health, Medicine and Life Sciences, Department of Health Service Research Focusing on Chronic Care and Ageing; 2011.

19. Bourdel-Marchasson I. How to improve nutritional support in geriatric institutions. J Am Med Dir Assoc. 2009 Jan;11(1):13-20.

20. Labossiere R, Bernard MA. Nutritional considerations in institutionalized elders. Curr Opin Clin Nutr Metab Care. 2008 Jan;11(1):1-6.

21. Pedersen PU. Nutritional care: the effectiveness of actively involving older patients. J Clin Nurs. 2005 Feb;14(2):247-55.

22. Rasmussen $\mathrm{HH}$, Kondrup J, Staun M, Ladefoged K, Lindorff K, Jorgensen LM, et al. A method for implementation of nutritional therapy in hospitals. Clin Nutr. 2006 Jun;25(3):515-23. 
23. Price RJG, McMurdo MET, Anderson AS. A personalized snack-based intervention for hip fracture patients: development, feasibility and acceptability. Journal of Human Nutrition and Dietetics. 2006;19(2):139-45.

24. Bachrach-Lindstrom M, Jensen S, Lundin R, Christensson L. Attitudes of nursing staff working with older people towards nutritional nursing care. Journal of Clinical Nursing. 2007;16(2014).

25. Porter EJ. Problems with preparing food reported by frail older women living alone at home. Ans. 2007 Apr-Jun;30(2):159-74.

26. Thorpe KE, Zwarenstein M, Oxman AD, Treweek S, Furberg CD, Altman DG, et al. A pragmaticexplanatory continuum indicator summary (PRECIS): a tool to help trial designers. J Clin Epidemiol. 2009 May;62(5):464-75.

27. Saunders RP, Evans MH, Joshi P. Developing a process-evaluation plan for assessing health promotion program implementation: a how-to guide. Health Promot Pract. 2005 Apr;6(2):134-47.

28. Baranowski T, Stables G. Process evaluations of the 5-a-day projects. Health Educ Behav. 2000 Apr;27(2):157-66.

29. Steckler A, Linnan LA. (2002a). Process evaluation for public health interventions and research San Francisco: Jossey-Bass.

30. Ondervoeding bij ouderen. The Hague: Gezondheidsraad, Health Council of the Netherlands. 2011.

31. van Asselt DZB, Olde Rikkert MGM. Gezondheidsraad miskent interacties bij ondervoeding van ouderen. Ned Tijdschr Geneeskd. 2012;156(A4446).

32. Saka B, Kaya O, Ozturk GB, Erten N, Karan MA. Malnutrition in the elderly and its relationship with other geriatric syndromes. Clin Nutr. 2010 Dec;29(6):745-8.

33. Halbert J, Crotty M, Whitehead C, Cameron I, Kurrle S, Graham S, et al. Multi-disciplinary rehabilitation after hip fracture is associated with improved outcome: A systematic review. J Rehabil Med. 2007 Sep;39(7):507-12.

34. Caplan GA, Williams AJ, Daly B, Abraham K. A randomized, controlled trial of comprehensive geriatric assessment and multidisciplinary intervention after discharge of elderly from the emergency department--the DEED II study. J Am Geriatr Soc. 2004 Sep;52(9):1417-23.

35. Arcares. Multidisciplinaire richtlijn verantwoorde vocht- en voedselvoorzieing voor verpleeghuis geindiceerden. 2001

36. Mensink PAJS DB, MAT, Remijnse-Meester TA, Kattemolle-van den Berg S, Liefaard AHB, Meijers JMM, Van Binsbergen JJ, Van Wayenburg CAM, Vriezen JA. Landelijke Eerstelijns Samenwerkings Afspraak Ondervoeding. Huisarts \& Wetenschap 2010;53(7):S7-10.

37. Linnan LA, Steckler A, Maman S, Ellenson M, French E, Blanchard L, et al. Engaging key stakeholders to assess and improve the professional preparation of $\mathrm{MPH}$ health educators. Am J Public Health. Oct;100(10):1993-9.

38. CSO dkvo, NFU, Nederlandse federatie van universitair medische centra, ZonMw. Toekomstige ouderenzorg; kernwaarden, opbrengsten en perspectief. De visie van CSO, NFU en ZonMw. 13 januari 2012.

39. Baker R, Camosso-Stefinovic J, Gillies C, Shaw EJ, Cheater F, Flottorp S, et al. Tailored interventions to overcome identified barriers to change: effects on professional practice and health care outcomes. Cochrane Database Syst Rev. 2010(3):CD005470.

40. Eccles $M$, Grimshaw J, Walker A, Johnston $M$, Pitts $N$. Changing the behavior of healthcare professionals: the use of theory in promoting the uptake of research findings. J Clin Epidemiol. 2005 Feb;58(2):107-12.

41. Wensing $M$, Bosch $M$, Grol R. Developing and selecting interventions for translating knowledge to action. Cmaj. 2010 Feb 9;182(2):E85-8.

42. Wensing M, Oxman A, Baker R, Godycki-Cwirko M, Flottorp S, Szecsenyi J, et al. Tailored Implementation For Chronic Diseases (TICD): a project protocol. Implement Sci. 2011;6:103.

43. Schouten L. Quality improvement collaboratives; Cost effectiveness and determinants of successs. Nijmegen: Radboud University; 2010.

44. van Herwaarden CLA L, RFJM, Leunissen RRM. Raamplan Artsopleiding 2009: Nederlandse Federatie van Universitaire Medische Centra; Juni 2009. Report No.: NFU-092168.

45. Grol R, Wensing, M., Eccles, M. Improving patient care; The implementation of change in clinical practice. Oxford: Elsevier; 2004. 
Summary 


\section{Summary}

This thesis describes a limited effect evaluation (on nutritional intake and nutritional status) and a process evaluation that were designed within the context of a multicentre Randomized Controlled Trial (RCT) on the effectiveness and costeffectiveness of a nutritional intervention in elderly subjects after hip fracture. Data on other outcomes and cost-effectiveness will be published in another thesis.

The objective of the RCT was to assess whether a nutritional intervention could improve the nutritional status and speed of recovery of elderly hip fracture patients. The process evaluation was aimed at assessing the feasibility of the intervention and generating insights with respect to barriers and facilitators for effective implementation of the nutritional intervention in an usual care setting.

We have considered the need for evaluation of complex interventions with respect to effect and process, and the lack of process evaluation data available with respect to the application of nutritional interventions in an integrated health care setting. A pragmatic approach was utilized in this RCT so that the application of the nutritional intervention and potential barriers for future implementation during study execution could be investigated in the current usual care setting. This usual care setting was the integrated clinical pathway for hip fracture patients, involving all patients' locations of stay, including hospitals, rehabilitation settings, and at home, and involving the professionals of all the locations of stay, including home care organizations.

Data concerning the nutritional intake and nutritional status of patients, as well as data concerning study execution were generated in order to determine the effects and feasibility of the nutritional intervention. To generate insights for effective implementation of the nutritional intervention on a larger scale, we investigated barriers and facilitators as perceived by the main stakeholders involved (patients and health care professionals). The aim of the present thesis was to evaluate the implementation of the nutritional intervention in hip fracture patients within the pragmatic study setting of a randomized controlled trial.

\section{Part 1: Effects and feasibility}

In Chapter 2, the design, aims, methodology, and content of the multicentre randomized controlled trail (RCT) on efficacy and cost effectiveness of a nutritional intervention for elderly hip fracture patients is presented.

Hip fracture patients often have an impaired nutritional status at the time of fracture, which can result in a higher complication rate, prolonged rehabilitation time, and increased mortality. Our multicenter RCT was designed to evaluate the effect of nutritional intervention on nutritional status, functional status, total length of stay, 
postoperative complications, and cost-effectiveness in elderly hip fracture patients (aged 55 years and above).

The nutritional intervention in the intervention group was a combination of regular dietetic counselling (through regular contacts with hospitalised patients, home visits, and telephone calls) and consumption of a multi-nutrient oral nutritional supplement (ONS) for a period of three months after surgery. This was started in the hospital soon after hip surgery and continued in the rehabilitation setting and/or patient's home. The intervention encompassed 10 dietician-patient contacts over the three-month intervention period. During each contact with the patient, the dietician monitored the patient's weight and nutritional intake (including the ONS) using a 24-hour dietary recall. The nutritional intervention was comprised of an energy- and protein-enriched diet, including an oral nutritional supplement (ONS), for three months. Based on the results of the assessments, the dieticians gave individually tailored recommendations with respect to foods and amounts, time of consumption, and the need for ONS. When the patient's diet met nutritional requirements, the consumption of ONS was gradually decreased. The dietician was responsible for ordering the ONS and the required foods for the patient's home or institution of stay.

Specially trained dieticians were responsible for the delivery of the nutritional intervention. They worked closely with the involved professional health caregivers (i.e. clinicians, nursing staff, and the nutritional assistants and dieticians) of the different health care organizations. The professional caregivers involved were all responsible for registering their nutritional intervention related activities in the patients' medical files. The control group received usual dietetic care as provided in the hospital, the rehabilitation setting, or at home, i.e. dietetic care of nutritional supplements were only provided on demand of the medical doctor in charge.

Outcome assessment was performed at three and six months after hip fracture, and consisted of an evaluation of dietary intake (by 24-hour dietary recalls), anthropometric measurements (i.e. body weight and height, upper arm circumference, skin fold thickness measurements, and handgrip strength measurements), and measuring of biochemical parameters in blood samples (i.e. albumin, pre-albumin, C-reactive protein, vitamin A, E, C, uric acid, homocysteïne, and 5-methyltetrahydrofolate). The other end-outcomes (hospital stay, functional recovery) will be reported in another thesis.

Chapter 3 presents the results of a 3-month nutritional intervention that combined dietetic counselling and oral nutritional supplementation for the purpose of investigating whether dietary intake improved nutritional intake and nutritional status in elderly subjects after hip fracture. Nutritional intake and nutritional status were assessed at baseline during hospitalization and at three and six months postoperatively.

One-hundred fifty-two patients were included in our study, of which 73 patients were randomized to the intervention group and 79 patients to the control group. 
Three months postoperatively, dietary intake of fat, fatty acids, calcium and vitamins, as well as weight, BMI, supra-iliac skin fold thickness, and blood levels of vitamin C and 5-methyl-tetrahydrofolate had increased to a significantly larger extent in the intervention group compared to the control group. At six months postoperatively, dietary intake was no longer significantly different between both groups, and with respect to nutritional status, only the increase of the supra-iliac skin fold thickness remained significantly different.

We concluded that three months of intensive dietetic counselling and oral nutritional supplementation improved the nutritional intake of both macro-and micro-nutrients, and induced weight gain and supra-iliac skin fold thickness in elderly hip fracture patients.

In Chapter 4, results of the quantitative process evaluation are presented. The aim of this study was to investigate the feasibility of the intervention with respect to number, type, duration, content of contacts, and the fit of the program within the present Dutch health care system. The nutritional intervention was evaluated with respect to dieticians' adherence to the study protocol, coverage of content of nutritional counselling, and patients' adherence to the given recommendations.

We included 66 patients (mean age of 76, range 55-92 years) from the intervention group; $74 \%$ of which were women. Dieticians' adherence to the study protocol was high: $83 \%$ of patients received all ten contacts as planned, but in $62 \%$ of the patients, one or more telephone calls had to be replaced by face to face contacts. Nutritional counselling was complete in $91 \%$ of contacts. Oral nutritional supplementation was needed for a median period of 76 days; $75 \%$ of patients took the supplements as recommended.

Based on the results of the present process evaluation, we concluded that implementation of a nutritional intervention is feasible with respect to number, duration, and content of contacts. However, individual tailoring of the intervention is recommended. The majority of hip fracture patients needed more than two months of oral nutritional supplements to meet their nutritional requirements.

\section{Part 2: Barriers and facilitators}

In part 2 of this thesis, the results of the stakeholder's perspectives on barriers and facilitators for large-scale implementation of the applied nutritional intervention are presented.

In Chapter 5, we present a prospective process evaluation from the patient's perspective, which was executed within the multicentre nutritional intervention RCT aimed at improving the nutritional status and speed of recovery of elderly hip fracture 
patients. The evaluation was aimed at identifying key issues necessary for improving the intervention program.

From August 2008 to June 2010, data were collected from 37 patients in two short questionnaire-structured, face-to face- interviews to evaluate patients' experiences with the nutritional intervention program (structure, content nutritional counselling, and role of the dietician), and to evaluate the use of ONS. An additional in-depth interview was performed in a selection of ten patients. Mean age of the patients was 75 years; 26 (70\%) were women. Patients perceived the nutritional intervention as useful (89\%) and adequate with respect to the number $(87 \%)$ and duration $(78 \%)$ of counselling contacts, as well as the period of ONS (65\%) and daily amount of ONS (76\%). Main reported positive aspects were: the individually tailored nutritional recommendations, the spreading of information, and the use of ONS. Factors limiting the execution of nutritional recommendations were: physical constraints, dependency on others, time needed to become accustomed to new dietary habits, and difficulties with the ONS-intake.

In general, hip fracture patients perceived the content, structure, and individual dietetic guidance of the nutritional intervention as useful, adequate, and valuable. However, assistance for nutritional care in institutions and at home was not always sufficient.

Chapter 6 presents the perspectives of the involved health care professionals' with respect to feasibility and perceived barriers in applying the nutritional intervention in the present usual care setting. The objective was to identify barriers and facilitators for implementation of the nutritional intervention on a larger scale.

In this qualitative interview, study data were collected through individual semistructured interviews and additional focus group interviews with key professional health care personnel (i.e. clinicians, nursing staff, dieticians, and nutritional assistants) from the three hospitals, 15 rehabilitation settings, four home care organizations, and the general practises involved in the study. A total of 22 interviews with professional caregivers and three focus group interviews with 13 involved dieticians and nurses were held.

At a professional level, results show that there is lack of knowledge about nutritional care, and lack of time available by nursing staff. At a system level, health care professionals reported: 1 . incomplete communication between institutions with respect to nutritional care; 2 . lack of clarity within institutions with respect to nutrition-related responsibilities; and 3. diversity in nutritional care policies between institutions, hindering the application of the nutritional intervention.

These barriers may be improved by forming multidisciplinary geriatric teams with clearly defined nutrition-related responsibilities, and by monitoring patients throughout the clinical pathway, including at home, based on a clinical practice guideline for geriatric nutritional care. 
Chapter 7 discusses the findings of the previous chapters in a broader context.

The main findings are summarized, compared with literature, methodological considerations are highlighted, and interpretations of findings with implications for practice and for future research are given.

Important issues discussed relate to:

1. the available evidence for dietary treatment in hip fracture patients;

2. the multiple barriers and facilitators encountered at the patient' level, the health care professionals' level, and the contextual level;

3. the difficulties in implementing change and the different possibilities to address the encountered barriers.

Based on the considerations of this thesis, the following recommendations were defined to improve nutritional intake in hip fracture patients:

1. Improvement of standardized attention for nutritional care is necessary.

2. To reach continuity in nutritional care, cooperation between health care professionals of different institutions in the integrated health care setting requires improvement.

3. Enhanced multidisciplinary cooperation targeted at individual patients' problems, especially for patients who stay at home must be further developed.

4. An integrated care nutritional guideline for geriatric patients, based on and connected to existing guidelines, must be developed to serve as a basis for standard incorporation of nutritional care activities in medical treatment in an integrated health care setting.

5. In order to increase chances for successful implementation of new work practices, current views recommend that implementation strategies consist of a set of multiple strategies on different levels, tailored to the local situation and identified barriers.

Finally, the themes for further research that emerge from the studies are discussed. First, a gold standard clinical practice guideline for nutritional care in the elderly in the integrated health care trajectory should be developed. Second, studies are needed to further improve integration of nutritional care in the clinical pathway. Third, studies are needed to explore barriers and facilitators at the organizational (management and regional organization) and the financial level. This would identify additional barriers and facilitators with respect to e.g. policy choices at the organizational level, support of introduction of new work practices, and availability of finances to support change. Finally, in the field of nutritional assessment, studies are needed to further develop practical screening tools for defining malnutrition. 
Samenvatting 


\section{Samenvatting}

Dit proefschrift geeft de resultaten weer van een beperkte effectevaluatie en een uitgebreide procesevaluatie van een voedingsinterventie die uitgevoerd is in het kader van een gerandomiseerde gecontroleerde studie (RCT) bij oudere patienten met een gebroken heup. De RCT was gericht op het bepalen van de effectiviteit en kosteneffectiviteit van een voedingsinterventie bij ouderen na een heupfractuur. In dit proefschrift worden de effecten van de voedingsinterventie op de voeding en voedingstoestand beschreven. Overige gegevens van de RCT met betrekking tot resultaten van de effectiviteitsmetingen en de kosteneffectiviteit worden gepubliceerd in een ander proefschrift.

De proces evaluatie had tot doel om de uitvoerbaarheid van de voedingsinterventie te bepalen en om inzicht te verkrijgen in knelpunten en in bevorderende factoren die een effectieve invoering van de voedingsinterventie in de huidige gebruikelijke zorg zouden kunnen beïnvloeden.

Bij complexe interventies is het van belang om naast bestudering van effecten ook een evaluatie van het proces uit te voeren. Daarnaast blijken weinig procesevaluatie gegevens beschikbaar te zijn over de toepassing van voedingsinterventies in de context van transmurale zorg (d.i. zorg buiten het ziekenhuis). Voor de procesevaluatie is een pragmatische aanpak gebruikt, waarbij bestudering van invoering van de voedingsinterventie en mogelijke knelpunten voor toekomstige toepassing van deze interventie in de huidige gebruikelijke zorg uitvoerig werden bestudeerd. Deze gebruikelijke transmurale zorg setting voor heupfractuurpatiënten betreft alle locaties waar de patiënten met een gebroken heup behandeld worden en verder revalideren, namelijk het ziekenhuis, de revalidatie setting en thuis. Onze procesevaluatie betrof de professionele zorgverleners betrokken bij de voedingsinterventie en alle organisaties die bij de zorg voor heupfractuur patiënten betrokken zijn (inclusief thuiszorg organisaties).

Gegevens over de voedingsinname en voedingstoestand van patiënten en gegevens met betrekking tot studie-uitvoering werden verzameld om de effectiviteit en de uitvoerbaarheid van de interventie vast te kunnen stellen. Om inzicht te verkrijgen in effectieve implementatie van de voedingsinterventie op grotere schaal werden knelpunten en bevorderende factoren onderzocht bij belangrijke betrokken partijen, namelijk de patiënten zelf en de zorgverleners. Het doel van dit proefschrift is om de invoering van de voedingsinterventie bij heupfractuurpatiënten te evalueren in de pragmatische context van een gerandomiseerde gecontroleerde studie 


\section{Deel 1: Effectiviteit en uitvoerbaarheid}

In Hoofdstuk 2 worden het ontwerp, de doelen, de toegepaste methodologie en de inhoud van de RCT naar effectiviteit en kosteneffectiviteit van de voedingsinterventie bij oudere heupfractuurpatiënten gepresenteerd.

Het is bekend dat heupfractuurpatiënten vaak een verslechterde voedingsstatus hebben op het moment dat de heupfractuur ontstaat, wat een hoger aantal complicaties, een verlengde tijd nodig voor de revalidatie en een verhoogde sterfte tot gevolg kan hebben. Onze gerandomiseerde gecontroleerde studie die gelijktijdig op meerder locaties in meerdere instellingen werd uitgevoerd, is gehouden om het effect van een voedingsinterventie bij heupfractuurpatiënten van 55 jaar en ouder te evalueren met betrekking tot voedingsstatus, functionele status, totale opnameduur, complicaties na de chirurgische ingreep en kosten.

De voedingsinterventie (in de interventiegroep) bestond uit een combinatie van regelmatige consultaties in de vorm van bezoeken en telefoongesprekken door een diëtist en de inname van een voedingssupplement in de vorm van volledige drinkvoeding (ONS, verrijkt in energie en eiwit ) over een periode van drie maanden vanaf de operatie. De voedingsinterventie werd gestart in het ziekenhuis, snel na de heupoperatie en werd vervolgd in de instelling voor revalidatiezorg en/of bij de patiënt thuis. De interventie bestond uit 10 diëtist-patiënt contacten over een periode van 3 maanden; de diëtist controleerde tijdens elk contact het verloop van het lichaamsgewicht en de voedingsinname (inclusief het gebruik van de drinkvoeding). Dit gebeurde door het navragen van de voeding over de laatste 24 uur (de zgn. 24-uurs voedings navraag methode of $24 \mathrm{~h}$ recall). De voedingsinterventie bestond uit een energie- en eiwitverrijkte voeding, met daarin opgenomen het gebruik van het drinkvoeding supplement, over een periode van 3 maanden. Op basis van de resultaten van de evaluaties door de diëtist met betrekking tot gewichtsverloop en voedingsinname, gaf de diëtist individuele adviezen aan de patiënt ten aanzien van het gebruik van soorten en hoeveelheden van voedingsmiddelen, tijdstippen van gebruik en ten aanzien van de drinkvoeding. Op het moment dat de voedingsinname van de patiënt in overeenstemming was met de behoeften werd de inname van de drinkvoeding geleidelijk verminderd en gestopt. De diëtist organiseerde de aanvraag van de drinkvoeding en benodigde voedingsmiddelen voor de patiënt in de instelling of bij de patiënt thuis.

Speciaal getrainde diëtisten waren verantwoordelijk voor de uitvoering van de voedingsinterventie. Zij werkten nauw samen met de gezondheidszorg professionals die werkzaam waren in alle betrokken gezondheidszorg instellingen en organisaties; dit waren de artsen, verpleegkundig personeel, voedingsassistenten en diëtisten. De betrokken zorgprofessionals waren verantwoordelijk voor de registratie van de voedinginterventie gerelateerde activiteiten waarvoor zij verantwoordelijk waren in het patiënten dossier. 
De patiënten in de controle groep ontvingen de gebruikelijk voedings- en diëtistische zorg zoals verleend in het ziekenhuis, in de revalidatie setting of door de thuiszorg organisatie; dit hield in dat diëtistische zorg alleen werd geleverd aan de patiënt op voorschrift van diens arts.

Metingen ten behoeve van de uitkomstmaten werden verricht drie en zes maanden na de heupfractuur. Deze metingen bestonden uit evaluatie van de voedingsinname (door middel van de 24-uurs navraag methode), meting van de lichaamssamenstelling (lichaamsgewicht, lichaamslengte, bovenarm omtrek, huidplooidikte en handknijpkracht), en meting van biochemische parameters in bloed (albumine, prealbumine, CRP, vitamine $A, E, C$, urinezuur, homocysteïne en foliumzuur).

Hoofdstuk 3 geeft de resultaten weer van de effecten van de 3-maandse voedingsinterventie met betrekking tot voedingsinname en voedingsstatus bij oudere heupfractuurpatiënten.

Honderd-twee-en-vijfig patiënten werden geïncludeerd in onze studie, waarvan 73 patiënten werden gerandomiseerd in (=door loting toegedeeld aan) de interventiegroep en 79 patiënten in de controle groep.

Drie maanden na de heupfractuur waren de voedingsinname van vet, vetzuren, calcium en vitamines, lichaamsgewicht, Body Mass Index (BMI), huidplooidikte van de supra-iliacale huidplooi (= huidplooi boven de heup) en bloedwaarden voor vitamine $C$ en foliumzuur, significant meer toegenomen in de interventiegroep dan in de controlegroep.

Zes maanden na de heupoperatie was de voedingsinname niet langer significant verschillend tussen de interventie- en de controlegroep. Met betrekking tot de voedingstoestand bleef alleen een significant verschil bestaan voor de toename van de supra-iliacale huidplooidikte.

Hieruit concluderen we dat intensieve voedingsbegeleiding door een diëtist gecombineerd met suppletie van drinkvoeding over en periode van drie maanden de voedingsinname van zowel micro- als macro nutriënten verbeterde, en dat deze interventie leidde tot versnelde gewichtstoename bij deze groep van oudere heupfractuur patiënten.

In Hoofdstuk 4 worden de resultaten van de kwantitatieve procesevaluatie gepresenteerd. Het doel van deze studie was de uitvoerbaarheid van de voedingsinterventie te onderzoeken, met betrekking tot het aantal, het type, de duur en de inhoud van de consulten door de diëtist, en om te onderzoeken of het programma past binnen het huidige Nederlandse gezondheidszorg systeem. De voedingsinterventie werd geëvalueerd ten aanzien van de mate waarin de voedingsinterventie was uitgevoerd door de diëtisten volgens het studieprotocol, in hoeverre de beschreven inhoud van de consulten aan de orde was gesteld tijdens de bezoeken en of patiënten de gegeven adviezen hadden opgevolgd. 
We hebben 66 patiënten geïncludeerd in deze studie met een gemiddelde leeftijd van 76 jaar (variërend van 55-92) uit de interventiegroep; 74\% waren vrouwen. De uitvoering van de voedingsinterventie volgens studieprotocol was hoog: $83 \%$ van de patiënten ontving alle tien consultaties zoals vooraf gepland, maar bij $62 \%$ van de patiënten moesten één of meerdere telefonische consulten worden vervangen door huisbezoeken, o.a. omdat patiënten problemen hadden met het communiceren via de telefoon, of vanwege een verslechterende conditie van de patiënt, of omdat de patiënt verhuisde naar een andere locatie om praktische regelingen ter plekke te treffen. Ook waren extra bezoeken nodig vanwege problemen met de inname van de drinkvoeding en heropname in het ziekenhuis. De geplande inhoud van de consulten was volledig uitgevoerd voor $91 \%$ van de consulten. De drinkvoeding bleek gemiddeld gesproken nodig te zijn voor een periode van 76 dagen (mediaan) en $75 \%$ van de patiënten gebruikte de drinkvoeding als aanbevolen.

Gebaseerd op onze bevindingen concluderen we dat invoering van een voedingsinterventie uitvoerbaar is met betrekking tot het aantal consulten en duur en inhoud van de consulten. Het is echter aan te raden de interventie hierin af te stemmen op de individuele behoefte van de patiënt. De meerderheid van de patiënten had gedurende meer dan 2 maanden aanvullend drinkvoeding nodig om hun voedingsbehoeften te dekken.

\section{Deel 2: Belemmerende en bevorderende factoren}

In deel 2 van dit proefschrift worden resultaten weergegeven vanuit het perspectief van belangrijke betrokken partijen ten aanzien van bevorderende en belemmerende factoren voor invoering van de toepaste voedingsinterventie op grotere schaal.

In Hoofdstuk 5 presenteren we resultaten van een prospectieve procesevaluatie vanuit het patiëntenperspectief, die uitgevoerd is binnen de context van de hierboven beschreven RCT bij heupfractuurpatiënten. De procesevaluatie had als doel de belangrijkste problemen bij de toepassing van de voedingsinterventie op te sporen om het voedingsinterventie programma te verbeteren.

Vanaf augustus 2008 tot juni 2010 zijn gegevens verzameld bij 37 patiënten. Bij deze patiënten werden twee korte gestructureerde individuele interviews op basis van een vragenlijst afgenomen, om de eigen ervaringen van de patiënten met de voedingsbegeleiding en met het gebruik van de drinkvoeding te evalueren. Een aanvullend diepte-interview werd gehouden bij een selectie van tien patiënten.

De gemiddelde leeftijd van de patiënten was 75 jaar; 26 (70\%) waren vrouwen. Patiënten beoordeelden de voedingsinterventie als nuttig (89\%) en goed met betrekking tot het aantal consulten (87\%), de duur van de consulten (78\%), de periode waarover drinkvoeding werd geadviseerd (65\%) en de geadviseerde dagelijkse hoeveelheid drinkvoeding (76\%). Belangrijke gerapporteerde positieve aspecten 
waren: de individuele voedingsadviezen die men ontving, de spreiding van gegeven informatie over meerdere consulten en het gebruik van aanvullende drinkvoeding. Factoren die de uitvoering van de voedingsadviezen belemmerden waren: ervaren fysieke klachten, afhankelijkheid van anderen, de benodigde tijd om te wennen aan nieuwe voedingsgewoonten en problemen met de inname van de drinkvoeding.

Over het algemeen, hebben de heupfractuur patiënten de inhoud, structuur en individuele begeleiding van de voedingsinterventie als toepasbaar, adequaat en waardevol ervaren. Echter, ondersteuning op het gebied van zorg voor voeding in instituten en thuis was niet altijd toereikend.

Hoofdstuk 6 presenteert de visies van de betrokken professionele zorgverleners op de uitvoerbaarheid en mogelijk belemmerende factoren bij de toepassing van de voedingsinterventie in de huidige gebruikelijke zorg. Het doel van dit onderzoek was het in beeld brengen van knelpunten en bevorderende factoren voor invoering van de voedingsinterventie op grote schaal.

In deze zgn. kwalitatieve studie werden gegevens verzameld door middel van individuele semigestructureerde interviews en aanvullende focus groep interviews met belangrijke betrokken professionele zorgverleners (artsen, verpleegkundigen, diëtisten en voedingsassistenten) van de 3 ziekenhuizen, 15 revalidatie-instellingen, 4 thuiszorgorganisaties en enkele huisartspraktijken. In totaal zijn 22 individuele interviews met professionele zorgverleners uitgevoerd en drie focus groep interviews met in totaal 13 diëtisten en verpleegkundigen.

De resultaten laten zien dat bij zorgprofessionals soms sprake is van gebrek aan kennis op het gebied van voedingszorg, terwijl verpleegkundigen vinden dat er te weinig tijd beschikbaar hebben. Op het niveau van het 'systeem' rapporteerden professionele zorgverleners: 1 . onvolledige communicatie tussen instelling met betrekking tot voedingszorg; 2. gebrek aan duidelijkheid binnen instellingen met betrekking tot voedingsgerelateerde verantwoordelijkheden; en 3 . variatie in voedingszorgbeleid tussen instellingen.

Deze knelpunten zouden verbeterd kunnen worden door het vormen van multidisciplinaire geriatrische teams met duidelijk gedefinieerde voedingsgerelateerde verantwoordelijkheden en door het volgen van de patiënt tijdens het gehele transmurale traject, vanaf opname in het ziekenhuis tot in thuissituatie. De voedingszorg zou hierbij gebaseerd moeten zijn op een klinische praktijk richtlijn voor geriatrische voedingszorg.

In hoofdstuk 7 worden de bevindingen van de voorafgaande hoofdstukken bediscussieerd en in een breder kader geplaatst.

Op basis van de resultaten gepresenteerd in dit proefschrift kunnen de volgende implicaties voor de praktijk worden geformuleerd; 
1. Verbetering van standaard aandacht voor voedingszorg is van belang.

2. Om continuïteit van voedingszorg te bereiken, zal de samenwerking tussen professionele zorgverleners van verschillende instellingen in de transmurale zorgsetting moeten worden verbeterd.

3. Versterkte multidisciplinaire samenwerking gericht op de problemen van de individuele patiënt, met speciale aandacht voor de patiënt die thuis verblijft, dient verder ontwikkeld te worden.

4. Om te bereiken dat voedingzorg een standaard onderdeel wordt van de medische behandeling van de geriatrische patiënt in de transmurale zorgsetting, is het van belang hiervoor een richtlijn te ontwikkelen, samenhangend met reeds bestaande richtlijnen voor deze patiëntengroep.

5. Om kansen op succesvolle implementatie van nieuwe richtlijnen te vergroten, wordt aanbevolen om implementatie strategieën toe te passen gericht op verschillende organisatorische niveaus en gericht op de op de locale situatie en geïdentificeerde knelpunten.

Tot slot worden in hoofdstuk 7 de thema's voor toekomstig onderzoek besproken.

Allereerst is verder onderzoek nodig om te komen tot een gouden transmurale voedingszorg standaard voor de geriatrische patiënt, waarin structuur en inhoud van de voedingszorg voor deze groep wordt vastgelegd. Ten tweede is onderzoek van belang om na te gaan wat de beste manier is om voedingszorg verder te integreren in de transmurale zorg. Ten derde is onderzoek nodig naar factoren die de implementatie van de voedingsinterventie op het organisatorische niveau (management and regionale organisatie) en op het financiële niveau beïnvloeden. Dit zal naar verwachting aanvullende knelpunten en bevorderende factoren opleveren met betrekking tot bijvoorbeeld beleidskeuzes op het organisatie niveau, aanwezige steun voor de invoering van nieuwe werkwijzen en beschikbaarheid van financiële middelen om de veranderingen te ondersteunen. Tenslotte is onderzoek naar de verdere ontwikkeling van een eenvoudig screeningsinstrument voor het vaststellen van ondervoeding van belang. 
Dankwoord 


\section{Dankwoord}

Dit proefschrift is het eindresultaat van de werkzaamheden die ik uitgevoerd heb in de context van de voedingsinterventie-studie bij heupfractuur patiënten (de zogenaamde HeVo-studie), waarvoor de hulp en steun van velen onmisbaar waren. Graag dank ik iedereen die heeft bijgedragen aan de uitvoering van deze studie en aan totstandkoming van dit proefschrift

De volgende personen wil ik in het bijzonder bedanken.

De leden van mijn promotieteam wil ik danken voor hun voortdurende inbreng en steun bij het ontwikkelen van de procesevaluatie en de totstandkoming van de verschillende wetenschappelijke artikelen.

Martin wil ik danken voor zijn steun, zijn heldere wetenschappelijke visie die altijd kort en bondig verwoord werden en zijn aandeel in het uitzetten van lijnen en afronden van het traject. Trudy wil ik danken voor haar belangrijke en deskundige inbreng, haar gedegen feedback op de stukken en haar vermogen te inspireren. Ook al had je weinig tijd, je wist toch tijd vrij te maken. Dit leidde tot een bijzonder waardevolle bijdrage aan dit promotieonderzoek.

Dan Pieter en Nel als geestelijk ouders van de Hevo-studie. Allereerst wil ik Pieter danken voor zijn betrokkenheid bij de studie, voor zijn creativiteit en voor de gegeven feedback. Je wist als geen ander helder te maken dat er altijd nog ruimte is voor verbetering. Je bood me de mogelijkheid om als diëtist de overstap te maken om als promovenda aan de slag te gaan en hiermee heb je me de kans geboden het wetenschappelijke pad te gaan bewandelen. Hiervoor ben ik je dankbaar. Nel wil ik danken voor haar inhoudelijke feedback en het delen van haar deskundigheid en voor haar gedrevenheid. Je bood altijd een luisterend oor en een gesprek met jou leverde altijd een keur aan nieuwe ideeën op, waar ik weer mee verder kon.

Alle verdere (co)auteurs (Chris Arts, Sven van Helden, Angela Hendrikx, Berry Meesters, Jos Schols, Marionne Vaessen, Aart Verburg, Paul Willems, Caroline Wyers) wil ik danken voor hun inhoudelijke feedback ter verbetering van de manuscripten van artikelen en voor hun steun.

De beoordelingscommissie onder leiding van Prof. dr. ir. van Schayck wil ik hartelijk bedanken voor het kritisch lezen van mijn proefschrift.

Mijn collega's van het Hevo-team zijn tijdens mijn werk gedurende de afgelopen jaren belangrijk voor mij geweest. Caroline: als collega AIO was je mijn maatje, steun en toeverlaat. Dank voor je luisterende oor, duidelijke mening, waardevolle hulp en vriendschap. Ik ben blij dat je als paranimf ook tijdens de verdediging van het proefschrift naast me wilt staan!

Angela en Marionne het was een genot om jullie als collega's te hebben, ondanks het feit dat we toch wel wat samengepakt zaten met zijn drietjes in een kleine ruimte. Marionne, je relativerende opmerkingen mis ik nog regelmatig! Angela, je 
betrokkenheid bij patiënten zal ik niet snel vergeten. Samen hebben we de klus geklaard!

Voor ondersteuning bij dataverwerking hebben Brigitte en Wietske mij (uit de brand) geholpen. Brigitte dank voor je hulp en geduld bij het coderen van de interviews. Wietske dank voor de data-invoer. Het was geweldig om van jullie hulp gebruik te mogen maken.

Alle collega's van de afdeling Epidemiologie wil ik danken voor hun belangstelling en betrokkenheid bij mijn promotieonderzoek. Nicole en Conny wil ik danken voor hun hulp bij het randomiseren van de patiënten in de studie. Het secretariaat van de afdeling wil ik danken voor hun geduld bij het beantwoorden van mijn vragen. Jos en Harry jullie nooit aflatende hulp bij (twee maal) een gecrashte computer of andere calamiteiten was altijd direct voor handen en bijzonder adequaat. Dank hiervoor!

Mijn collega AIO's en oud collega-AIO's (Anne, Anke, Audrey, Carin, Carolina, Caroline, Catherine, Colinda, Daniëlle, Dianne, Denise, Eline, Emilou, Esther, Fleur, Ivette, Jessie, Karolina, Laura, Petra, Milan, Mirjam, Nadine, Sander, Thomas, Vivian) wil ik danken voor de vele gezellige lunches en andere ontstressingsmomenten, waarin ervaringen gedeeld werden en er zeker ook ruimte was voor ontspanning. Ik ben blij dat ik jullie in mijn huidige werk weer regelmatig zie!

Mijn huidige collega's in de EnCoRe studie (Energy for life after ColoRectal cancer study) (Eline, Matty, Martijn, Petra, Nicole, Christel, Ivan en alle overige betrokkenen) wil ik danken voor hun vertrouwen en de mogelijkheid die me geboden is aan de slag te gaan binnen dit team. Jullie professionaliteit, gedrevenheid en oprechtheid maken dat ik me gelukkig prijs met jullie te mogen samenwerken.

Er waren vele gezondheidszorg instellingen en organisaties waarmee we in de Hevostudie hebben samengewerkt. Dit waren onder andere de Universiteit Maastricht, het academisch ziekenhuis Maastricht, Vivre, azM Herstelzorg, Groene Kruis Domicura, 't Brook Voerendaal, Orbis Medisch Centrum, Orbis Revalidatie, Orbis Thuis, Thuiszorg Westelijke Mijnstreek, Atrium Medisch Centrum, Atrium Brunssum, Verpleegkliniek Heerlen, Hambos Kerkrade, Dormig, Revalidatiecentrum Hoensbroek (Vilance). De managers, specialisten, huisartsen, verpleegkundigen, receptionisten en voedingsassistenten op de verpleegafdelingen, diëtisten op de afdelingen diëtetiek, medewerkers centrale keuken en medewerkers van de voedingsadministratie waarmee ik heb samengewerkt in al deze ziekenhuizen, revalidatiecentra c.q. afdelingen voor revalidatiezorg, instellingen voor ouderenzorg en bij de thuiszorgorganisaties en huisartspraktijken, wil ik allen heel hartelijk danken voor de goede samenwerking. De bereidwilligheid om deel te nemen aan de studie van alle bij de studie betrokken instellingen en organisaties was hierbij opvallend, evenals de mogelijkheden die geboden werden om de studie goed uit te voeren en de bijzonder 
prettige samenwerking hierin met alle betrokkenen zowel op het management niveau als op het uitvoerende niveau.

Veel dank is verschuldigd aan de medewerkers van de afdelingen Chirurgie en Orthopedie, de leidinggevenden en verpleegkundigen van de verpleegafdelingen Chirurgie en Orthopedie van het academische ziekenhuis Maastricht, het Atrium Medisch Centrum en het Orbis Medisch Centrum in deze ziekenhuizen waar veel moeite is gedaan om de uitvoering van de Hevo-studie te faciliteren. Dit was geweldig! Dank hiervoor!

Een speciaal woord van dank is op zijn plaats voor de afdelingen Diëtetiek van de betrokken instellingen. De diëtisten stelden werkplekken en computers beschikbaar, en zorgden ervoor dat ik en mijn collega's als studiediëtisten konden werken binnen de ziekenhuizen en ander instellingen. Geweldig dat dit allemaal kon. Dank collega's! Ik ben eenieder hiervoor zeer erkentelijk.

Ten behoeve van de procesevaluatie heb ik veel vraaggesprekken gehouden met patiënten en met zorgverleners (dokters, verpleegkundigen, voedingsassistenten, en diëtisten) over hun ervaringen met de toepassing van de voedinginterventie. Ik wil hen bijzonder danken voor hun medewerking aan en hun openhartigheid tijdens de interviews.

Ook alle patiënten die bereid waren deel te nemen aan de studie wil ik danken voor hun deelname en vertrouwen. In het bijzonder ook de patiënten die in een interview hun ervaringen met de voedinginterventie met ons wilden delen. Het was een bijzondere ervaring deze gesprekken met u te voeren.

Wetenschappelijk onderzoek naar toegepaste behandelmethodes in het werk van de diëtist kan alleen wanneer dit onderzoek geworteld is in de dagelijkse praktijk van het werk van de diëtist en deze weerspiegelt. Dank ben ik dan ook verschuldigd aan de collega diëtisten die lid zijn van het Diëtisten Overleg Regio Maastricht (DORM). Ondanks mijn veelvuldige afwezigheid in de bijeenkomsten is het fijn dat jullie me de mogelijkheid bieden bij de praktijk en ontwikkelingen in het beroep van diëtist betrokken te blijven. Dank hiervoor en voor jullie steun en betrokkenheid.

Voor de praktische afronding van het proefschrift heb ik deskundige ondersteuning gehad: Laura dank voor het editen van stukken. Yvonne, dank ik voor de vele praktische tips en lay-out adviezen. Tiny dank ik voor het lay-outen van het proefschrift. Tot slot dank ik René voor het ontwerpen van de omslag van het boekje. Het resultaat is prachtig!

Gelukkig ben ik niet de enige in mijn vriendenkring, die met een volle agenda kampt en is het voor iedereen normaal dat niet de kwantiteit maar de kwaliteit van de contacten telt! Dit wordt nog eens versterkt door het feit dat onze veelvuldige verhuizingen maakt dat nogal wat vrienden niet in onze directe omgeving wonen. Gelukkig maakt 
dat bij jullie niet uit en genieten we van de momenten samen die er wel zijn. Dank lieve vrienden en vriendinnen voor jullie begrip en voor de belangrijke afschakelmomenten met jullie!

De reden van mijn onvermogen om vrienden frequent te bezoeken is ook gelegen in de grootte van mijn familie. Komende uit een groot gezin ( 4 zussen en 1 broer), getrouwd met een man die 5 broers en 2 zussen heeft, maakt dat onze directe familie op dit moment 53 personen telt (exclusief mijn eigen gezin). Dit grote aantal familieleden maakt de contacten niet minder intens. Mijn familie heeft een belangrijke plaats in mijn / ons leven. Het aloude familie gezegde 'doe maar gewoon dan doe je al gek genoeg' heeft mij altijd en in deze promotietijd al helemaal, met beide benen op de grond gehouden. Een promotie is bijzonder, maar er zijn andere dingen in het leven die er toch meer toe doen. Het feit dat mijn moeder deze promotie niet mag meemaken is daar een voorbeeld van. Zij zou echter als geen ander trots zijn op deze prestatie! Lieve papa, schoonouders, zussen en broer, schoonzussen en zwagers, nichten en neven, dank voor jullie nooit aflatende steun. Het is een voorrecht jullie als familie te hebben.

Om ook mijn familie aan mijn zijde te hebben tijdens de verdediging van mijn proefschrift is het niet meer dan logisch ook een zus of broer als paranimf te kiezen. Rinie, ik ben er trots op dat je mijn paranimf bent.

Tot slot aandacht voor de allerbelangrijkste personen in mijn leven.

Paul, het feit dat het afronden van mijn proefschrift veel tijd van mij vergde, deerde jou niet. Je vond het wel lekker rustig zo met een partner achter de computer! Ondertussen nam je noodzakelijke klussen thuis van me over, zonder daar ook maar één woord aan vuil te maken. Dank voor je nooit aflatende steun. Ik hoop overigens dat het nu weer even gedaan is met de rust!

Eva, Stan en Roos, jullie hebben je net als pap de afgelopen tijd aangepast aan de omstandigheden. Ongemerkt namen jullie het boodschappen doen en koken over. Daarnaast zorgden jullie natuurlijk voor de broodnodige afleiding! Lieve schatten blijf me afleiden, zodat de balans tussen thuis en werk in evenwicht is en blijft. Dank voor jullie liefde en steun. 
About the author 


\section{About the author}

José Breedveld-Peters was born in Didam, The Netherlands, on December 20, 1961. She completed secondary school (HAVO) at the Liemers College in Zevenaar in 1980. After that, she started studying Nutrition and Dietetics at the Akademie Diëtetiek Nijmegen. During this study she fulfilled an internship at the Stadsmaten Hospital, presently called the Medisch Spectrum Twente, in Enschede, where she accepted a job after graduation as a dietician in 1984. An important part of this job was to guide the introduction of the automation of the nutritional services in the hospital.

From 1990 until 1993 José has been working as a dietician in Mantsonyane (Lesotho) at the St. James' Mission Hospital. Her main tasks were to increase the staffs' awareness, knowledge and skills with respect to prevention, detection and treatment of nutrition related problems within the hospital and in several regional clinics. She conducted courses for health care professionals and wrote a manual on the main nutritional problems to guide health care workers in their daily work.

From 1994 until 1997, José worked as a dietician at 'La Vita Sana' health- and sporting centre in Venlo, in which she guided individual clients as well as groups.

In 1997 José started working as a free lance dietician, delivering nutritional and dietetic counselling to individual clients and groups, e.g. in sporting centres, as part of national nutritional campaigns, and replacing colleagues.

From 2000 onwards José started working as a research dietician and quality manager in scientific research at NutriScience bv, a research institute in Maastricht. In this period she developed dietary guidelines for application in the studies executed. As a quality manager she was responsible for the construction and development of the quality system according to the guidelines for good clinical practice (GCP).

In 2007 and 2008 she worked as a dietician in the nutritional intervention study of this thesis, entitled 'Effectiveness and cost-effectiveness of nutritional intervention after hip-fracture' at the Department of Epidemiology (CAPHRI, school for Public Health and Primary Care) of the University of Maastricht. In this period she was responsible for the communication with all involved institutions, she shaped the nutritional intervention, and conducted the dietetic guidance as offered to the hip fracture patients participating in the study. In November 2008 the position of dietician in the nutritional intervention study was changed into a position of PhD student resulting in this thesis.

In 2012, José has been working in a qualitative survey on reasons for early discontinuation of home enteral tube feeding for the EOI foundation (Eerstelijns Ondervoedings Instituut).

Presently, José is working for the Energy for life after ColoRectal cancer (EnCoRe) study at the department of Epidemiology (GROW School for Oncology and Developmental Biology) of the Maastricht University.

José is married to Paul Breedveld and mother of Eva, Stan and Roos. 
